Aus der Klinik für Anästhesiologie

(Prof. Dr. med. K. Meissner)

der Medizinischen Fakultät der Universität Göttingen

\title{
DIFFERENZIERUNG VON ESCHERICHIA COLI UND PSEUDOMONAS AERUGINOSA MITTELS IONENMOBILITÄTSSPEKTROMETRIE
}

\author{
INAUGURAL-DISSERTATION \\ zur Erlangung des Doktorgrades \\ der Medizinischen Fakultät der \\ Georg-August-Universität zu Göttingen
}

$$
\begin{gathered}
\text { vorgelegt von } \\
\text { Julia Göpel } \\
\text { aus }
\end{gathered}
$$

Eisenhüttenstadt 
Dekan:

Referent:

Ko-Referent:

Datum der mündlichen Prüfung:
Prof. Dr. med. W. Brück

Priv. Doz. Dr. med. T. Perl

Prof. Dr. med. M. Weig

9. Februar 2022 
Hiermit erkläre ich, die Dissertation mit dem Titel "Differenzierung von Escherichia coli und Pseudomonas aeruginosa mittels Ionenmobilitätsspektrometrie" eigenständig angefertigt und keine anderen als die von mir angegebenen Quellen und Hilfsmittel verwendet zu haben.

Göttingen, den

(Unterschrift) 
Die Daten, auf denen die vorliegende Arbeit basiert, wurden publiziert:

Kunze N, Göpel J, Kuhns M, Jünger M, Quintel M, Perl T (2013): Detection and validation of volatile metabolic patterns over different strains of two human pathogenic bacteria during their growth in a complex medium using multi-capillary column-ion mobility spectrometry (MCC-IMS). Appl Microbiol Biotechnol 97, 3665-3676 


\section{INHALTSVERZEICHNIS}

ABBILDUNGSVERZEICHNIS ................................................................................ III

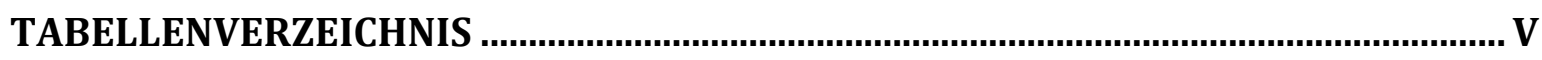

ABKÜRZUNGSVERZEICHNIS ............................................................................... VI

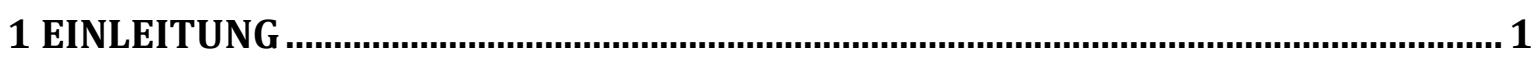

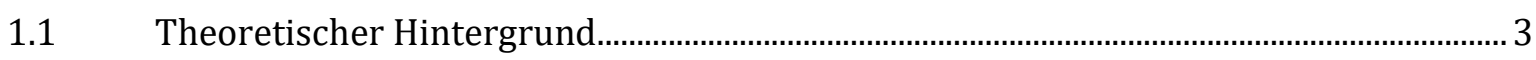

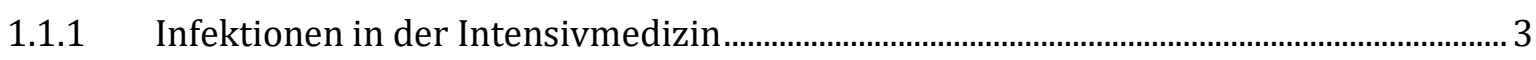

1.1.2 Verfahren zur Erregerdiagnostik .......................................................................................

1.1.2.1 Konventionelle mikrobiologische Diagnostik ………….........................................................

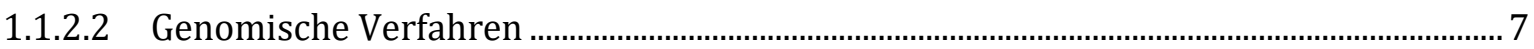

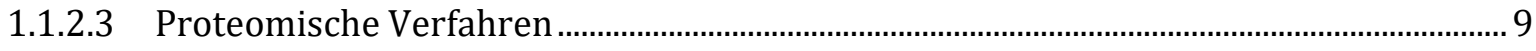

1.1.2.4 Metabolomischer Ansatz …………………............................................................... 10

1.1.3 Ionenmobilitätsspektrometrie ...................................................................................... 12

1.1.3.1 Allgemeines Funktionsprinzip ........................................................................................ 13

1.1.3.2 Ionenerzeugung mittels radioaktiver Strahlungsquelle.................................................... 14

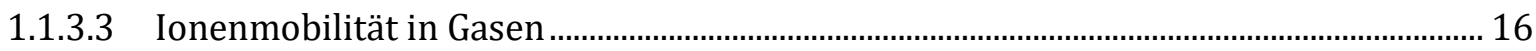

1.1.3.4 Kopplung des IMS an Trennungsverfahren ....................................................................... 18

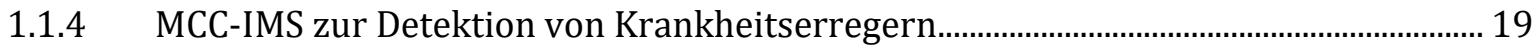

2 MATERIAL UND METHODEN

$2.1 \quad$ Verwendetes MCC-IMS und Probennahme.......................................................................... 21

$2.2 \quad$ Ventilstellungen des 6-Wege-Ventils................................................................................... 23

$2.3 \quad$ Datenerfassung und Visualisierung ……………………….......................................... 25

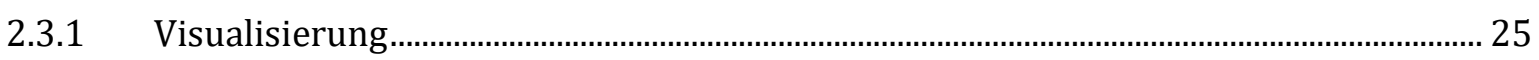

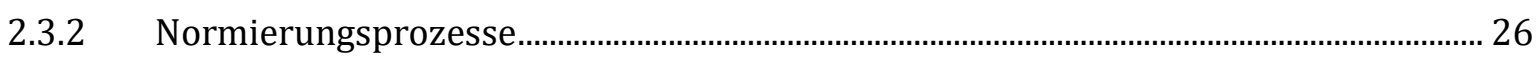

2.4 Mikrobiologischer Versuchsteil ....................................................................................... 28

2.4.1 Herstellung und Analyse des Nährmedium ...................................................................... 28

2.4.2 Mikrobiologische Arbeiten und Wachstumskurven....................................................... 28

2.4.3 Zeitlicher Verlauf der MCC-IMS-Messungen................................................................... 31

2.4.4 Referenzmessungen zur Analyse des Nährmediums........................................................ 32

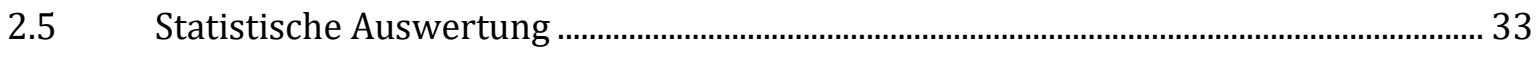

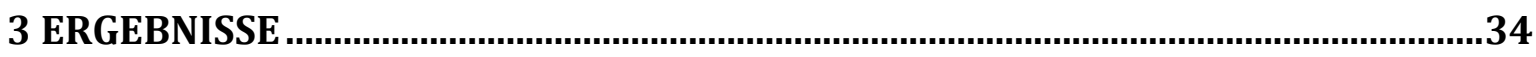

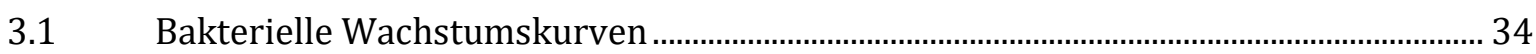

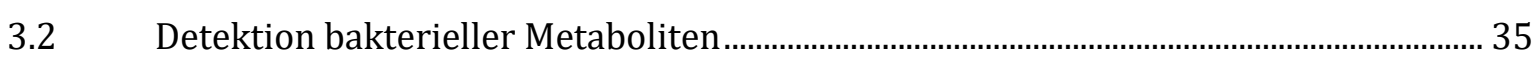

3.3 Vergleich der Referenzstämme und klinischen Isolate................................................... 37

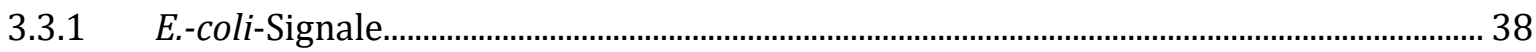


Inhaltsverzeichnis

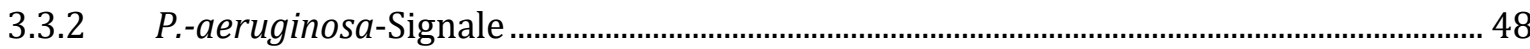

3.4 Differenzierung anhand keimspezifischer VOCs ................................................................. 54

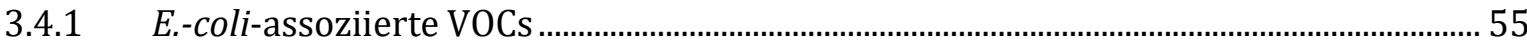

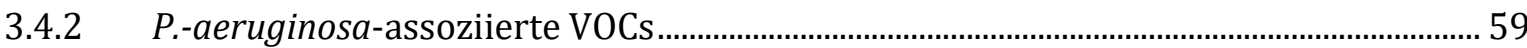

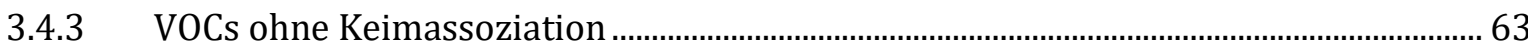

4 DISKUSSION

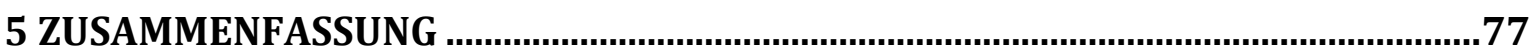

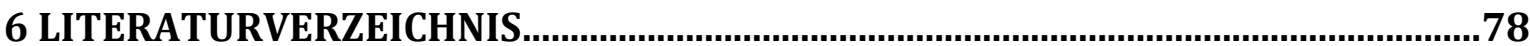




\section{ABBILDUNGSVERZEICHNIS}

Abbildung 1. Aufbau der Driftröhre des IMS …………………………….................... 13

Abbildung 2. Ionenmobilitätsspektrum des verwendeten IMS ………........................... 15

Abbildung 3. Querschnitt einer Multikapillarsäule............................................................. 19

Abbildung 4. Schematischer Aufbau des MCC-IMS. ........................................................... 21

Abbildung 5. Darstellung des 6-Wege-Ventils in Ventilstellung A _................................. 24

Abbildung 6. Darstellung des 6-Wege-Ventils in Ventilstellung B.................................. 24

Abbildung 7. Zweidimensionale Darstellung eines MCC-IMS Datensatzes.................. 26

Abbildung 8. Übersicht der verwendeten Bakterien und deren Ursprung.................. 29

Abbildung 9. Messreihen...................................................................................................... 31

Abbildung 10. Wachstumskurven E. coli........................................................................ 34

Abbildung 11. Wachstumskurven P. aeruginosa …………….............................................. 35

Abbildung 12. Graphische Darstellung der 19 Peaks........................................................... 36

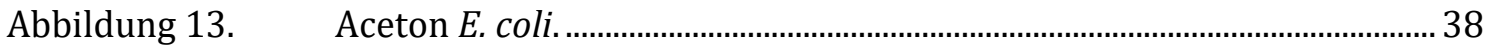

Abbildung 14. Ammoniak (Dimer) E. coli. ……….................................................................. 39

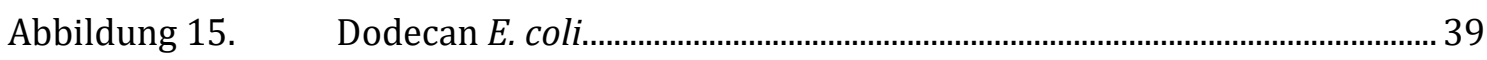

Abbildung 16. Nonanal E. coli........................................................................................ 40

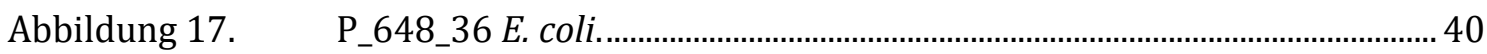

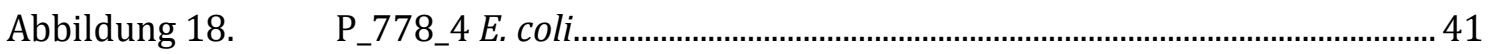

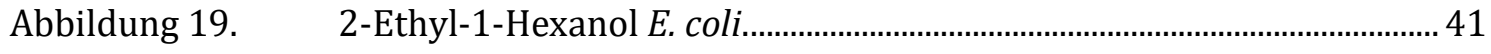

Abbildung 20. 5-Methyl-3-Heptanon Messung E. coli........................................................... 42

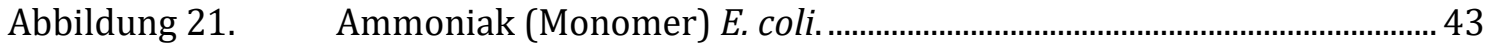

Abbildung 22. Decan-1-ol E. coli.......................................................................................... 43

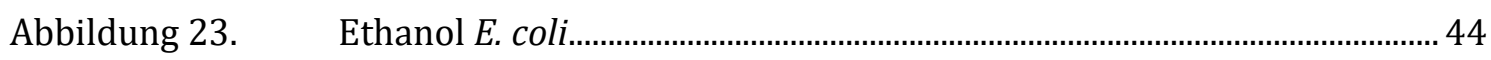

Abbildung 24. Indol E. coli............................................................................................... 44

Abbildung 25. 1-Octanol (Monomer) E. coli............................................................................ 45

Abbildung 26. 1-Octanol (Dimer) E. coli............................................................................... 45

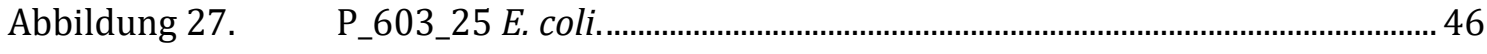

Abbildung 28. P_642_48 E. coli.................................................................................... 46

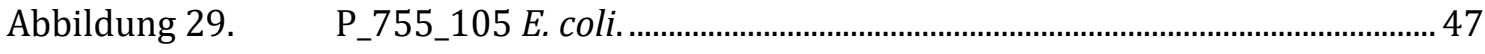

Abbildung 30. Phenylacetaldehyd E. coli. ……................................................................... 47

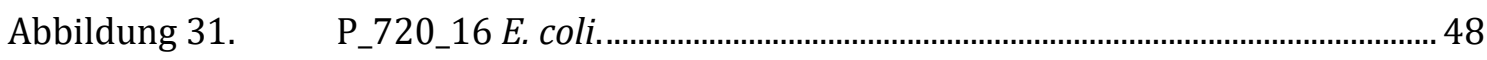

Abbildung 32. Aceton P. aeruginosa.................................................................................. 49

Abbildung 33. Ammoniak (Monomer) P. aeruginosa ............................................................... 49 
Abbildung 34. Ammoniak (Dimer) P. aeruginosa ………………………............................. 50

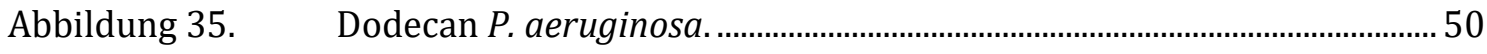

Abbildung 36. P_503_27 P. aeruginosa ............................................................................. 51

Abbildung 37. P_603_25 P. aeruginosa............................................................................ 51

Abbildung 38. P_648_36 P. aeruginosa................................................................................. 52

Abbildung 39. P_778_4 P. aeruginosa.................................................................................... 52

Abbildung 40. 2-Ethyl-1-Hexanol P. aeruginosa. ………………………………………..... 53

Abbildung 41. 5-Methyl-3-Hetanon P. aeruginosa. .............................................................. 53

Abbildung 42. P_720_16 P. aeruginosa................................................................................ 54

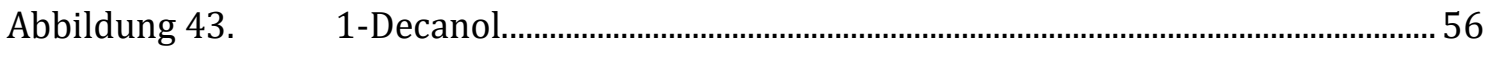

Abbildung 44. Ethanol........................................................................................................ 56

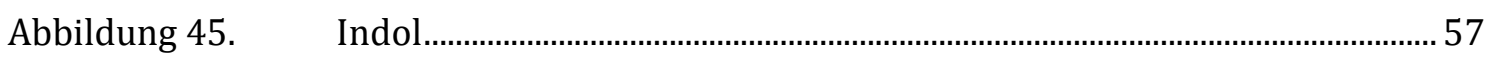

Abbildung 46. 1-Octanol (Monomer)................................................................................. 57

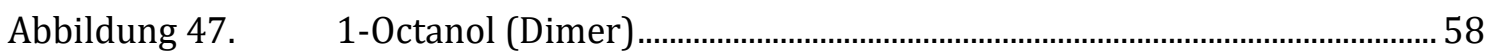

Abbildung 48. P_755_105 …………………….......................................................... 58

Abbildung 49. Aceton ......................................................................................................... 59

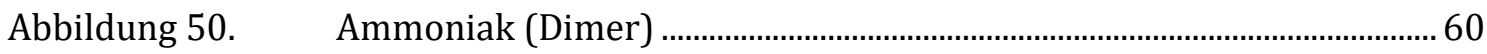

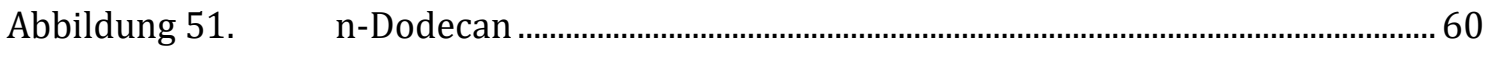

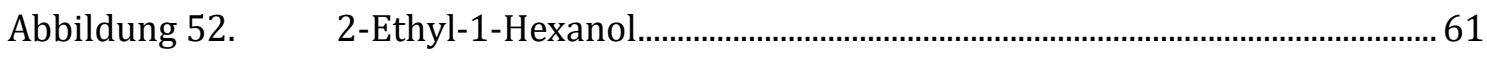

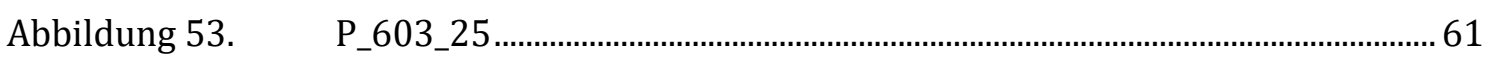

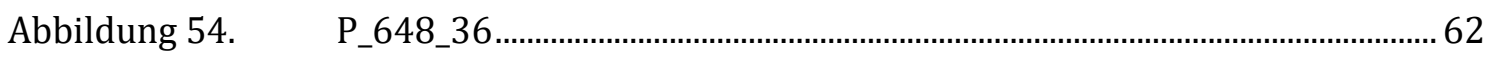

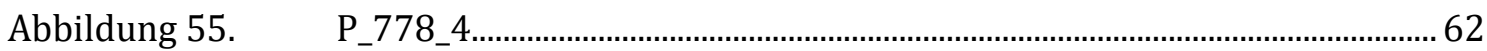

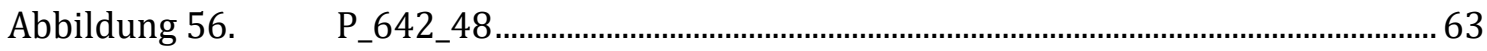

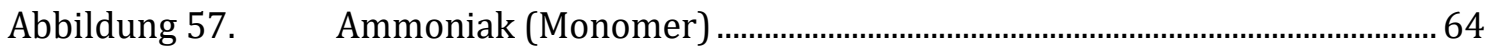

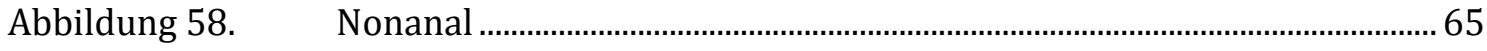

Abbildung 59. Phenylacetaldehyd .......................................................................................... 65

Abbildung 60. 5-Methyl-3-Heptanon................................................................................... 66

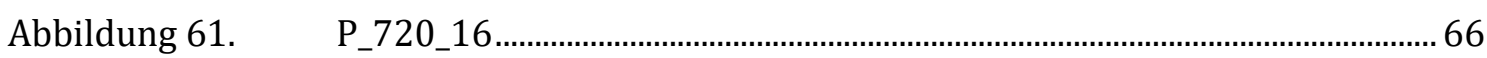




\section{TABELLENVERZEICHNIS}

Tabelle 1. Einstellungsparameter MCC-IMS................................................................... 22

Tabelle 2. Ursprung der klinischen Isolate..................................................................... 29

Tabelle $3 . \quad$ Verdünnungsverhältnisse E. coli.................................................................... 32

Tabelle 4. Verdünnungsverhältnisse P. aeruginosa.................................................. 32

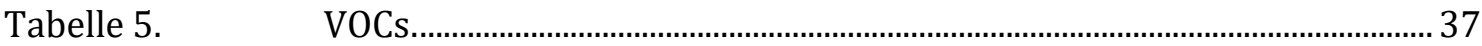

Tabelle 6. VOCs mit der Assoziation zu E. coli oder P. aeruginosa.............................67 


\section{ABKÜRZUNGSVERZEICHNIS}

A

DNA

DNS

DSM

DSMZ

$\mathrm{e}^{-}$

E. coli

$E_{d}$

ESBL

$\mathrm{eV}$

FISH

GBH

GC-MS

IMS

ITS

$k$

K

$\mathrm{keV}$

KI

$K_{0}$

Lag

LB

$l_{d}$

$\log 1$
Analytmoleküle

Desoxyribonukleinsäure, desoxyribonucleic acid (engl.)

Desoxyribonucleinsäure

Deutsche Sammlung von Mikroorganismen

Deutsche Sammlung von Mikroorganismen und Zellkulturen $\mathrm{GmbH}$

Elektron

Escherichia coli

Elektrische Feldstärke

Extended-spectrum beta-Laktamasen

Elektronenvolt

Fluoreszenz-in-situ-Hybridisierung

Gammahydroxybuttersäure

Gaschromatrgraphie-Massenspektrometrie

Ionenmobilitätsspektrometer

Internal-transcribed-spacer

Boltzmann-Konstante

Proportionalitätskonstante/Ionenmobilität

Kiloelektronenvolt

Konfidenzintervall

Reduzierte Ionenmobilität

Anlaufphase

Lysogeny Broth

Driftröhrenlänge

Logarithmische Phase 1 (früh) 


\begin{tabular}{|c|c|}
\hline $\log 2$ & Logarithmische Phase 2 (spät) \\
\hline$\mu$ & Reduzierte Masse \\
\hline$m$ & Ionenmasse \\
\hline M & Masse \\
\hline MALDI-TOF-MS & $\begin{array}{l}\text { Matrix assisted laser desorption ionization - time of flight-mass } \\
\text { spectrometry }\end{array}$ \\
\hline Mbq & Megabecquerel \\
\hline MCC & Multikapillarsäule, multi capillary column (engl.) \\
\hline MCC-IMS & Multikapillarsäulen-Ionenmobilitätsspektrometer \\
\hline MAP & Mycobacterium avium ssp. paratuberculosis \\
\hline mPCR & Multiplex-PCR \\
\hline MS & Massenspektrometer \\
\hline MVOC & $\begin{array}{l}\text { flüchtige organische Verbindung, microbial volatile organic } \\
\text { compound (engl) }\end{array}$ \\
\hline $\mathrm{m} / \mathrm{z}$ & Masse/Ladung (Ionenmobilität) \\
\hline$n$ & Molekülzahl \\
\hline OD & optische Dichte \\
\hline ONP & o-Nitrophenol \\
\hline ONPG & o-Nitrophenol Galaktopyranoside \\
\hline$P$ & Atmosphärendruck \\
\hline P. aeruginosa & Pseudomonas aeruginosa \\
\hline PCR & Polymerase Kettenreaktion, polymerase chain reaction (engl.) \\
\hline$q$ & Ionenladung \\
\hline rDNA & Ribosomale Desoxyribonukleinsäure \\
\hline Ref. & Referenznummer \\
\hline RIN & negative Reaktantionen, negative reactant ions (engl.) \\
\hline RIP & Reaktionsionenpeak \\
\hline RT & Retentionszeit \\
\hline
\end{tabular}


Abkürzungsverzeichnis

SELDI-TOF-MS

Surface enhanced laser desorption ionization- time of flight-mass spectrometry

S. aureus

Staphylococcus aureus

S. epidermidis

Staphylococcus epidermidis

Stat

statische Phase

$T$

Temperatur

$t_{d}$

Zeit

TRIS

Tris(hydroxymethyl)aminomethan

VOC

flüchtige organische Verbindung, volatile organic compound (engl.)

$v_{d}$

Driftgeschwindigkeit

$\Omega_{D}$

Stoßquerschnitt 


\section{EINLEITUNG}

In der Intensivmedizin sind Infektionen eine häufige Komplikation, die einen negativen Einfluss auf Morbidität und Mortalität der betroffenen Patienten hat (Vincent et al. 2009). Auslöser können Viren, Pilze, Protozoen, Parasiten und vor allem Bakterien sein. Eine gefürchtete Komplikation von Infektionen ist die Sepsis. Hier kann die Mortalität bei bis zu $55 \%$ liegen, sofern die Patienten an einer schweren Sepsis erkrankt sind (Engel et al. 2007). $33 \%$ der Septikämien treten erst im Rahmen einer intensivmedizinischen Behandlung auf (Engel et al. 2007). Es resultieren verlängerte intensivmedizinische Liegezeiten, sowie erhöhte Therapiekosten (Laupland et al. 2006).

Essentiell für die Prognose der betroffenen Patienten ist der unverzügliche Beginn einer adäquaten antibiotischen Therapie. Kumar et al. (2009) beschreiben eine fünffach erhöhte Mortalitätsrate bei Patienten mit septischen Schock, die initial keine adäquate Therapie erhalten haben. Voraussetzung für eine gezielte antibiotische Therapie ist ein direkter Erregernachweis, der in der Regel durch die Anzucht der Erreger aus klinischem Probenmaterial erfolgt. Die Ergebnisse dieser konventionellen mikrobiologischen Diagnostik liegen normalerweise nach 48-72 Stunden vor. Problematisch ist der Zeitfaktor, da während dieser Zeit unklar ist, ob die antibiotische Therapie adäquat ist oder nicht. Bis zum Erregernachweis wird schnellstmöglich mit einer breit wirksamen empirischen Antibiotikatherapie begonnen, da ein früher Therapiebeginn Mortalität und Liegezeit positiv beeinflussen kann (Houck et al. 2004).

Eine schnelle Alternative zur konventionellen mikrobiologischen Diagnostik könnte die Keimidentifizierung durch die Detektion und Zuordnung von flüchtigen organischen Verbindungen (volatile organic compounds, VOCs), mittels Multikapillarsäulengekoppelter Ionenmobilitätsspektrometrie (MCC-IMS) sein. Ionenmobilitätsspektrometer (IMS) ermöglichen den Nachweis sehr geringer Substanzmengen in einer Gasprobe. Die Technologie hat sich in den letzten beiden Jahrzehnten vor allem im Sicherheitswesen und beim Militär etabliert. Sie wird beispielsweise an Flughäfen zur Detektion von Sprengstoffen und Drogen eingesetzt (Hill et al. 1990). Die Kopplung eines IMS mit einer Multikapillarsäule (MCC) ermöglicht eine Vortrennung des zu analysierenden Gases, wodurch die Analyse komplexer und feuchter Gasgemische ermöglicht wird (Baumbach JI 2009). 
Bereits 1921 beschrieben Zoller und Clark, dass Bakterien während ihres Wachstums Endund Zwischenprodukte ihrer Stoffwechselprozesse emittieren (Zoller und Clark 1921). Mittlerweile sind über 300 solcher mikrobieller VOCs bekannt und können teilweise bestimmten Organismen zugeordnet werden (Schulz und Dickschat 2007). Im Jahr 1991 gelang es Snyder et al. Escherichia coli (E. coli), welches in einem Nährmedium kultiviert wurde, mit einem Ionenmobilitätsspektrometer nachzuweisen (Snyder et al. 1991). Aktuelle Forschungsergebnisse zeigten, dass Bakterien und Pilze anhand ihrer VOC-Profile differenzierbar sind (Jünger et al. 2012). Jedoch liegen bislang keine Informationen zur Korrelation der bakteriellen Wachstumsphasen und der VOC-Produktion vor.

In der vorliegenden Arbeit wurden entlang der Wachstumskurven von Escherichia coli und Pseudomonas aeruginosa mittels MCC-IMS die von den Bakterien emittierten VOCs analysiert. Dabei wurde untersucht, wann die VOCs auftraten und wie sich ihre Konzentrationen während der Wachstumsphasen veränderten. Weiterhin wurde überprüft, ob sich das spezifische VOC-Muster eines Bakteriums auf andere Stämme der gleichen Spezies übertragen lassen. Hierzu wurden auch klinische Isolate derselben Spezies einbezogen. In der Literatur beschäftigten sich einige Forschungsgruppen bisher nur mit einzelnen Bakterienstämmen und mit deren Unterschieden zu anderen Spezies (Maddula et al. 2009; Jünger et al. 2012). 


\subsection{Theoretischer Hintergrund}

Im folgenden Abschnitt wird die Relevanz von Infektionen in der Intensivmedizin erörtert und ein Überblick über die aktuellen diagnostischen Möglichkeiten zum Nachweis humanpathogener Erreger anhand des aktuellen Forschungsstands gegeben. Anschließend werden die Grundlagen der Ionenmobilitätsspektrometrie dargestellt. Zudem wird auf die MCC-IMS zur Detektion von Krankheitserregern eingegangen.

\subsubsection{Infektionen in der Intensivmedizin}

Infektionen und kardiovaskuläre Erkrankungen stellen weltweit nach wie vor die häufigsten Todesursachen dar (GBD 2016 Causes of Death Collaborators 2017). Besonders häufig führen Infektionen in der Intensivmedizin zu komplizierten Krankheitsverläufen. Hierzu zählt die Sepsis, eine lebensbedrohliche Organdysfunktion, die durch eine dysregulierende Immunantwort auf infektiöse Erreger und deren Toxine hervorgerufen wird (Singer et al. 2016). Es werden Mortalitätsraten von über 40,4\% bei Patienten beschrieben, die an einer schweren Sepsis oder einem septischen Schock erkrankt sind (SepNet Critical Care Trials Group 2016). Es führen jedoch nicht nur Infektionen mit kombinierter Organdysfunktion zu erhöhten Mortalitätsraten: Patienten die eine intensivmedizinische Therapie benötigen und zeitgleich an einer Infektion leiden, haben eine Mortalitätsrate von $25 \%$, verglichen mit Patienten ohne infektiöses Geschehen (Vincent et al. 2009). Die Gesamtletalität während des Krankenhausaufenthaltes dieser Patientengruppe ist ebenfalls mehr als doppelt so hoch und liegt bei $33 \%$ (Vincent et al. 2009).

Vincent et al. konnten $64 \%$ der Infektionen dem Respirationstrakt zuordnen. In fallender Häufigkeit werden weiterhin abdominelle Infektionen (20\%), Blutstrominfektionen (15\%) und Harnwegsinfektionen (14\%) genannt (Vincent et al. 2009). Diese Häufigkeitsverteilung spiegelt sich auch bei septischen Patienten wider. In der 2013 durchgeführten INSEP Studie wurde bei 12,6 \% aller intensivmedizinisch therapierten Patienten eine schwere Sepsis oder ein septischer Schock diagnostiziert. 57,2\% dieser Patienten hatte eine nosokomial erworbene Infektion (Marx et al. 2018). Insbesondere Pneumonien sind die vorherrschenden nosokomialen Infektionen auf Intensivstationen, gefolgt von Bakteriämien und Harnwegsinfektionen (European Centre for Disease 
Prevention and Control 2019). Besonders häufig sind bei den grampositiven Erregern Staphylococcus aureus und bei den gramnegativen Erregern Pseudomonas Spezies, Escherichia coli und Klebsiellae Spezies zu finden (Vincent et al. 2009; Sander et al. 2014).

Die Zahlen sind alarmierend. Ein Rückgang der Infektionen ist nicht zu verzeichnen. Vergleicht man die Daten der 2003 durchgeführten Sepsis-Studie von Engel et al. (2007) mit denen der INSEP-Studie die zehn Jahre später durchgeführt wurde (Marx et al. 2018), steigt die Inzidenz einer schweren Sepsis oder eines septischen Schocks sogar von $11 \%$ auf $12,6 \%$ an.

Das Risiko an Infektionen zu erkranken, steigt mit der Verweildauer eines Patienten auf der Intensivstation (Vincent et al. 2009). Zudem werden längere Liegezeiten und ein daraus resultierender Kostenanstieg beschrieben (Laupland et al. 2006).

Die oben genannten Risiken belegen, wie wichtig eine adäquate und frühzeitig begonnene Antibiotikatherapie für die Betroffenen ist. Mortalitätsraten, Kostenvolumina und die Aufenthaltsdauer auf Intensivstationen können dadurch gesenkt werden (Houck et al. 2004).

Die Forderung nach einer frühen und gleichzeitig adäquaten Therapie stellt in der Versorgungsrealität aber weiterhin eine große Herausforderung dar.

Eine gezielte Antibiose setzt die Erregeridentifikation voraus, sodass zunächst auf eine sog. empirische oder kalkulierte Antibiotikatherapie zurückgegriffen werden muss. Ziel ist es, das wahrscheinliche Erregerspektrum abzudecken. Besonders bei intensivpflichtigen Patienten ist eine breite kalkulierte Antibiotikatherapie frühzeitig notwendig, da hier aufgrund der Schwere der Grunderkrankung keine Zeitverzögerung durch lang andauernde Diagnostik-Verfahren zur Erregeridentifikation toleriert werden kann.

Nach erfolgreicher Erregeridentifikation, Bestimmung eines Antibiogramms und des Resistenzprofils kann die kalkulierte Antibiotikatherapie in der Regel nach drei Tagen angepasst werden. Entsprechend den Ergebnissen kann dann eine Deeskalation möglich sein, oder die Eskalation der Therapie notwendig werden. Eine Studie von Patienten die an einer Pseudomonas aeruginosa Bakteriämie erkrankt waren, zeigte, dass ca. $25 \%$ dieser Patienten initial keine adäquate Therapie gegen Pseudomonaden erhalten hatten. Die Sterblichkeit dieser Patienten war fast doppelt zu hoch, wie die der Patienten mit einer optimalen Therapie (Micek et al. 2005). 


\subsubsection{Verfahren zur Erregerdiagnostik}

Neben den konventionellen, mikrobiologischen Verfahren existieren verschiedene innovative Ansätze mit dem Ziel einer schnelleren Erregerdiagnostik. Diese lassen sich in genomische und proteomische Verfahren unterscheiden. Eine Sonderstellung nehmen Verfahren zur Detektion des mikrobiellen Metaboloms ein, zudem auch der in der vorliegenden Arbeit untersuchte methodische Ansatz mittels MCC-IMS zählt. Das nachfolgende Kapitel gibt einen Überblick über die konventionelle mikrobiologische Diagnostik, sowie die hier genannten Verfahren.

\subsubsection{Konventionelle mikrobiologische Diagnostik}

Aktuell können Infektionserkrankungen zügig anhand klinischer und laborchemischer Parameter diagnostiziert werden. Eine Identifikation der Erreger dauert jedoch erheblich länger. Seit Jahrzehnten ist die konventionelle mikrobiologische Diagnostik ein etabliertes und wissenschaftlich validiertes Verfahren. Ziel ist es, aus gewonnenem Probenmaterial die Erreger zu identifizieren und deren Resistenzmuster gegenüber bestimmten Antibiotika zu bestimmen. Die Arbeitsschritte umfassen die Kultivierung der Erreger in Nährmedien, sowie die Mikroskopie zur Identifizierung morphologischer Merkmale. Hans Christian Gram entwickelte 1884 die Gram-Färbung, ein noch heute routinemäßig verwendetes Färbeverfahren zur Differenzierung von Bakterienklassen. Die verschieden aufgebauten Zellwandstrukturen von Bakterien nehmen die Farbstoffe unterschiedlich auf und zeigen resultierend unterschiedliche Färbungen. Es folgte eine Einteilung in grampositive und gram-negative Bakterien (Gram 1884).

In der Weiterentwicklung wurden Ende des 19. die ersten biochemischen Reaktionen zur Identifizierung von E. coli durch Wissenschaftler wie Voges und Proskauer aufgezeigt, berichtet Baumgärtel (1945). Sie fügten Kalilauge zu Traubenzuckerbouillonkulturen hinzu und beobachteten eine eosinrote Färbung bei einer Spezies von Bakterien. Im Laufe der Zeit konnten viele weitere biochemische Reaktionen, welche auf pH-Änderungen, enzymatischen Reaktionen oder Kohlenstoffassimilation basieren, etabliert und zum Nachweis von Bakterienspezies genutzt werden. Diese Tests bestanden aus flüssigen Testseren. 1963 wurde durch Vracko und Sherris eine Filterpapier-Testmethode zum Nachweis von Indol bei einigen Enterobakterien erfolgreich eingeführt. In der 
Weiterentwicklung folgten 1965 Filterpapierteststreifen, die mehrere Testsubstanzen enthielten, um eine breitere Testung besonders klinisch relevanter humanpathogener Bakterien zu ermöglichen (Mann und Gaudelmann 1965). Seitdem sind weltweit Teststreifen zur Identifikation von Erregern mittels biochemischer Reaktionen etabliert. Beispielhaft kann hier das API-System (Analytischer Profile Index) von BioMérieux (Nürtingen, Deutschland) genannt werden. Es erhält Kammern mit Testseren, die mit der kultivierten Nährlösung zusammengefügt werden und durch einen Farbumschlag das Ergebnis präsentieren. Die Auswertung erfolgt anhand erstellter Zahlencodes und dem Abgleich der dazugehörigen Datenbank von BioMérieux. Aktuell können 15 APITeststreifen zur Identifikation von über 700 Spezies herangezogen werden. O’Hara beschreibt in einem Review dass sich ständig erweiternde Spektrum der Taxonomie, welches zur Identifikation der einzelnen Spezies verwendet wird (O'Hara 2005). Allerdings weist O'Hara auf die Nachteile der langen Inkubationszeiten und die Variabilität einzelner Stoffwechseleigenschaften hin. Auch Maurer et al. verweisen auf den zeitliche Aufwand des Verfahrens, dass Ergebnisse oft erst nach 48 oder mehr Stunden (h) zur Verfügung stehen (Maurer et al. 2017).

Die stark ausgeweiteten Testmöglichkeiten bedingen einen hohen personellen Aufwand. Diesem wirkten Aldrige et al. 1977 entgegen. Sie entwickelten für die Raumfahrt ein automatisiertes Testsystem. Die beimpften und verschlossenen Mikroküvetten wurden in einem geschlossenen System inkubiert, die optische Dichte photometrisch gemessen und mit einem Computer ausgewertet (Aldrige et al. 1977). Seither sind unterschiedliche automatische Identifikationssysteme routinemäßig im Einsatz. In Europa werden häufig VITEK-Systeme von BioMérieux oder das BD-Phoenix-System von Becton Dickinson $\mathrm{GmbH}$, Heidelberg, eingesetzt. Beide können eine zusätzliche Empfindlichkeitsprüfung antimikrobiell wirksamer Substanzen leisten. Die Forschungsgruppe um Leverstein-van Hall et al. evaluierte die Genauigkeit der vorher genannten Systeme zur Identifizierung von Extended-Spektrum-Betalaktamasen (ESBL) in multiresistenten E. coli und Klebsiella Spezies. In dieser Arbeit konnten über 78\% der ESBL identifiziert werden. Das PhoenixSystem hatte mit $89 \%$ ein besseres Ergebnis (Leverstein-van Hall et al. 2002). Andere Arbeiten verglichen das VITEK2-System mit dem API-System. Hier konnten durch das VITEK2-System bis zu $95 \%$ der Proben korrekt identifiziert werden (Ling et al. 2001; Nagassar et al. 2013; Funke et al. 1998). Bei der Empfindlichkeitstestung konnten korrekte Antibiotika-Empfindlichkeitsprüfungen und Resistenzbestimmungen bei $84,2 \%$ bis zu 95,6\% der Spezies erreicht werden (Ling et al. 2001). Die Kombination aus automatisierter Erregeridentifikation und Resistenzprüfung macht das System in vielen mikrobiologischen Laboren derzeit zum Standard. Die Analysezeiten betragen 
durchschnittlich zwischen 5,32 und 10,57 Stunden (Nagassar et al. 2013). In der Arbeit von Funke et al. wird die gegebene Analysezeit mit nur drei Stunden beschrieben (Funke et al. 1998).

\subsubsection{Genomische Verfahren}

Genomische Verfahren basieren auf der Analyse des bakteriellen Erbguts, vor allem den spezifischen Gensequenzen der ribosomalen (r)DNA. Vertreter der genom-basierten Verfahren sind die klassische Polymerase-Kettenreaktion (polymerase chain reaction (PCR)), die Fluoreszenz-in-situ-Hybridisierung (FISH) und die noch jungen Multiplex-PCRAnwendungen.

Das PCR-Verfahren basiert auf einer Vervielfältigung ausgewählter DNA-Abschnitte. Diese DNA-Abschnitte werden temperaturabhängig denaturiert, sodass eine Auftrennung der DNA-Stränge erfolgt. Durch das Hinzufügen von Primern, welche sich an die entsprechenden DNA-Abschnitte anlagern, kann nun durch die DNA-Polymerase der entsprechende DNA-Abschnitt vervielfältigt werden. Dieser Prozess besteht aus bis zu 50 Zyklen und die neu gewonnenen DNA-Abschnitte bezeichnet man als Amplifikate. Im letzten Schritt werden diese Amplifikate durch Agarose-Gelelektrophorese anhand ihrer Größe identifiziert und verglichen. $\mathrm{Zu}$ Beginn des PCR-Verfahrens zur Erregeridentifikation ist zunächst eine Erregeranzucht, wie beispielsweise eine positive Blutkultur, notwendig (Müller und Prange 2016).

Ein ähnliches Verfahren ist die FISH-Analyse. Dabei werden die Erreger nach der Anzucht fixiert und für sogenannte Sonden permeabel gemacht. Diese Sonden bestehen aus Fluoreszenz-markierten DNS-Sequenzen, welche sich an Zielstrukturen der Erreger-DNA anlagern und dadurch unter einem Fluoreszenzmikroskop sichtbar gemacht werden können (Huber et al. 2018).

Grundsätzlich können beide Verfahren die Identifikation von Erregern beschleunigen, jedoch kann die erregerspezifische Kultivierungszeit nicht bei der vorher notwenigen Anzucht verkürzt werden. Als Weiterentwicklung dieser Verfahren ohne vorherige Anzucht wurde 1993 erstmalig ein PCR-Verfahren zum direkten Nachweis von Bakterien aus Vollblut entwickelt. Hierbei wurden Primer synthetisiert, die einen Abschnitt des Salmonella-typhi-Gens enthalten. Blutproben von Patienten mit Verdacht auf Typhus wurden mittels PCR analysiert und in ca. $92 \%$ positiv getestet (Song et al. 1993). 
Eine Weiterentwicklung der PCR ist die Multiplex-PCR, die seit Beginn des 21. Jahrhunderts Einzug in die klinische Mikrobiologie gefunden hat. Durch die Zugabe mehrerer Primerpaare ist der Nachweis von mehr als einem Genomabschnitt möglich. Zielsequenzen der Primer sind die Internal-transcribed-spacer-Regionen (ITS-Regionen). Sie sind spezielle, artspezifische und variable Abschnitte der rDNA von Bakterien und Pilzen (Lodes et al. 2011). Auch hier wird nach Amplifikation der Zielsequenzen eine Sequenzierung zur Spezieserkennung durchgeführt. Multiplex-PCR-Ansätze eignen sich für die Diagnostik von Infektionen oder Erbkrankheiten.

Zur Sepsis-Diagnostik wurde ein Multiplex-PCR-Kit, LightCyclerSeptiFast (Roche, Mannheim, Deutschland) kommerziell eingeführt, welches direkt mit Patienten-Vollblut verwendet werden kann. Es ist auf das Spektrum der häufigsten Sepsis-Erreger ausgelegt. Getestet werden hierbei die Zielsequenzen der 25 wichtigsten gram-positiven und gramnegativen Bakterien, sowie die von relevanten Pilzen. Die Genauigkeit des SeptiFastTests verglichen mit konventionellen mikrobiologischen Verfahren wird mit 77-98,8\% angegeben (Dierkes et al. 2009; Lehmann et al. 2008). Falsche Ergebnisse lieferte der SeptiFast Test aufgrund identischer ITS-Regionen zwischen den Klebsiellae- und Enterobacter-Spezies (Lehmann et al. 2008). Als limitierend erweist sich die Anzahl der Primer in einem Multiplex-PCR-Ansatz. Bei erhöhten Primer-Zahlen kann es zu Interaktionen und Heteromerbildungen kommen, sodass weniger ITS-Regionen erkannt werden (Pletz et al. 2011).

Eine Weiterentwicklung der Multiplex-PCR-Ansätze (mPCR) enthält zusätzlich Resistenzmarker um die entsprechenden Resistenzgene zu identifizieren. Kunze et al. haben einen solchen mPCR-Ansatz für nosokomial erworbene Pneumonien in einer klinischen Studie getestet. Der Vergleich der Ergebnisse der mPCR mit den konventionell über die Mikrobiologie gewonnenen Ergebnisse ergab eine nur $60 \%$ ige Übereinstimmung. Als schwierig erwies sich die Tatsache, dass manche Resistenzgene wie beispielsweise mecA (Resistenz für Oxacillin und Methicillin) bei Staphylococcus aureus (S. aureus) und Staphylococcus epidermidis (S. epidermidis) auftreten. Der mPCR-Ansatz enthielt jedoch nur die DNA für $S$. aureus, sodass hier eine falsche Resistenzbestimmung stattfinden könnte (Kunze et al. 2015). 


\subsubsection{Proteomische Verfahren}

Einen anderen Ansatz der Erregeridentifikation bieten massenspektrometrische Verfahren zur Protein- und Peptidanalyse. Bei der Massenspektrometrie werden ionisierte Teilchen nach ihrem Masse/Ladungs-Verhältnis (m/z) aufgetrennt und analysiert (Burak und Gehrt 2010). Bereits Mitte der siebziger Jahre wurden erste Versuche von Anhalt und Fenselau (1975) unternommen, Bakterien durch Massenspektrometrie zu charakterisieren. Systeme, wie die Kopplung aus Matrix-unterstützter LaserDesorption/Ionisation und Massenspektrometrie mit Flugzeitanalyse, das sog. MALDITOF-MS (engl. matrix-assisted laser desorption ionization time-of-flight mass spectrometry), oder die Kombination aus oberflächen-gestützter Laser-Desorption/Ionisation und Massenspektrometrie mit Flugzeitanalyse, dem sog. SELDI-TOF-MS (engl. surfaceenhanced laser desorption ionization time-of-flight mass spectrometry) wurden in den neunziger Jahren entwickelt und sind von aktuellem Forschungsinteresse in der Erregerdiagnostik.

Besonders im 21. Jahrhundert wird die MALDI-TOF-MS für die mikrobiologische Diagnostik zunehmend relevanter. Die besonders kurzen Analysezeiten von der Vorbereitung der Probe bis zum Vorliegen eines validen Ergebnisses in 30 Minuten mittels MALDI-TOF können für die Therapieentscheidung bei Infektionen entscheidend sein (He et al. 2010). Die Erreger werden zusammen mit einer Matrix-Lösung auf eine Targetplatte aufgebracht. Nach Auskristallisation kann die Targetplatte in das MALDI-TOF-MS Analysegerät inseriert werden. Ein Laser verdampft die aufgetragene Probe und die entstanden Ionen wandern in einem elektrischen Feld zu einem Detektor. Auf diesem Weg erfolgt die Separierung anhand ihrer Masse und ihres Ionisationsgrades, sodass sie nach unterschiedlichen Zeiten auf dem Detektor auftreffen. Es entsteht ein Massenspektrum, das zur Erregeridentifikation mittels einer Datenbank genutzt wird (Burkhardt et al. 2009)

Van Veen et al. und Moussaoui et al. haben in ihren Studien verschiedene Bakterienkulturen mittels MALDI-TOF-MS analysiert und die Ergebnisse mit denen konventioneller Methoden verglichen. Hierbei konnte eine bis $\mathrm{zu} 90 \%$ ige Übereinstimmung der Resultate gezeigt werden (Van Veen et al. 2010; Moussaoui et al. 2010). Eine noch größere Genauigkeit von 95,4\% wurde durch die Arbeitsgruppe von Seng et al. anhand 1660 klinischer Isolate nachgewiesen (Seng et al. 2009). 
Eine weitere Methode zum Nachweis komplexer Proteingemische kann die SELDI-TOF-MS Analyse sein. Hierbei werden Proteine auf speziell ausgewählten Proteinchip-Arrays angereichert und anschließend massenspektrometrisch analysiert. Fenollar et al. (2006) untersuchten Serumproben von Patienten mit Verdacht auf bakterielle Endokarditis mit der SELDI-TOF-MS Technik und konnten in fast $90 \%$ der Serumproben korrekte Ergebnisse im Vergleich zu konventionellen Techniken nachweisen.

Obwohl für die obengenannten Methodiken in vielen Studien gezeigt wurde, dass sie die Fähigkeit besitzen, pathogene Keime zu identifizieren, haben sie sich bisher nicht für den routinemäßigen Gebrauch außerhalb von Kliniken der Maximalversorgung durchgesetzt. Gründe hierfür könnten der hohe Zeitaufwand, die Komplexität einzelner Verfahren oder auch hohen Kosten sein, so dass die konventionelle mikrobiologische Diagnostik weiter ihren Stellenwert als Standardverfahren behält.

\subsubsection{Metabolomischer Ansatz}

Seit dem frühen 20. Jahrhundert ist bekannt, dass Bakterien spezifische Stoffwechselprodukte produzieren, die teilweise als flüchtige Substanzen an die Umwelt abgegeben werden. Zoller und Clark konnten die ersten Zusammenhänge zwischen der Entstehung von Butter- und Ameisensäure bei Shiga- und Nicht-Shiga-produzierenden Bakterien unter der Zugabe von Glucose nachweisen, und den möglichen Zusammenhang mit gastrointestinalen Problemen durch diese Toxine herleiten (Zoller und Clark 1921).

Aus diesen frühen Beobachtungen entstand die Idee, Bakterien anhand ihrer Stoffwechselprodukte zu unterscheiden. Die von den Mikroorganismen emittierten volatilen organischen Verbindungen bilden das sog. Metabolom eines Bakteriums ab und könnten eine Identifizierung der Mikroorganismen ermöglichen. Schulz und Dickschat beschreiben die Entstehung von 346 unterschiedlichen VOCs durch Bakterienwachstum. Einige von ihnen scheinen für bestimmte Bakterienspezies spezifisch zu sein (Schulz und Dickschat 2007). Die VOC-Emission von Bakterien dient dabei beispielsweise der Kommunikation innerhalb der Kolonie (im Sinne einer Chemotaxis), wie etwa die Emission wachstumsfördernder oder -inhibierender Substanzen (Kai et al. 2009).

Ein Analyseverfahren, das für den Nachweis von VOCs geeignet ist, ist die Gaschromatographie-Massenspektrometrie (GC-MS). Durch die hohe Sensitivität und die Möglichkeit Stoffgemische mit ihren Einzelsubstanzen zu analysieren erwies sie sich als 
sehr zuverlässige Methode. Jede Substanz ist durch ihren spezifischen Kovats-RetentionsIndex zu identifizieren. Diese Ergebnisse werden in Datenbanken hinterlegt, jedoch besteht hier noch keine Vollständigkeit (Kai et al. 2009). Die Methode ist zudem sehr zeitund materialaufwändig. Eine direkte Proben-Analyse ist mit den meist sehr großen GCMS-Laboraufbauten nicht möglich, so dass regelmäßig auf die Verwendung von Thermodesorptionsröhrchen (z. B. Tenax-Röhrchen) als Probenträger zurückgegriffen werden muss.

Ein alternatives Verfahren zur Detektion und Identifikation von VOCs ist die Ionenmobilitätsspektrometrie. In den siebziger Jahren war diese Methode noch unter dem Namen „Plasmachromatographie“ bekannt und wurde zunächst für militärische Zwecke zur Sprengstoff-, Kampfstoff- und Drogendetektion genutzt (Karasek 1974; Hill et al. 1990). Mittlerweile erweist sie sich jedoch als sehr vielfältig anwendbare Methode zum Nachweis von leicht flüchtigen organischen Verbindungen und wird $u$. a. in der Lebensmittelindustrie und im Bauwesen angewendet (Tiebe et al. 2009).

In den vergangenen Jahren hat die Ionenmobilitätsspektrometrie auch Einzug in die Medizin gehalten. Forschungsgruppen konzentrierten sich auf die Analyse von Körperflüssigkeiten und Atemgasen. So ist z. B. die Detektion illegaler Drogen mittels IMS möglich. Mercer et al. (2006) wiesen beispielsweise Gamma-Hydroxybuttersäure (GHB, sog. „Liquid Ecstasy“) in Urin- und Atemluftproben nach. Auch in der Krebsforschung wird die Ionenmobilitätsspektrometrie genutzt. Isailovic et al. haben Seren von Patienten mit Leberzirrhose, hepatozellulärem Karzinom und gesunden Probanden anhand von enzymatisch freigesetzten Glycanen aus Glycoproteinen untersucht. Hierbei konnten verschiedene Ionenmobilitäten $(\mathrm{m} / \mathrm{z})$ detektiert und zur Unterscheidung der Erkrankungen der Probanden herangezogen werden (Isailovic et al. 2008).

Aufgrund fehlender Vortrennung ist die Analyse komplexer Gasproben (wie z. B. Atemluftproben) allein mit einem IMS problematisch, weil die Differenzierung von Substanzen mit ähnlicher Masse bzw. Polarität durch sich überlagernde Driftzeiten erschwert wird. Erste Versuche diesen Limitierungen entgegenzuwirken, bestanden darin einen Gaschromatographen an ein IMS zu koppeln, um eine Vortrennung von komplexen Proben zu ermöglichen (Karasek und Keller 1972; Snyder et al. 1993; Simpson et al. 1996).

Eine platz- und zeitsparende Alternative zur Vortrennung komplexer und feuchter Gasgemische ist die Kopplung des IMS mit einer Multikapillarsäule (multi-capillary column, MCC). Eine Multikapillarsäule setzt sich aus vielen gebündelten Kapillaren, die im Inneren eine stationäre und eine mobile Phase aufweisen, zusammen. Die stationäre Phase 
besteht aus gebundenen Silikonen, die im Inneren jeder einzelnen Kapillare eine Oberfläche mit spezifischen Eigenschaften bildet und an die Molekülgruppen je nach ihrer Affinität zu dieser Oberfläche unterschiedlich lange binden (Baumbach et al. 1997). Mit der mobilen Phase, die aus einem Trägergas besteht, werden die Molekülgruppen durch die Kapillaren transportiert. Aus dieser Auftrennung der Moleküle resultiert für jede Substanz eine spezifische Retentionszeit, die für die Identifikation der Substanzen herangezogen werden kann.

Die Kopplung aus Multikapillarsäule und Ionenmobilitätsspektrometer (MCC-IMS) ermöglicht die Analyse komplexer Gasgemische in kurzer Zeit und erweitert damit die möglichen Anwendungsgebiete. Besonders geeignet ist die MCC-IMS für feuchte Gasgemische, da die Wassermoleküle der Probe von den zu analysierenden Substanzen nahezu vollständig getrennt werden können. Es kommt nicht zu einer Verringerung der Signalintensität der zu detektierenden Ionen durch Clusterbildung (Vautz et al. 2004). Dieser Umstand ist in der medizinisch-mikrobiologischen Forschung von besonderer Bedeutung, da Gasproben in diesem Bereich häufig einen hohen Wasseranteil aufweisen (Atemluftproben, Headspace-Proben über Bakterienkulturen).

\subsubsection{Ionenmobilitätsspektrometrie}

Das folgende Kapitel orientiert sich an dem Review „Ion Mobility Spectrometry in analytical chemistry" von St. Louis et al. (1990) sowie an der Monographie „Ion Mobility Spectrometry" von Eiceman und Karpas (2005).

Die Ionenmobilitätsspektrometrie ist ein analytisches Verfahren zur Identifizierung und Quantifizierung von gasförmigen organischen Verbindungen im Spurenbereich (Pikogramm) mit kurzen Analysezeiten. Grundlage dieses Verfahrens ist die Ionisation gasförmiger Moleküle, die im Anschluss durch ein homogenes elektrisches Feld geleitet werden. Die Zeit bis zum Auftreffen der Moleküle auf einem Detektor wird gemessen und daraus die Ionenmobilität abgeleitet. Substanzen können qualitativ durch ihre Ionenmobilität (reduzierte Ionenmobilität $\mathrm{K}_{0}$ oder relative Driftzeit) unterschieden werden. Mithilfe der konzentrationsabhängigen Signalintensität kann darüber hinaus eine Aussage über die Quantität der ermittelten Substanz getroffen werden. 


\subsubsection{Allgemeines Funktionsprinzip}

Die Hauptkomponente des Ionenmobilitätsspektrometers (IMS) ist die Driftröhre (Abb. 1). Ein Pulsgitter unterteilt die Driftröhre in einen Ionisationsraum mit ß-StrahlenIonisationsquelle und einen Driftraum. Am Ende der Driftröhre befindet sich ein Detektor.

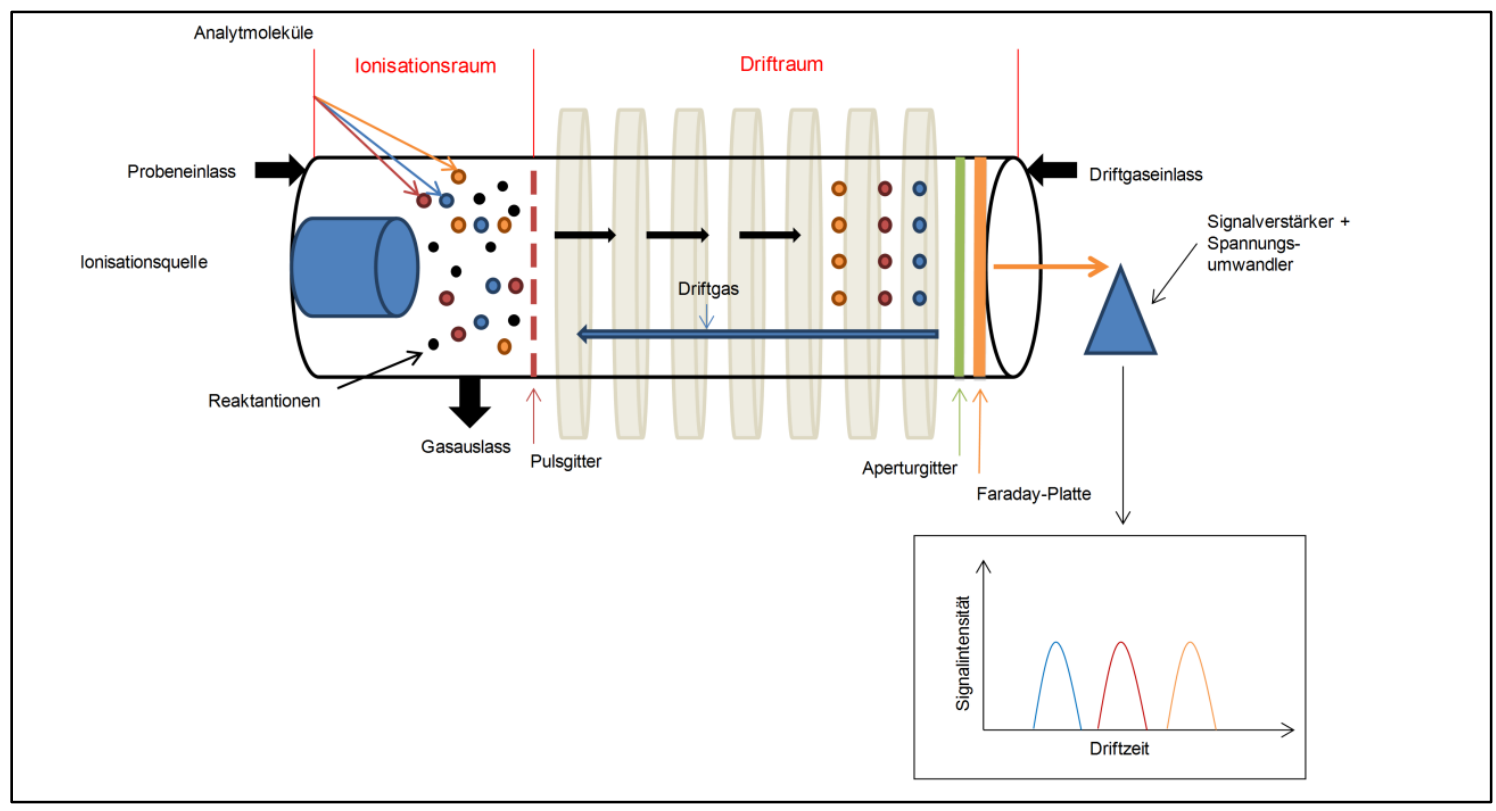

Abbildung 1. Aufbau der Driftröhre eines IMS.

Im Ionisationsraum befindet sich die Ionisationsquelle die sogenannte Reaktant-Ionen bildet. Nach dem Zuführen von Analyt-Molekülen durch den Probeneinlass in den Ionisationsraum, werden diese durch einen Protonentransfer von den Reaktant-Ionen ionisiert.

Ein Driftgas, häufig synthetische Luft, durchströmt den Driftraum in Richtung Ionisationsraum. Durch die periodische Öffnung des Pulsgitters gelangen die nun protonierten Analyt-Moleküle in den Driftraum. Hier herrscht ein homogenes elektrisches Feld von typischerweise 200-300 V/cm. Dieses Feld wird mittels einer Widerstandskette, bestehend aus miteinander verbundenen Metallringen und Isolationsmaterial (Keramik, Teflon), erzeugt und aufrecht erhalten. Die Ionen wandern entlang der elektrischen Feldlinien in Richtung des Detektors (Faraday-Platte) und kollidieren dabei mit Driftgasmolekülen, die ihnen entgegen strömen. Dadurch wird eine Clusterbildung mit 
neutralen Ionen verhindert. Die Kollisionen bremsen die Ionen bei der Drift zum Detektor ab und verleihen ihnen charakteristische Driftgeschwindigkeiten. Diese sind abhängig von der Größe und Form der Ionen. Aus der Driftgeschwindigkeit lässt sich die Zeit, die ein Ion benötigt um die Driftröhre zu durchwandern, bestimmen. Diese Zeit nennt man Driftzeit und sie ist spezifisch für eine Art von Analyt-Molekülen. Die Driftzeit wird in Millisekunden (ms) angegeben.

Vor dem Detektor am Ende der Driftröhre befindet sich ein Aperturgitter, welches der kapazitiven Entkopplung der Ionen in der Driftstrecke und der Faraday-Platte dient. Das Auftreffen der Ionen auf die Faraday-Platte erzeugt ein Signal, das durch einen Strom-/Spannungswandler verstärkt und für die weitere Datenverarbeitung digitalisiert wird. Graphisch ergibt sich ein Driftzeitspektrum, welches die Signalstärke in Abhängigkeit der Driftzeit wiedergibt.

\subsubsection{Ionenerzeugung mittels radioaktiver Strahlungsquelle}

In der Ionenmobilitätsspektrometrie werden verschiedene Ionisationsquellen verwendet. Häufig finden radioaktive $\beta$-Strahlenquellen wie 63Nickel (63Ni) oder Tritium Anwendung. Weitere Ionisationsquellen können z. B. Koronarentladung, Elektrospray-, Photo- und Laserionisation sein.

Im Folgenden wird die Ionisation durch eine radioaktive 63Ni-Strahlenquelle (550 MBq) erläutert. Hierbei werden $\beta$-Teilchen mit einer maximalen Energie von $67 \mathrm{keV}$ (Kiloelektronenvolt) emittiert, die bei Kollision mit Driftgasmolekülen diese ionisieren (Pellizzari 1974). Als Driftgas kann synthetische Luft $\left(\mathrm{O}_{2}+\mathrm{N}_{2}\right)$, die sich durch einen hohen Reinheitsgrad auszeichnet, oder Stickstoff $\left(\mathrm{N}_{2}\right)$ verwendet werden. Die $\beta$-Teilchen ionisieren den molekularen Stickstoff und benötigen für die Bildung eines Ionenpaares 35 $\mathrm{eV}$ (Elektrovolt). Dieser Prozess findet so lange statt, wie die Energie der $\beta$-Teilchen über dem Ionisationspotential von $\mathrm{N}_{2}$ von 15,58 eV liegt (Pellizzari 1974). Die folgende Gleichung zeigt den oben beschriebenen Prozess:

$$
N_{2}+\beta \rightarrow N_{2}^{+}+\beta^{`}+e^{-}
$$

In der obigen Gleichung entspricht $\beta$ ` einem $\beta$ mit reduzierter Energie (Sielemann 1999) und $e^{-}$einem produzierten Elektron durch die Ionisation des molekularen Stickstoffs.

In synthetischer Luft sind stets Spurenelemente, wie Wasser $\left(\mathrm{H}_{2} \mathrm{O}\right)$, Stickstoffmonoxid 
(NO) und Ammoniak $\left(\mathrm{NH}_{4}\right)$, enthalten. Sie sind immer vorhandene, minimale Verunreinigungen. Der ionisierte Stickstoff reagiert mit den Spurenelementen und bildet positive Reaktionsionen: $\left(\mathrm{H}_{2} \mathrm{O}\right)_{\mathrm{x}} \mathrm{H}+,\left(\mathrm{H}_{2} \mathrm{O}\right)_{y} \mathrm{NO}^{+}$und $\left(\mathrm{H}_{2} \mathrm{O}\right)_{\mathrm{z}} \mathrm{NH}_{4}{ }^{+}$. Folgende Grundlage kann angenommen werden: $\mathrm{x}=2,3$ oder $4 ; \mathrm{y}=0$ oder $1 ; \mathrm{z}=0$ oder 1 (Carroll et al. 1975). Eiceman et al. (1985) und Good et al. (1970) zeigten, dass $\left(\mathrm{H}_{2} \mathrm{O}\right)_{\mathrm{x}} \mathrm{H}^{+}$die häufigsten gebildeten Reaktionsionen sind und mit der Flussrate des Driftgases variieren können. Aufgabe der Reaktionsionen ist die Abgabe von Protonen an Analyt-Moleküle, wenn diese in den Ionisationsraum geleitet werden. In einem IMS-Spektrum sind die Reaktionsionen $\left(\left(\mathrm{H}_{2} \mathrm{O}\right)_{\mathrm{x}} \mathrm{H}^{+}\right.$Ionen) graphisch als Reaktionsionenpeak (RIP) dargestellt (Abb. 2). Der wesentlich kleinere, linksliegende Pre-RIP spiegelt die $\left(\mathrm{H}_{2} \mathrm{O}\right)_{\mathrm{z}} \mathrm{NH} 4+$ wider. Durch ihr zu geringes Vorkommen sind die $\left(\mathrm{H}_{2} \mathrm{O}\right)_{\mathrm{y}} \mathrm{NO}^{+}$nicht zu erkennen.

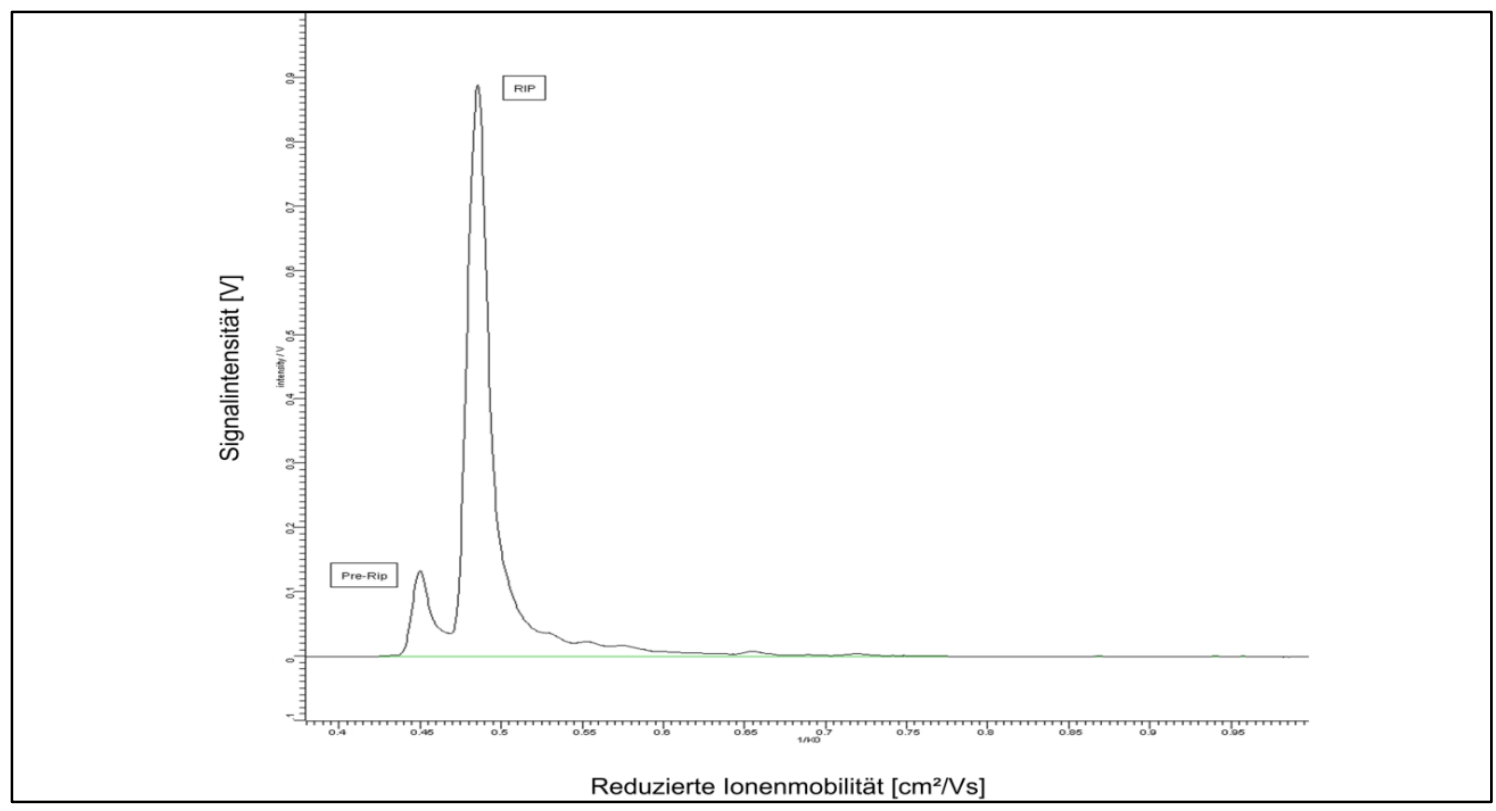

Abbildung 2. Darstellung eines Ionenmobilitätsspektrums des verwendeten IMS mit 63NiStrahlenquelle. RIP: $\left(\mathrm{H}_{2} \mathrm{O}\right)_{\mathrm{x}} \mathrm{H}^{+}$, Pre-RIP: $\left(\mathrm{H}_{2} \mathrm{O}\right)_{2} \mathrm{NH}_{4}{ }^{+}$.

Der im Driftgas enthaltene Sauerstoff $\left(\mathrm{O}_{2}\right)$ bildet durch Anlagerung negativer Elektronen zeitgleich negative Reaktionsionen. Abhängig vom Einstellungsmodus des IMS (negativ Modus) können diese als negative reactant ions (RIN) im Ionenmobilitätsspektrum sichtbar sein. Die Bildung von $\mathrm{O}_{2}^{-}\left(\mathrm{H}_{2} \mathrm{O}\right)_{2}$ dominiert unter Verwendung von feuchter Luft (Carr 1979).

Im positiven IMS-Modus findet in der Reaktionszone im Ionisationsraum die Bildung positiver Produkt-Ionen statt. Die Reaktionsionen kollidieren mit neutralen AnalytMolekülen (A) und bilden sogenannte Analytionen. Diese Protonen-Transfer-Reaktion ist durch eine höhere Protonenaffinität der Analyt-Moleküle möglich. 


$$
\begin{gathered}
\left(\mathrm{H}_{2} \mathrm{O}\right)_{x} H^{+}+A \rightarrow A H^{+}\left(\mathrm{H}_{2} \mathrm{O}\right)_{x} \rightarrow A H^{+}+x \mathrm{H}_{2} \mathrm{O} \\
\text { [Reaktionsion + Analyt-Molekül } \rightarrow \text { Cluster-Ion } \rightarrow \text { Analytion + Wasser] }
\end{gathered}
$$

Die entstandenen Analytionen werden durch Ablösung von Wassermolekülen stabilisiert. Dabei verringert sich der RIP und es bildet sich ein Analytionen-Peak.

Dissoziation oder Fragmentierung der Analytionen sind selten zu beobachten. Bei höheren Konzentrationen vorhandener Analyt-Moleküle und Abhängigkeit von der Protonenaffinität kann es zu einer Dimerbildung, wie in Gleichung 3 beschrieben, kommen.

$$
A+A H^{+} \rightarrow A_{2} H^{+}
$$

Des Weiteren besteht die Möglichkeit der höherwertigen Clusterbildung, welche von Temperatur, Feuchtigkeit und der Reinheit des Driftgases abhängig ist.

\subsubsection{Ionenmobilität in Gasen}

Ziel der Ionenmobilitätsspektrometrie ist die Differenzierung von ionisierten Molekülen durch ihre Bewegung in einem homogenen elektrischen Feld. Die Ionenmobilität wird durch die Proportionalitätskonstante $K\left[\mathrm{~cm}^{2} / \mathrm{Vs}\right]$ beschrieben. Sie postuliert eine direkte Proportionalität zwischen der Driftgeschwindigkeit $v_{d}[\mathrm{~cm} / \mathrm{s}]$ von Ionen und dem elektrischen Feld. Die Ionen erfahren durch das homogene elektrische Feld eine Beschleunigung, jedoch kommt es zu Dezelerationen (Geschwindigkeitsverlusten) durch Kollisionen mit neutralen Gasmolekülen (Driftgas). Hieraus resultiert eine mittlere Driftgeschwindigkeit innerhalb der Driftröhre. Diese Driftgeschwindigkeit ist spezifisch für das ionisierte Molekül und direkt proportional zur elektrischen Feldstärke $E_{d}[\mathrm{~V} / \mathrm{cm}]$.

$v_{d}=K \times E_{d}=\frac{l_{d}}{t_{d}}$

Die Driftgeschwindigkeit $v_{d}$ berechnet sich aus dem Quotienten der Driftröhrenlänge $l_{d}$ und der Zeit $t_{d}$, in der die Ionen die Driftröhre passieren und den Detektor erreichen. Beim Auftreffen auf den Detektor findet eine Ladungsübertragung statt, die ein elektrisches Signal erzeugt.

Durch Umstellung der Variablen der obigen Gleichung 4 lässt sich die Ionenmobilität $K$ aus der gemessenen Driftzeit bestimmen. 
$K=\frac{l_{d}}{t_{d} \times E_{d}}$

Das ideale Gasgesetz besagt, dass Unterschiede in Atmosphärendruck $p$ und Temperatur $T$ die Dichte eines Gases verändern. Um bei der Auswertung der Ionenmobilität vergleichbare Ergebnisse zu erzielen, wird die reduzierte Ionenmobilität $K_{0}\left[\mathrm{~cm}^{2} / \mathrm{Vs}\right]$ eingeführt. Diese geht zunächst von den Standardbedingungen $\mathrm{p}_{0}=1013,2 \mathrm{hPa}$ und $\mathrm{T}_{0}=$ 273,2 K aus.

$K_{0}=K\left(\frac{p}{p_{0}}\right)\left(\frac{T_{0}}{T}\right)$

$p$ und $T$ der obigen Gleichung sind die aktuellen oder während des jeweiligen Messvorgangs erfassten Temperatur- und Druckwerte der IMS-Driftzelle.

Revercomb und Mason veröffentlichten 1975 eine Gleichung zur Berechnung der Mobilität von Ionen unter Berücksichtigung der gaskinetischen Gesetze (Revercomb und Mason 1975):

$K=\frac{3}{16} \frac{q}{N}\left(\frac{1}{m}+\frac{1}{M}\right)^{1 / 2}\left(\frac{2 \pi}{k T}\right)^{1 / 2} \frac{1}{\Omega_{D}}$

In der Gleichung bezeichnet $q$ die Ladung des Ions, $N$ die Molekülzahl des Driftgases, $m$ die Ionenmasse, $M$ die Masse der neutralen Driftmoleküle, $k$ die Boltzmann-Konstante, $T$ die Temperatur des Driftgases und $\Omega_{D}$ den temperaturabhängigen Stoßquerschnitt, welcher die Wahrscheinlichkeit von Wechselwirkungen zwischen den Ionen beschreibt. Zudem ist anzunehmen, wenn $m>M$ ist, dass ein Korrekturfaktor kleiner 0,02 anzuwenden ist.

Aus Gleichung 7 lässt sich schlussfolgern, dass die Mobilität von Ionen abhängig von ihrer Masse und umgekehrt proportional zu der Größe der Ionen ist. Daraus resultiert laut Revercomb und Mason, dass

$K^{-1} \propto \mu^{1 / 2} \Omega_{\mathrm{D}}$

wobei $\mu\left(\mu=\frac{m M_{m}}{m+M_{m}}\right)$ die reduzierte Masse und $\Omega_{D}$ die Größe der Ionen wiederspiegelt (Revercomb und Mason 1975). $\Omega_{D}$ ist für atomare Ionen annähernd konstant und die Mobilität der Ionen wird von der reduzierten Masse $\mu$ kontrolliert. 


\subsubsection{Kopplung des IMS an Trennungsverfahren}

Die Analyse komplexer Gasgemische mittels IMS ohne Vortrennung ist problematisch, da wie bereits in Kapitel 1.1.3.2 geschildert - Peak-Überlagerungen durch ähnliche Driftzeiten verschiedener Metaboliten und Clusterbildungen auftreten können. Durch eine gaschromatographische Vortrennung des Analysegases können diese Probleme umgangen werden. Die Vortrennung ermöglicht einen zeitversetzten Einlass der Analyt-Moleküle in das IMS. Die Identifikation ist nun durch die Driftzeit und die neu entstandene molekülspezifische Retentionszeit (RT) möglich.

Erste Versuche einer gaschromatographischen Vortrennung erfolgten 1972 von Karasek und Keller. Sie koppelten einen Gaschromatographen an ein IMS zur Analyse von Moschus Ambrette. Die hierbei auftretenden Probleme konnten durch technische Änderungen weitgehend überwunden werden (Karasek und Keller 1972). Allerdings ist die Gaschromatographie ein aufwendiges Verfahren mit langen Analysezeiten.

Alternativ wurde Mitte der 90er Jahre die Multikapillarsäule entwickelt und dem IMS vorgeschaltet. Sie besteht aus ca. 1.000 Kapillaren mit einem Innendurchmesser von $43 \mu \mathrm{m}$. Zusammen ergeben sie eine einzelne Glassäule. Die Filmdicke einer Kapillare beträgt 0,2 $\mu \mathrm{m}$ (Sibertech Ltd.). Die benötigte Zeit zur Vortrennung von Gasgemischen liegt bei einigen Sekunden bis zu wenigen Minuten. Multikapillarsäulen können in einem Temperaturbereich von $20-300{ }^{\circ} \mathrm{C}$ betrieben werden. Besonders geeignet für die Kopplung an ein IMS sind die unterschiedlichen Flussraten von 5 bis zu $300 \mathrm{ml} / \mathrm{min}$ im Vergleich zur herkömmlichen Gaschromatographie $(<1,5 \mathrm{ml} / \mathrm{min})$. In Abbildung 3 ist ein Querschnitt durch eine Multikapillarsäule abgebildet. 


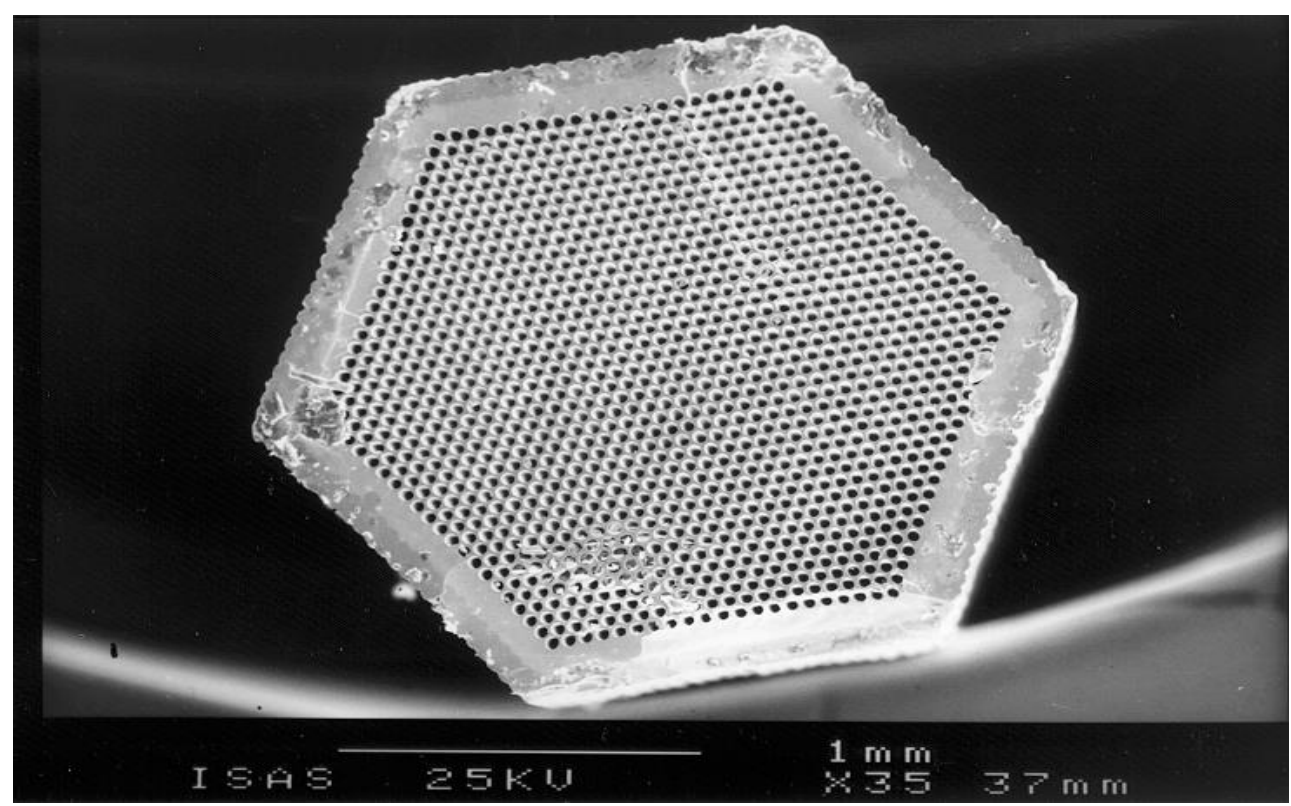

Abbildung 3. Querschnitt einer Multikapillarsäule (MCC). Hersteller: Sibertech Ltd., Novosibirsk, Russland. (Sielemann et al. 1999) Die Verwendung erfolgt mit freundlicher Genehmigung vom Autor.

\subsubsection{MCC-IMS zur Detektion von Krankheitserregern}

Die Detektion und Identifikation mikrobieller VOCs mittels MCC-IMS erscheint aufgrund der Schnelligkeit und Empfindlichkeit des Verfahrens von besonderem Interesse für die Humanmedizin. Arbeitsgruppen beschäftigen sich mit der Analyse unterschiedlicher Probenmaterialien wie beispielsweise Atemluft, Blut und Urin. Flüssige Medien müssen häufig erst aufgearbeitet werden, um sie mittels MCC-IMS analysieren zu können. Die direkte Analyse von Atemluft eines Patienten eröffnet die Möglichkeit einer schnellen, nicht-invasiven und patientennahen Diagnostik.

Zu Beginn der 1990er Jahre konnten erste Stoffwechselprodukte enzymatischer Reaktionen von E. coli mit einem Ionenmobilitätsspektrometer/Massenspektrometer (IMS/MS) nachgewiesen werden. Snyder et al. detektierten o-Nitrophenol (ONP), das aus der Reaktion zwischen ß-Galaktosidase mit dem Substrat (o-Nitrophenyl)Galaktopyranoside (ONPG) in E. coli Bakterien entsteht (Snyder et al. 1991). Mit dem Wissen, dass mehrere metabolische Aktivitäten und damit unterschiedliche Stoffwechselprodukte während des bakteriellen Wachstums auftreten, arbeiten Forscher an der Erstellung spezies-spezifischer VOC-Profile mit dem MCC-IMS. Maddula et al. erbrachten den Nachweis vier flüchtiger organischer Verbindungen, die typisch für das Wachstum von E. coli sind: Ethanol, Aceton, 2-Nonanone und 2-Heptanone (Maddula et al. 
2009). Eine Weiterentwicklung war die Arbeit von Jünger et al., die sich mit dem Vergleich 15 verschiedener humanpathogener Bakterien beschäftigte. Jedes Bakterium wurde auf Schafsblut-Agar angezüchtet, 24 Stunden lang inkubiert und der Headspace über der Kultur anschließend mittels MCC-IMS analysiert. Anhand der erstellten VOC-Profile konnten die Keime voneinander unterschieden werden (Jünger et al. 2012).

Ein Versuch zur Detektion von Pneumonie-Erregern unmittelbar aus der Atemluft wurde u. a. von Rabis et al. unternommen, die Atemgasproben von Patienten mit und ohne Pseudomonas aeruginosa-Besiedelung der Atemwege untersuchten. Dabei zeigten sich 21 Signale, die zur Differenzierung beider Patientengruppen herangezogen werden konnten (Rabis et al. 2011). Ein ähnlicher experimenteller Ansatz zur Sepsis-Diagnostik wurde in einem Tierversuch mit infizierten und gesunden Ratten durchgeführt. Den Tieren wurde ein Lipopolysaccarid von E. coli injiziert, um einen vergleichbare Immunantwort bei Sepsis hervorzurufen. Anhand einer Atemgasanalyse konnten die Versuchstiere mit einer gesunden Kontrollgruppe von Ratten verglichen und differenziert werden (Guamán et al. 2012).

Neben dem Ansatz einer direkten in-vivo-Analyse (z. B. anhand von Atemluftproben), beschäftigten sich Arbeitsgruppen vor allem mit in-vitro-Fragestellungen, für die Mikroorganismen meist in spezifischen oder komplexen Medien angezüchtet wurden. O'Hara und Mayhew zeigten, dass das eingesetzte Nährmedium einen Einfluss auf die VOCProduktion hat. Zwar wiesen die Autoren jener Studie bei Verwendung unterschiedlicher Nährmedien jeweils dieselben Metaboliten nach, jedoch zeigten sich Abweichungen bei den zeitlichen Verläufen des Auftretens dieser VOCs (O’Hara und Mayhew 2009).

Die oben genannten Beispiele zeigen, wie weit sich die Forschung mit MCC-IMS in den letzten Jahren entwickelt hat. Zunächst wurden spezies-spezifische VOCs identifiziert, es wurde aber auch bereits der Versuch einer in-vivo-Erregerdiagnostik mit der Methode begonnen.

Ziel der vorliegenden Arbeit ist die Untersuchung der VOC-Profile von E. coli und $P$. aeruginosa während ihres Wachstums in einem komplexen Flüssignährmedium. Zentrale Fragestellung ist dabei, ob und wann sich die beiden Bakterien unterscheiden lassen. Der Zeitpunkt des Auftretens spezifischer VOCs und deren Veränderung über die Wachstumsphasen sollten Aufschluss über die metabolischen Aktivitäten liefern. Weiterhin soll überprüft werden, ob sich die VOC-Muster verschiedener Bakterienstämme einer Spezies unterscheiden. Hierfür wurden neben Referenzstämmen auch klinische Isolate der genannten Bakterien untersucht. 


\section{MATERIAL UND METHODEN}

\subsection{Verwendetes MCC-IMS und Probennahme}

Das allgemeine Funktionsprinzip der Ionenmobilitätsspektrometrie wurde in Kapitel 1.1.3 ausführlich erläutert.

Für diese Arbeit wurde ein MCC-IMS vom Typ Breath Discovery der Firma B\&S-Analytik (B\&S-Analytik GmbH, Dortmund, Deutschland) verwendet. Das Gerät hatte eine Größe von 36,5x52x32,5 cm und wog ca. $18 \mathrm{~kg}$. Es enthielt eine Nickel-63-Ionisationsquelle. Dem Probeneinlass vorgeschaltet war die Multikapillarsäule vom Typ MCC-OV-5 (Sibertech Ltd., Novosibirsk, Russland). Eine Software erlaubte die Steuerung des IMS. Mit der Software VOCan (B\&S-Analytik GmbH, Dortmund, Deutschland) wurden Einstellungen des Gerätes und die Probenahme gesteuert. Die schematische Abbildung 4 zeigt den Aufbau des MCC-IMS.

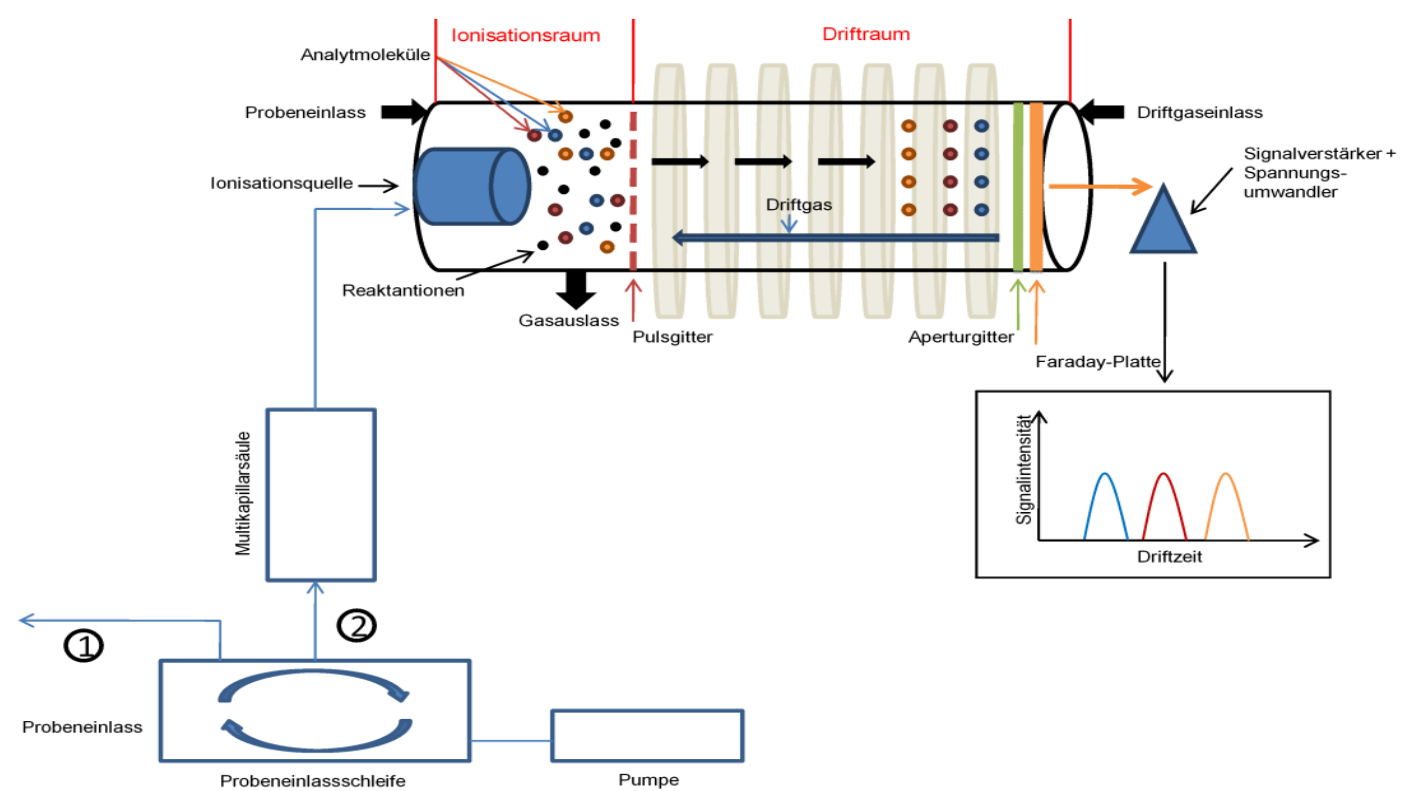

Abbildung 4. Schematischer Aufbau des MCC-IMS. (1) Die Probenschleife wird bei dieser Einstellung mit synthetischer Luft rückgespült. Für die Analyse wird diese mit dem Probengas gespült und die Probe wird in die Multikapillarsäule weitergeleitet (2). 
Die MCC ist dem Ionisationsraum vorgeschaltet. Sie enthält eine Säulenheizung mit der eine Temperaturregulation zwischen $20^{\circ} \mathrm{C}$ und $70{ }^{\circ} \mathrm{C}$ möglich ist. Die stationäre Phase der MCC setzt sich aus $95 \%$ Dimethylsiloxan und $5 \%$ Phenylsiloxan zusammen. Durch die MCC wird ein stetiger Gasfluss (Trägergas) als mobile Phase dem IMS zugeführt. Der Gasfluss wird über ein vorgeschaltetes 6-Wege-Ventil gesteuert. Die MCC ist durch PTFESchläuche und dichte Edelstahl-Fittings mit dem Ionisationsraum des IMS verbunden.

Als Träger- und Driftgas wurde synthetische Luft (Air Liquide Deutschland GmbH, Düsseldorf, Deutschland) verwendet.

Tabelle 1 zeigt alle Einstellungsparameter des Ionenmobilitätsspektrometers und der Multikapillarsäule die während dieser Arbeit verwendet wurden.

Tabelle 1. Einstellungsparameter MCC-IMS.

\begin{tabular}{l|l}
\hline Parameter & Einstellungen \\
\hline Strahlungsquelle & 63 Nickel (550 MBq) \\
Drift- und Trägergas & Synthetische Luft \\
Driftgasfluss & $100 \mathrm{ml} / \mathrm{min}$ \\
Trägergasfluss & $150 \mathrm{ml} / \mathrm{min}$ \\
Elektrisches Feld & $\approx 330 \mathrm{~V} / \mathrm{cm}$ \\
Pulsgitteröffnungszeit & $300 \mu \mathrm{s}$ \\
Betriebsmodus & positiv \\
Probenahmedauer & $10 \mathrm{~s}$ \\
MCC-Temperatur & $40{ }^{\circ} \mathrm{C}$ \\
IMS-Temperatur & Umgebungstemperatur \\
Druck & Umgebungsdruck \\
\hline
\end{tabular}

Für die Probennahme wurde eine Laborflasche mit dem zu prüfenden Medium über ein Anschlusssystem aus speziellen Gasleitungen mit dem MCC-IMS verbunden. Diese Gasleitungen bestanden aus Teflonschläuchen (Durchmesser 1,6 mm, Firma Bohlender, Grünsfeld, Deutschland), die aufgrund ihrer niedrigen Oberflächenspannung ein Anhaften von Probenbestandteilen unwahrscheinlich machen. Die Verbindung zwischen dem MCCIMS und den Teflonschläuchen erfolgte mit 1/8“ Edelstahl Swagelok ${ }^{\circledR}$-Fittings (Swagelok, Solon, Ohio, USA). Das Anschlusssystem bestand aus einem Schraubverschluss mit zwei 
Ports, an denen die Teflonschläuche befestigt sind. Über einen Teflonschlauch wurde der Probenflasche synthetische Luft zugeführt und über den zweiten Schlauch wurde die Headspace-Probe zum MCC-IMS geleitet.

\section{$2.2 \quad$ Ventilstellungen des 6-Wege-Ventils}

Das 6-Wege-Ventil hat zwei Zuleitungen, eine für das Trägergas und eine für das Spülgas bzw. die Probenzufuhr. Während der Probennahme befindet sich das 6-Wege-Ventil zunächst in Ventilstellung A (Grundstellung). Das Trägergas (synthetische Luft) wird direkt durch die MCC in das IMS geleitet, währenddessen die Probenschleife (Volumen $10 \mathrm{ml}$ ) mit der zu analysierenden Probe gespült wird (Abb. 5). Soll nun die Probe für eine IMS-Messung weitergeleitet werden, wird über die Computereinheit die Ventilstellung gesteuert. Die Umstellung auf Ventilstellung B ändert die Gasflüsse, sodass die Probe mit Hilfe einer Vakuum-Pumpe und einer Gasflussgeschwindigkeit von $500 \mathrm{ml} / \mathrm{min}$ für 10 Sekunden in das MCC-IMS geleitet wird (Abb. 6). Nach der Probennahme wird automatisch die Grundventilstellung wieder eingenommen. Sie dient zudem der Reinhaltung der Probenschleife nach vorherigen Probeninjektionen und beugt damit Unreinheiten im System und bei erneuten Messungen vor.

In den Zeiträumen zwischen den Messungen, befand sich eine leere Laborflasche am Anschlusssystem. Ein kontinuierlicher Trägergasfluss von $150 \mathrm{ml} / \mathrm{min}$ durchströmte Leitungssystem und MCC-IMS, um Verunreinigungen zu vermeiden. 
Ventilstellung $A$

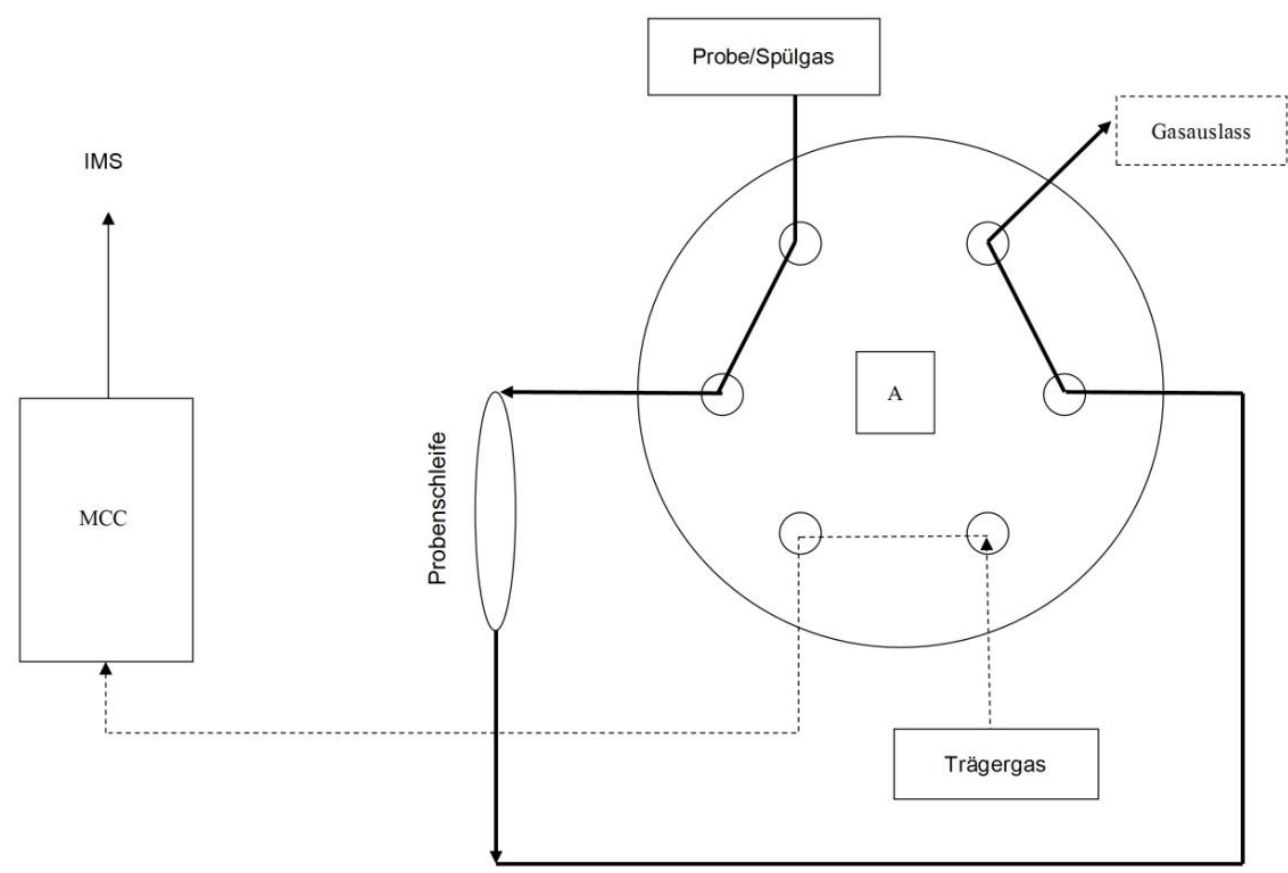

Abbildung 5. Darstellung des 6-Wege-Ventils in Ventilstellung A (Grundstellung): Das Spülgas oder die Probe durchfließen die Leitungen und entweichen über den Gasauslass. Das reine Trägergas (synthetische Luft) fließt in die MCC.

Ventilstellung B

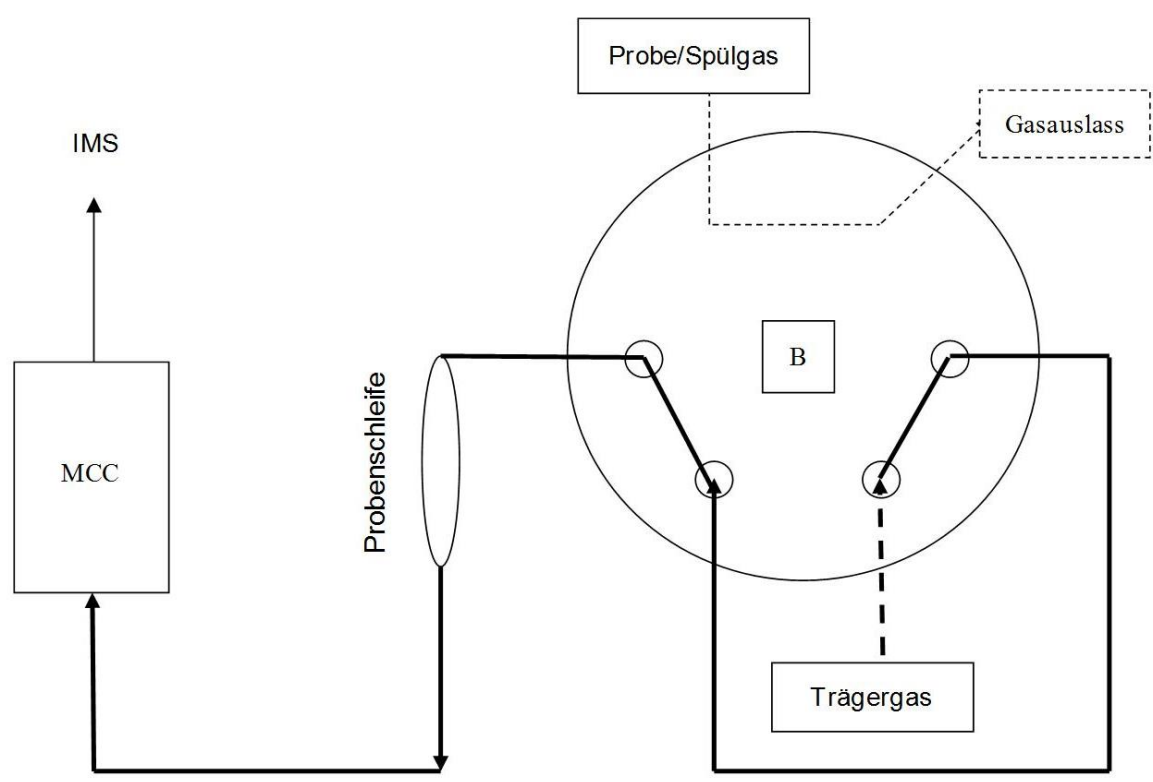

Abbildung 6. Darstellung des 6-Wege-Ventils in Ventilstellung B: Die zuvor in Ventilstellung A angereicherte Probe in der Probenschleife wird nun mit dem Trägergas in die MCC geleitet. Das Spülgasverlässt das Ventil direkt durch den Gasauslass. 


\subsection{Datenerfassung und Visualisierung}

Die vom IMS erzeugten Messsignale lagen im Nanoampere-Bereich. Sie wurden an der Faraday-Platte detektiert und für die Auswertung verstärkt. Das MCC-IMS war über ein USB-Datenkabel mit einem Notebook verbunden. Die Messdaten wurden in Form von sog. commaseparatedfiles (.csv-Format) auf das Notebook übertragen und dort gespeichert. Eine Software (VisualNow Version 1.2, B\&S Analytik, Dortmund, Deutschland) ermöglichte die Visualisierung, das Alignment und die Auswertung der Messdaten.

\subsubsection{Visualisierung}

Mit der Software VisualNow wurden die übertragenen Datensätze mit ihren Parametern Retentionszeit, Ionenmobilität und Signalintensität dargestellt. Es entstand eine dreidimensionale Grafik mit einer x-, y- und z-Achse. Die Retentionszeit ergab sich aus der Vortrennung der Probe durch die Multikapillarsäule und wurde in Sekunden (s) auf der y-Achse dargestellt. Die Driftzeit der Ionen ist die Ionenmobilität. Um reproduzierbare Ergebnisse zu erlangen und diese vergleichen zu können, wurde in der Darstellung die reduzierte Ionenmobilität $K_{0}[\mathrm{~cm} 2 / \mathrm{Vs}]$ verwendet. Sie befand sich auf der x-Achse. Die Signalintensität wurde in Volt gemessen und in der Grafik farblich wiedergegeben (z-Achse). 


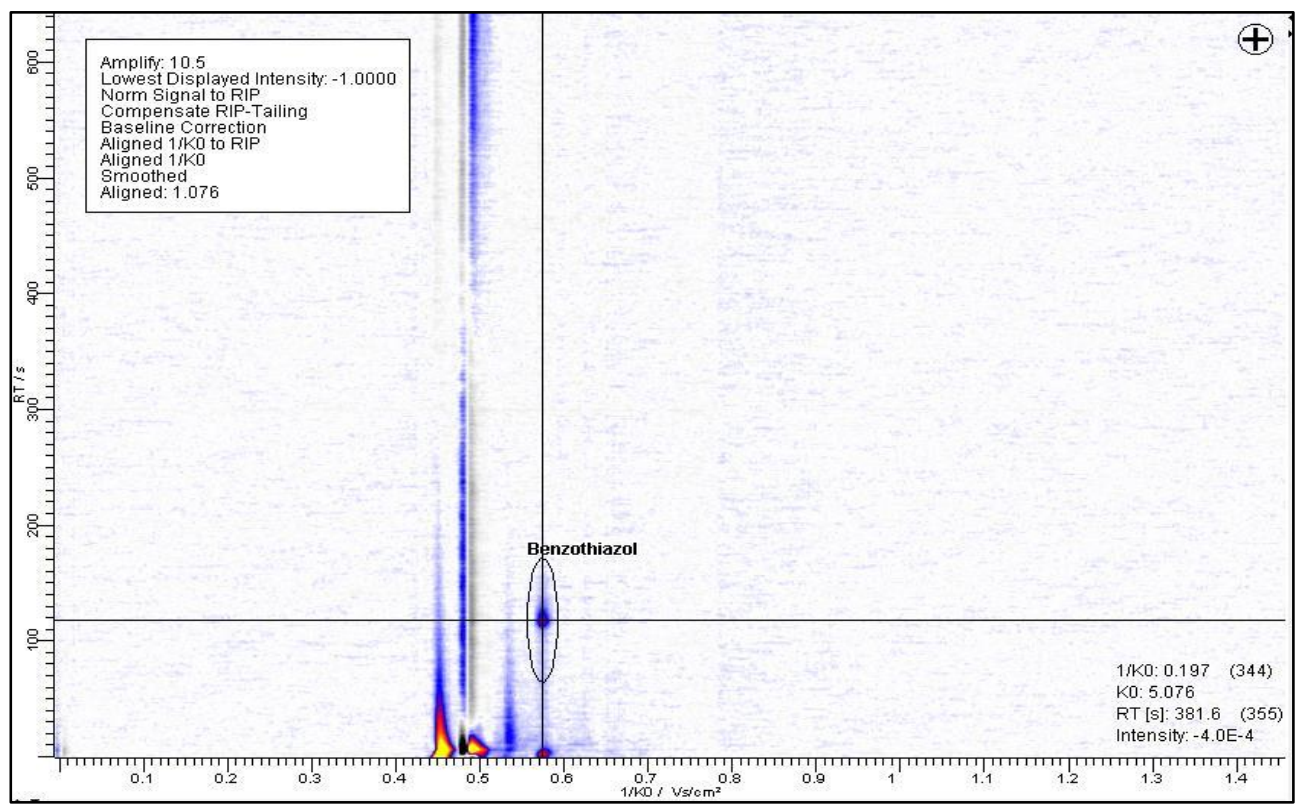

Abbildung 7. Zweidimensionale Darstellung eines Datensatzes (Carstens 2010). x-Achse: Retentionszeit (s), y-Achse: reduzierte Ionenmobilität $K_{0}$ [cm2/Vs], z-Achse: Signalintensität (V) Farbspektrum: gelb - höchste Spannung, weiß - keine Spannung.

In der Software VisualNow ist eine Referenzdatenbank hinterlegt, die zur Identifikation der Substanzen herangezogen werden kann. Mit den Peak-Koordinaten kann eine Übereinstimmung festgestellt werden. Handelte es sich um eine unbekannte Substanz, erfolgte die Nomenklatur der Substanz anhand der Koordinaten als P_x_y, z. B. P_778_4.

\subsubsection{Normierungsprozesse}

Bei Temperatur-, Luftdruck- und Feuchtigkeitsdifferenzen können die Ergebnisse bei der Nutzung desselben Gerätes variieren. Dabei ist es wichtig eine Vergleichbarkeit der Ergebnisse verschiedener MCC-IMS zu ermöglichen. Bereits kleine Unterschiede in der Gerätekonfiguration können als Störfaktor wirken. Ziel der Normierungsprozesse ist es, eine möglichst hohe Vergleichbarkeit, Reliabilität und Validität der Messergebnisse zu erzielen.

Für die Erstellung von Datenbanken zur Peakidentifikation ist es unerlässlich, bei der Datensammlung nur solche Messdaten und Ergebnisse zuzulassen, die bei mehreren Messungen identische, oder zumindest nahezu identische Werte aufweisen. Um dies zu ermöglichen, wurden Normierungsprozesse für die reduzierte Ionenmobilität, Signalintensität und Retentionszeit entwickelt. Die zusammenfassende Bezeichnung für diese Prozesse lautet Alignment. 
Die zunehmende Nutzung von MCC-IMS in der Medizin erfordert zudem, dass Ergebnisse, die weltweit erfasst und veröffentlicht werden, insbesondere die Ionenmobilität, reproduzierbar und vergleichbar sind. Mit der Einführung der reduzierten Ionenmobilität wurde ein Parameter entwickelt, der unabhängig von den Umgebungskonditionen (Außentemperatur, Druck und Driftgastemperatur) ist. Die Normierung der reduzierten Ionenmobilität erfolgt anhand des Reaktionsionen-Peak (RIP) dessen reduzierte Ionenmobilität als konstant betrachtet werden kann. Die Bedienungssoftware normiert den RIP auf eine identische reduzierte Ionenmobilität. Dadurch werden auch die neu ermittelten reduzierten Ionenmobilitäten der Probe anhand des RIP normiert und vergleichbar gemacht. Eine Studie von Vautz et al. führte 1200 Messungen verschiedener Substanzen mit verschiedenen MCC-IMS durch und normierte die reduzierte Ionenmobilität des RIP. Es konnte gezeigt werden, dass die Ergebnisse eine signifikant höhere Zuverlässigkeit und Genauigkeit aufwiesen. Dadurch wurde es auch möglich, Abweichungen der Laborbedingungen zu kompensieren (Vautz et al. 2009).

Die Signalintensität wird in Volt gemessen und in einem Farbspektrum von gelb (stärkste Intensität - hohe Volt-Zahl) über rot und blau (Volt-Zahl abnehmend) bis weiß (keine Intensität) wiedergegeben. Für eine Normierung wird der Reaktionsionenpeak eines Spektrums auf die Intensität von einem Volt normiert.

Die durch die Vortrennung mittels Multikapillarsäule gewonnene Retentionszeit muss ebenfalls für eine Vergleichbarkeit der Ergebnisse normiert werden. Perl et al. haben in einer Studie Abweichungen der Retentionszeit von bis zu $25 \%$ durch minimale Temperatur- und Gasflussänderungen der MCC beschrieben. Zur Normierung eignet sich als Referenzsubstanz Benzothiazol. Diese ist als Kontaminationskomponente in synthetischer Luft enthalten und dadurch bei jeder Messung nachweisbar. Mit mehreren Messungen wurde so die mittlere Retentionszeit von Benzothiazol bei vorgegebener Geräteeinstellung ermittelt. Sie betrug 118,3 Sekunden. Dieser Wert kann bei weiteren Messungen mit der Maximalintensität in der Benzothiazolregion gleichgesetzt werden. Dadurch werden Retentionszeiten anderer Moleküle anhand von Benzothiazol abgeglichen und normiert (Perl et al. 2010). Die Berechnung erfolgt mithilfe der Analysesoftware. 


\subsection{Mikrobiologischer Versuchsteil}

Im nachfolgenden Abschnitt werden die Arbeitsmethoden für die Herstellung der Nährmedien und Kultivierung der Bakterien beschrieben.

\subsubsection{Herstellung und Analyse des Nährmedium}

Als Nährmedium wurde LysogenyBroth (LB) (Carl Roth GmbH, Karlsruhe, Deutschland) verwendet. LB wurde 1951 von G. Bertani bei einem Experiment mit Phagen von E. coli entwickelt (Bertani 1951). Es enthält Trypton, welches als Aminosäure- und Stickstofflieferanten dient, sowie Hefeextrakt, Natriumchlorid $(\mathrm{NaCl})$ und Glukose. Ein Liter Nährlösung setzt sich aus $1.000 \mathrm{ml}$ zweifach destilliertem Wasser (Aqua bidestillata) und $20 \mathrm{~g}$ LB-Medium Trockensubstanz zusammen. Um ein optimales Wachstum zu gewährleisten, wurde ein pH-Wert von 7,2 mittels eines pH-Meters pMX 2000 (Wissenschaftlich-technische Werkstätten, Weilheim, Deutschland) bei $37^{\circ} \mathrm{C}$ mit HCLTRIS-Puffer eingestellt. Nach Verteilung der Nährlösung in Laborflaschen (Schott Duran, Mainz, Deutschland) wurden diese bei $121^{\circ} \mathrm{C}$ für 25 Minuten bei 1,0 bar autoklaviert. Die Nährlösung kann bis zu 48 Stunden bei $37^{\circ} \mathrm{C}$ gelagert werden.

\subsubsection{Mikrobiologische Arbeiten und Wachstumskurven}

In der vorliegenden Arbeit wurden folgende Bakterienstämme als Referenzkulturen untersucht: Escherichia coli (DSM 25944) und Pseudomonas aeruginosa (DSM 1117). Sie stammten aus der Deutschen Sammlung von Mikroorganismen und Zellkulturen (DSMZ, Braunschweig, Deutschland). Das Institut für medizinische Mikrobiologie der Universitätsmedizin Göttingen stellte für diese Arbeit zudem zwölf zufällig ausgewählte klinische Patientenisolate von E. coli und $P$. aeruginosa zur Verfügung. Tabelle 2 gibt einen Überblick über den Ursprung dieser Isolate. 
Tabelle 2. Ursprung der klinischen Isolate von E. coli und P. aeruginosa.

\begin{tabular}{l|l|l}
\hline Isolate & Escherichia coli & Pseudomonas aeruginosa \\
\hline Referenzstamm & DSM 25944 & DSM 1117 \\
Klinisches Isolat 1 & Blutkultur & Trachealsekret \\
Klinisches Isolat 2 & Bronchialsekret & Wundabstrich Unterschenkel \\
Klinisches Isolat 3 & Wundabstrich & Abstrich Ohr \\
Klinisches Isolat 4 & Urinkultur & Abstrich Unterschenkel \\
Klinisches Isolat 5 & Urinkultur & Wundabstrich Oberschenkel \\
Klinisches Isolat 6 & Urinkultur & Urinkultur \\
Klinisches Isolat 7 & Abstrich Abdomen & Wundabstrich \\
Klinisches Isolat 8 & Abstrich Abszess & Intraoperativer Abstrich Niere \\
Klinisches Isolat 9 & Trachealsekret & Abstrich Abszess \\
Klinisches Isolat 10 & Blutkultur & Urinkultur \\
Klinisches Isolat 11 & Abstrich Leiste & Wundabstrich Schulter \\
Klinisches Isolat 12 & Urinkultur & Blutkultur \\
\hline
\end{tabular}

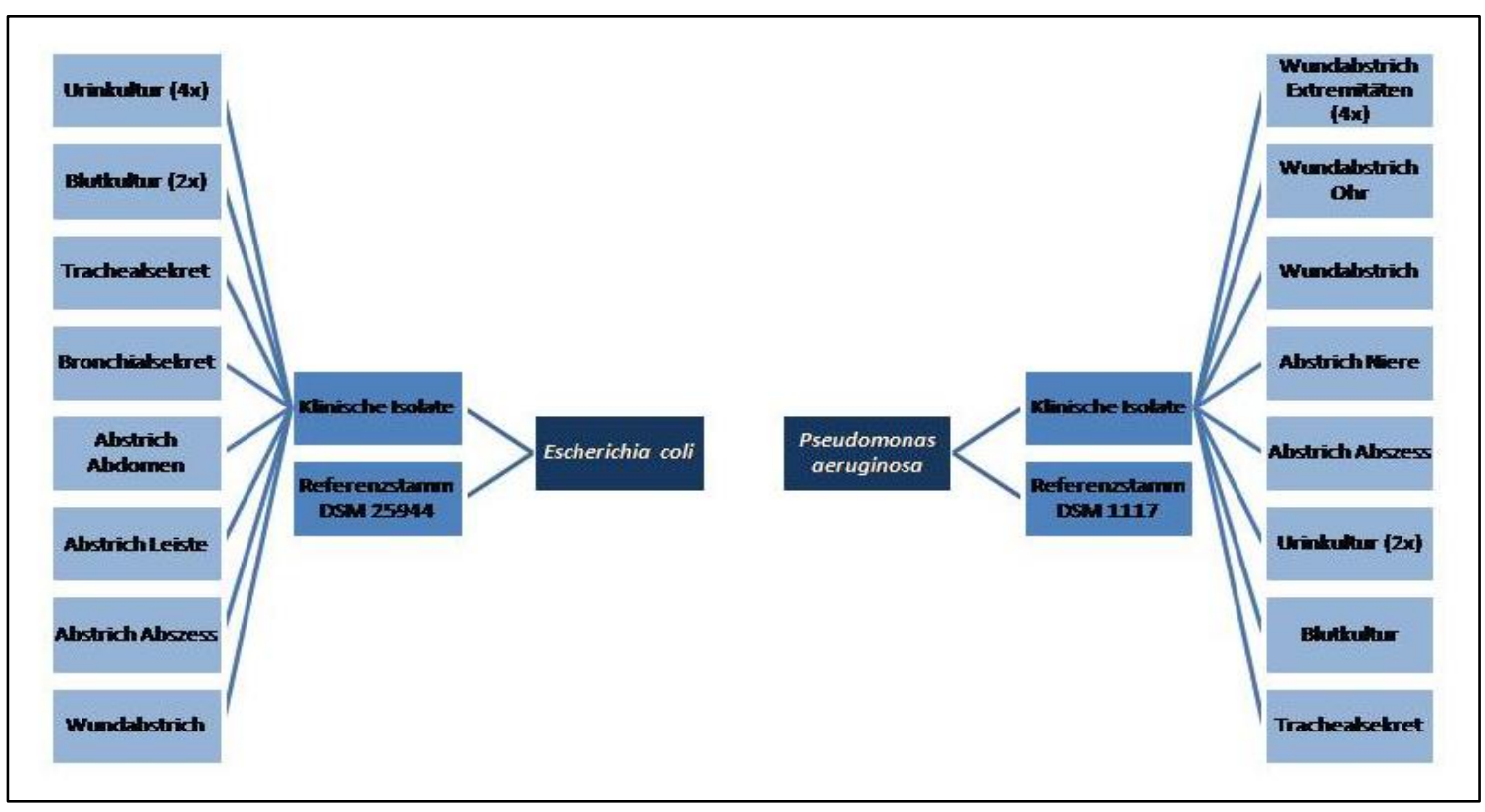

Abbildung 8. Übersicht der verwendeten Bakterien und deren Ursprung. 
Für die Herstellung von Lagerkulturen wurden zunächst die Referenzkulturen und klinischen Isolate auf Columbia Schafsblutagar-Platten (Ref. 43041; BioMérieux, Nürtingen, Deutschland) ausgestrichen und bebrütet. Anschließend wurden die Kulturen in $25 \mathrm{ml}$ LB überführt und in einem Schüttelinkubator über Nacht aerob inkubiert. $1.000 \mu \mathrm{l}$ dieser Kultur wurden mit $1.000 \mu \mathrm{l}$ eines Lagermediums, bestehend aus $22 \mathrm{mM}$ KH2PO4, $40 \mathrm{mM}$ K2HPO4, $2 \mathrm{mM}$ Na-Citrat, 0,8 mM MgSO4 und $55 \%$ Glycerin, in Eppendorf-Cups (Eppendorf-Netheler-Hinz GmbH, Hamburg, Deutschland) gemischt und bei $-80^{\circ} \mathrm{C}$ gelagert. Sie sind die Ausgangskulturen für die Messreihen.

Vor Beginn jeder Messreihe wurde eine Arbeitskultur aus der entsprechenden Lagerkultur angesetzt. Für den täglichen Gebrauch im Rahmen der Studie wurden analog zu den Lagerkulturen kleinere Mengen der Arbeitskulturen 1:1 mit dem Lagermedium versetzt und bei $-80^{\circ} \mathrm{C}$ gelagert. Hieraus wurde für jeden Versuchstag eine Übernachtkultur vorbereitet, die jeweils zwölf Stunden unter Schütteln inkubiert wurde. Am Morgen des Versuchstags erfolgte eine Verdünnung der Übernachtkultur auf 1:1.000 mithilfe der LBNährlösung. Mit dieser verdünnten Kultur $(200 \mathrm{ml}$ Volumen in einer $2.000 \mathrm{ml}$ Laborflasche) erfolgten die Versuche. Die Versuchskultur wurde unter ständiger Bewegung (55 revolutions per minute) bei konstanter Temperatur $\left(37^{\circ} \mathrm{C}\right.$ ) in einem Schüttelinkubator für die Dauer der Messreihe inkubiert. Zu diesem Zeitpunkt begann die Messreihe für die jeweilige Kultur. Durch die Verdünnung der Kultur wurden gleiche Ausgangskonditionen geschaffen, um die Erstellung der Wachstumskurven anhand der optischen Dichte zu ermöglichen.

Mithilfe eines Spektralphotometers (Prim Advanced, Schott Instruments, Mainz, Deutschland) wurde in regelmäßigen Abständen die optischen Dichte (Wellenlänge $=600$ nm) der Kultur bestimmt. Für E. coli-Kulturen erfolgten die OD-Messungen im Abstand von 30 Minuten, beginnend 15 Minuten nach dem Ansetzen der Kultur. Aufgrund der längeren Generationszeit von P. aeruginosa erfolgten die Messungen der OD hier im Abstand von 45 Minuten. Die Wachstumskurve von E. coli wurde bis 405 Minuten nach Ansetzen dargestellt, für P. aeruginosa ergab sich ein Messzeitraum von 760 Minuten. 


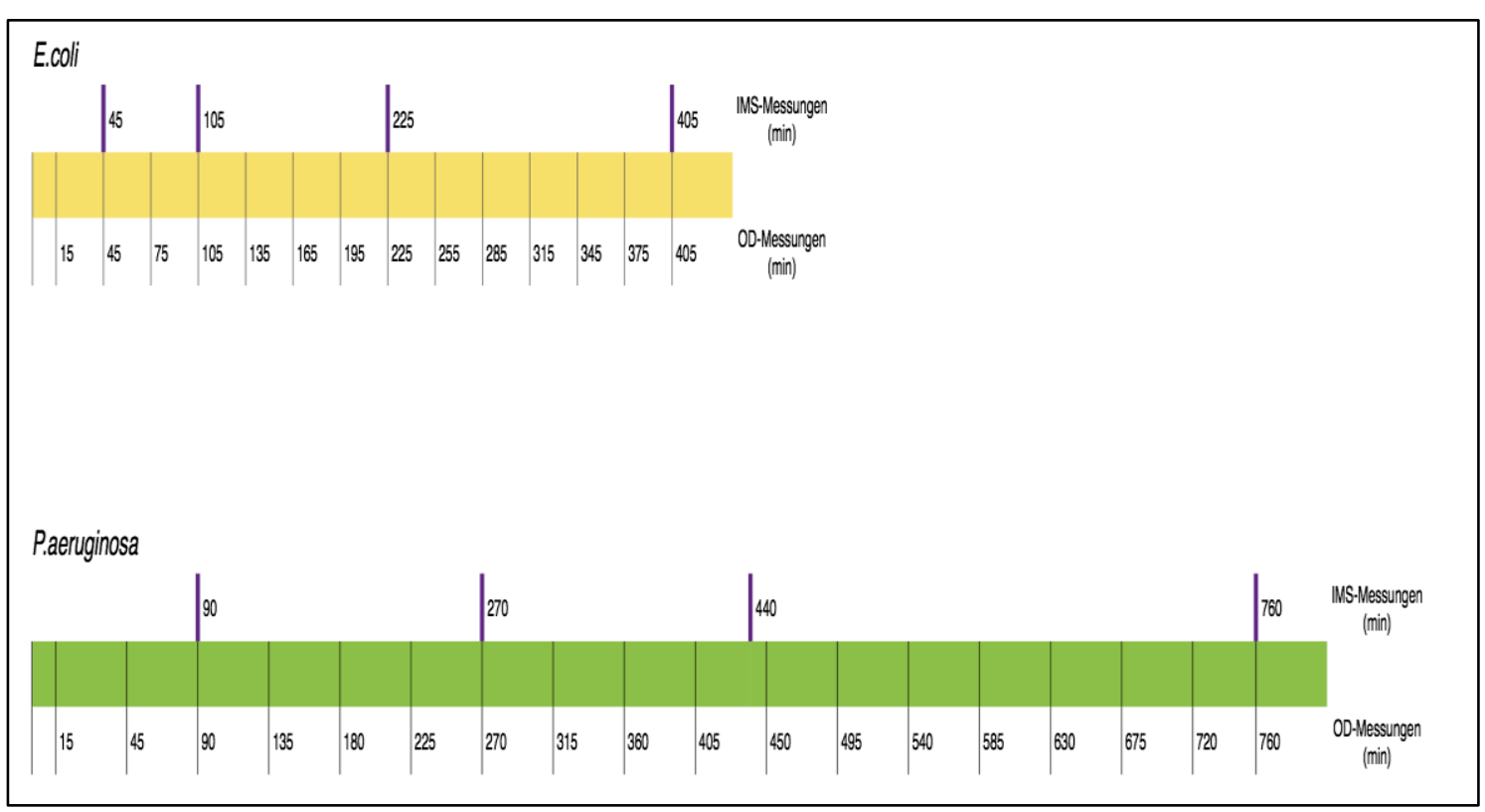

Abbildung 9. Übersicht der Messreihen von E. coli und P. aeruginosa. Zeitliche Markierungen für die IMS-Messungen und Messungen der optischen Dichte.

\subsubsection{Zeitlicher Verlauf der MCC-IMS-Messungen}

Anhand der Wachstumskurven wurden für beide Spezies vier Wachstumsphasen benannt: lag-Phase (Lag), frühe logarithmische Phase (Log1), späte logarithmische Phase (Log2) und die statische Phase (Stat). In jeder Wachstumsphase von E. coli und P. aeruginosa erfolgte eine MCC-IMS-Messung (s. Abschnitt 2.3). Abbildung 9 zeigt den zeitlichen Verlauf einer Messreihe für die jeweilige Kultur.

MCC-IMS-Messungen für E. coli wurden 45 (Lag), 105 (Log1), 225 (Log2) und 405 (Stat) Minuten nach Ansetzten der Kultur durchgeführt. MCC-IMS-Messungen für P. aeruginosa wurden 90 (Lag), 270 (Log1), 440 (Log2) und 760 (Stat) Minuten nach Ansetzten der Kultur durchgeführt. Für die Referenzkulturen wurden jeweils zwölf Messungen zu den oben genannten Zeiten durchgeführt $(n=12)$. Die zwölf klinischen Isolate wurden je einmal $\mathrm{zu}$ jedem Zeitpunkt analysiert $(\mathrm{n}=1)$. Zusätzlich erfolgte $\mathrm{zu}$ diesen Zeitpunkten ein Plattenausstrich mit entsprechender Verdünnung der Kultur auf Columbia-Agar-Platten (BioMérieux, Nürtingen, Deutschland) (Tab. 3 und 4). Diese wurden jeweils $24 \mathrm{~h}$ in einem Wärmeschrank Hera Cell 150 (Thermo Fisher Scientific, Schwabach, Deutschland) bei $37^{\circ} \mathrm{C}$ inkubiert und anschließend die gewachsenen kolonien-bildenden Einheiten gezählt. 
Tabelle 3. Verdünnungsverhältnisse in Korrelation zur optischen Dichte für E. coli.

\begin{tabular}{l|l}
\hline Optische Dichte & Verdünnung \\
\hline $0,001-0,349$ & $1: 100.000$ \\
$0,350-0,549$ & $1: 10.000 .000$ \\
$0,550-0,699$ & $1: 100.000 .000$ \\
$0,700-1,049$ & $1: 10.000 .000 .000$ \\
$0,700-1,049$ & $1: 100.000 .000 .000$ \\
$1,05-1,399$ & $1: 1.000 .000 .000 .000$ \\
$>1,4$ & $1: 1.000 .000 .000 .000 .000$ \\
\hline
\end{tabular}

Tabelle 4. Verdünnungsverhältnisse in Korrelation zur optischen Dichte für P. aeruginosa.

\begin{tabular}{l|l}
\hline Optische Dichte & Verdünnung \\
\hline $0,001-0,349$ & $1: 100.000$ \\
$0,350-0,549$ & $1: 10.000 .000$ \\
$0,550-0,699$ & $1: 100.000 .000$ \\
$0,700-1,049$ & $1: 10.000 .000 .000$ \\
$0,700-1,049$ & $1: 100.000 .000 .000$ \\
$1,05-1,399$ & $1: 1.000 .000 .000 .000$ \\
$>1,4$ & $1: 1.000 .000 .000 .000 .000$ \\
\hline
\end{tabular}

\subsubsection{Referenzmessungen zur Analyse des Nährmediums}

Es erfolgte eine Analyse der im Nährmedium enthaltenen VOCs mit dem MCC-IMS sowie Leermessungen der Laborflaschen. Mit jeweils zwölf Messungen konnte ein Profil der Signale erstellt werden, die bereits vor dem bakteriellen Wachstum detektierbar sind. 


\subsection{Statistische Auswertung}

Zur Erstellung der Grafiken und Berechnung der statistischen Ergebnisse wurde das Statistik-Programm STATISTICA 10 (StatSoft Inc., Tulsa, Oklahoma, USA) verwendet.

Soweit nicht anders angegeben, erfolgt die Darstellung der Ergebnisse anhand des Mittelwertes und des 95 \%igen Konfidenzintervalles. Der Mittelwert wird in den Grafiken als Symbol (Dreieck, Kreis, Viereck) abgebildet, die Fehlerbalken zeigen das Konfidenzintervall an. 


\section{ERGEBNISSE}

\subsection{Bakterielle Wachstumskurven}

Entsprechend der in Kapitel 2.4.2 beschriebenen Methodik wurden anhand der optischen Dichte Wachstumskurven für die Bakterienkulturen erstellt. Abbildung 10 zeigt die Wachstumskurve von E. coli und Abbildung 11 zeigt die Wachstumskurve von $P$. aeruginosa.

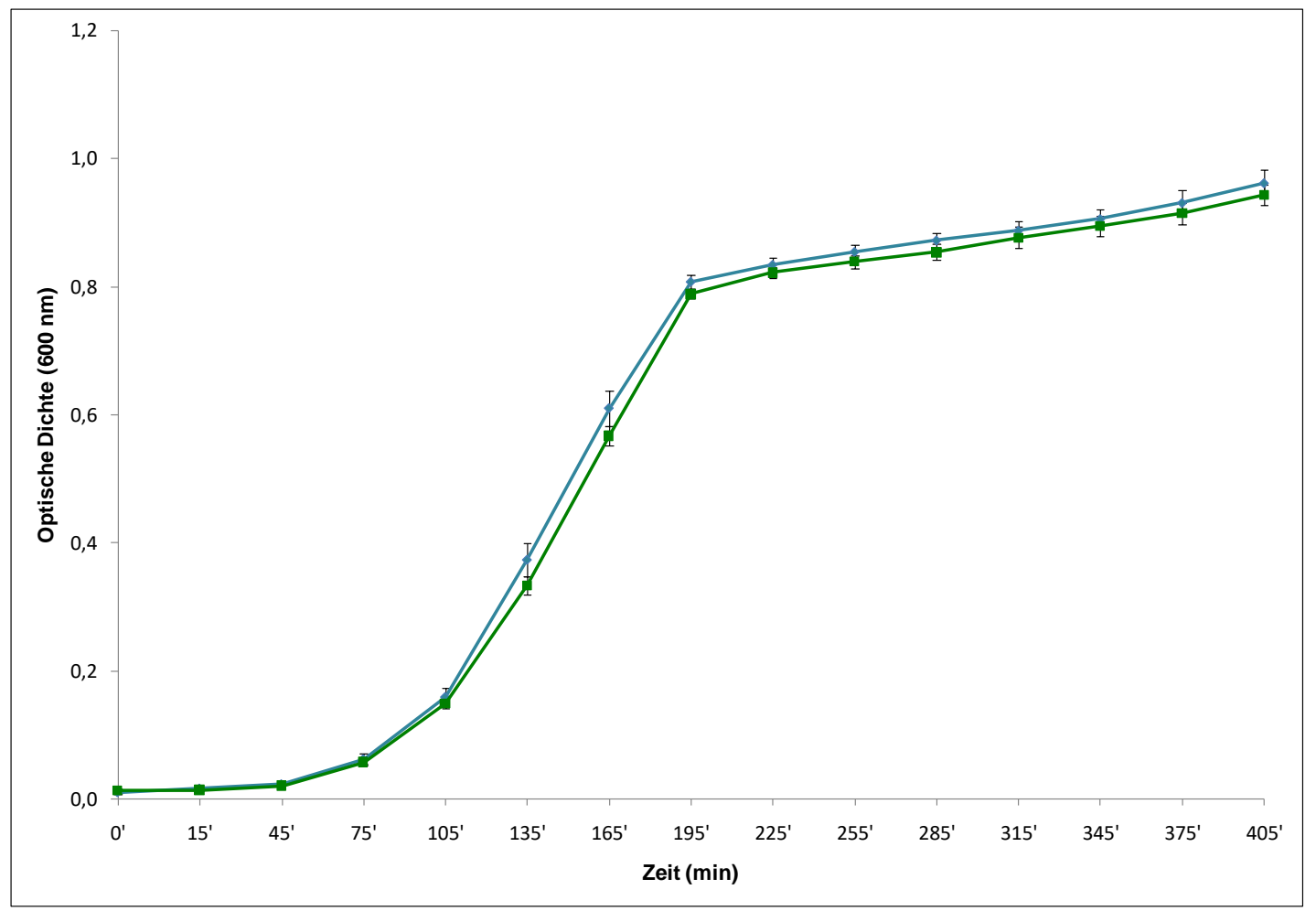

Abbildung 10. Wachstumskurve des Referenzstammes (blau) sowie der klinischen Isolate (grün) von E. coli. 


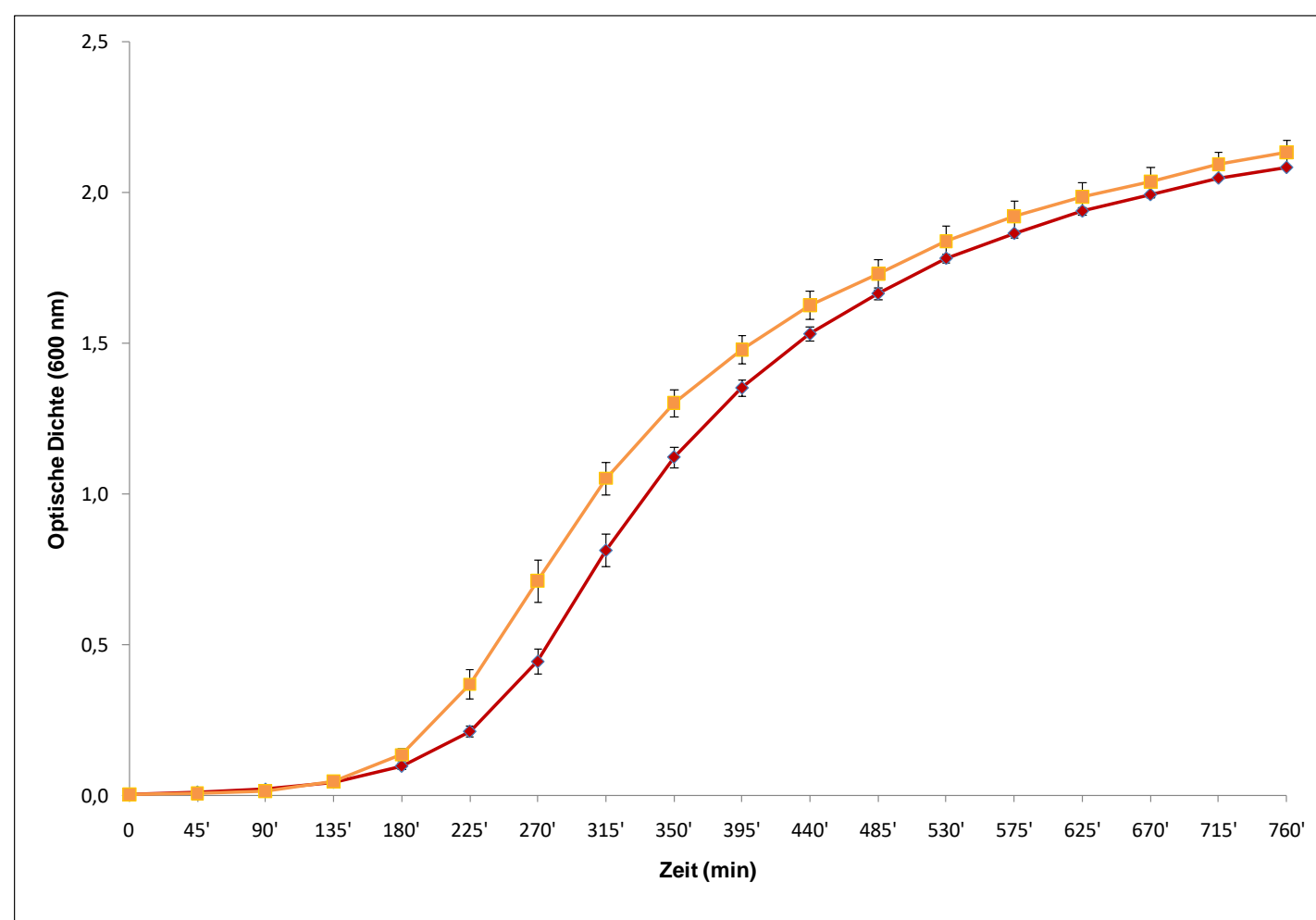

Abbildung 11. Wachstumskurve des Referenzstammes (rot), sowie der klinischen Isolate (gelb) von P. aeruginosa.

Die Wachstumskurven zeigten bei beiden Keimen nach einer initialen Anlaufphase (LagPhase) das typische exponentielle Wachstum (Log1- und Log2-Phase). Die anschließende statische Phase begann bei E. coli nach etwa 200-220 Minuten und bei P. aeruginosa nach ca. 700 Minuten.

Es zeigten sich keine relevanten Abweichungen im Wachstumsverhalten zwischen den Referenzstämmen und den klinischen Isolaten der gleichen Spezies. Lediglich in der frühen logarithmischen Phase beim Wachstum des Referenzstammes von $P$. aeruginosa waren kleinere zeitliche Verzögerungen gegenüber den klinischen Isolaten zu beobachten.

\subsection{Detektion bakterieller Metaboliten}

19 Peaks zeigten relevante Veränderungen ihrer Signalstärke oder tauchten während des bakteriellen Wachstums neu auf. Abbildung 12 zeigt die Positionen dieser 19 Peakregionen im IMS-Plot. Die dazu gehörigen reduzierten Ionenmobilitäten und Retentionszeiten sind in Tabelle 5 aufgeführt. 13 dieser VOCs traten jeweils nur bei einer Bakterienspezies auf, sodass sie als hilfreich für die Differenzierung zwischen $E$. coli und $P$. 
aeruginosa angesehen wurden. Dies waren Aceton, Ammoniak (Dimer), Ethanol, Indol, nDodecan, 1-Decanol, 1-Octanol (Monomer), 1-Octanol (Dimer), 2-Ethyl-1Hexanol, P603_25, P_648_36, P_778_4 und P_755_105.

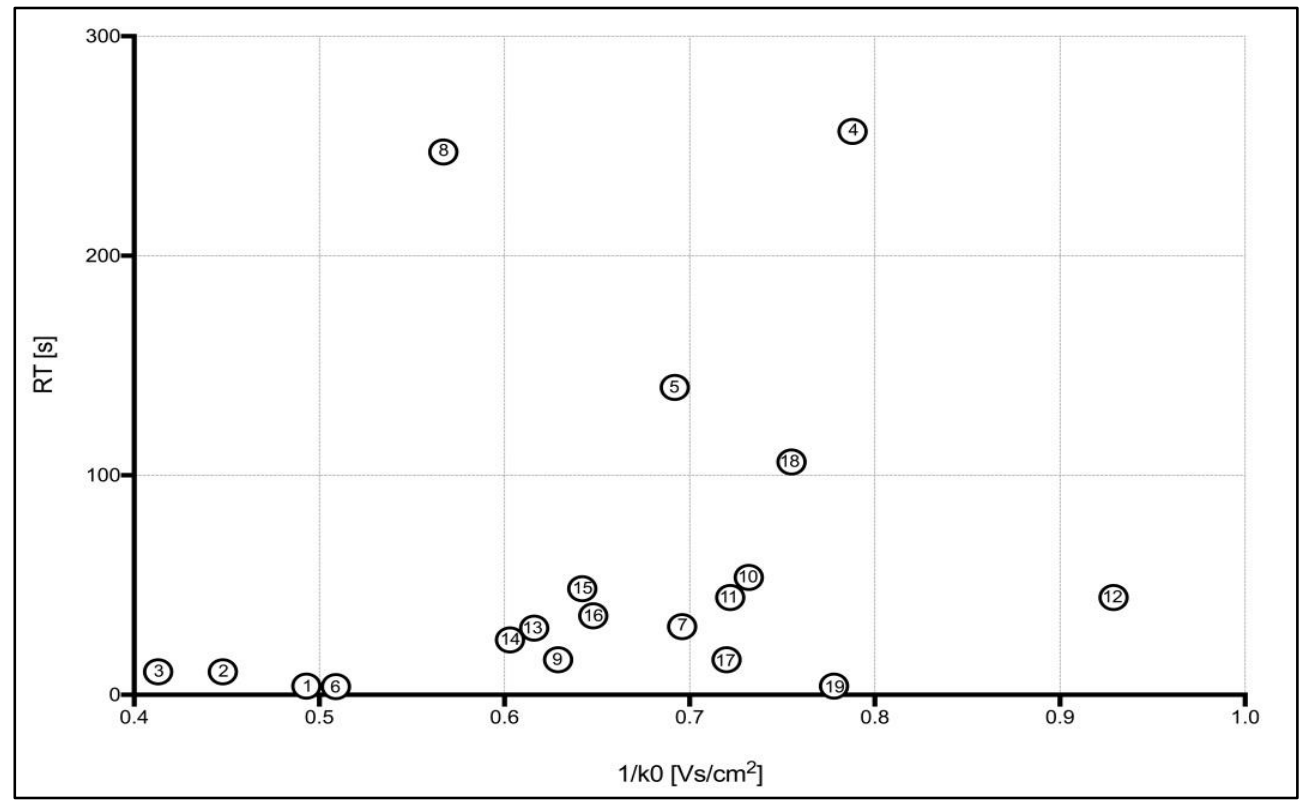

Abbildung 12. Graphische Darstellung der 19 Peaks mit der Nummerierung entsprechend Tabelle 5. 
Tabelle 5. Auflistung der VOCs mit Angabe der spezifischen reduzierten Ionenmobilität $(1 / K o)$ und der Retentionszeit (RT).

\begin{tabular}{|c|c|c|c|}
\hline Peak-Nr. & VOC-Name & $1 / K o\left[\mathrm{Vs} / \mathrm{cm}^{2}\right]$ & RT [s] \\
\hline 1 & Aceton & 0,493 & 3,9 \\
\hline 2 & Ammoniak (Monomer) & 0,448 & 10,5 \\
\hline 3 & Ammoniak (Dimer) & 0,413 & 10,5 \\
\hline 4 & 1-Decanol & 0,788 & 256,6 \\
\hline 5 & n-Dodecan & 0,692 & 140,0 \\
\hline 6 & Ethanol & 0,509 & 3,7 \\
\hline 7 & 2-Ethyl-1-Hexanol & 0,696 & 31,0 \\
\hline 8 & Indol & 0,567 & 247,2 \\
\hline 9 & 5-Methyl-3-Heptanon & 0,629 & 16,0 \\
\hline 10 & Nonanal & 0,732 & 53,5 \\
\hline 11 & 1-Octanol (Monomer) & 0,722 & 44,3 \\
\hline 12 & 1-Octanol (Dimer) & 0,929 & 44,3 \\
\hline 13 & Phenylacetaldehyd & 0,616 & 30,4 \\
\hline 14 & P_603_25 & 0,603 & 25,0 \\
\hline 15 & P_642_48 & 0,642 & 48,3 \\
\hline 16 & P_648_36 & 0,648 & 36,0 \\
\hline 17 & P_720_16 & 0,720 & 16,0 \\
\hline 18 & P_755_105 & 0,755 & 106,0 \\
\hline 19 & P_778_4 & 0,778 & 4,0 \\
\hline
\end{tabular}

\subsection{Vergleich der Referenzstämme und klinischen Isolate}

Die folgenden Grafiken zeigen den Verlauf der Signalintensität jeweils eines VOC im Verlauf der Wachstumsphasen. Die Darstellung erfolgt getrennt für die E. coli-Kulturen und die P. aeruginosa-Kulturen. Jede Grafik stellt den Verlauf der Signalintensitäten beim jeweiligen Referenzstamm sowie den dazugehörigen klinischen Isolaten gegenüber. 


\subsubsection{E.-coli-Signale}

Insgesamt konnten in den Messungen über E. coli 19 Signale detektiert werden, die sich im Wachstumsverlauf veränderten (Abb. 13-31).

Aceton, Ammoniak (Dimer), Dodecan, Nonanal, P_648_36, P_778_4, 2-Ethyl-1-Hexanol und 5-Methyl-3-Hepatanon (Abb. 13-20) waren bereits im volatilen Hintergrund nachweisbar, der über der sterilen LB-Lösung gemessen wurde. Sie zeigten über die Wachstumsphasen hinweg bei Referenzstamm und klinischen Isolaten nahezu gleichbleibende Signalintensitäten.

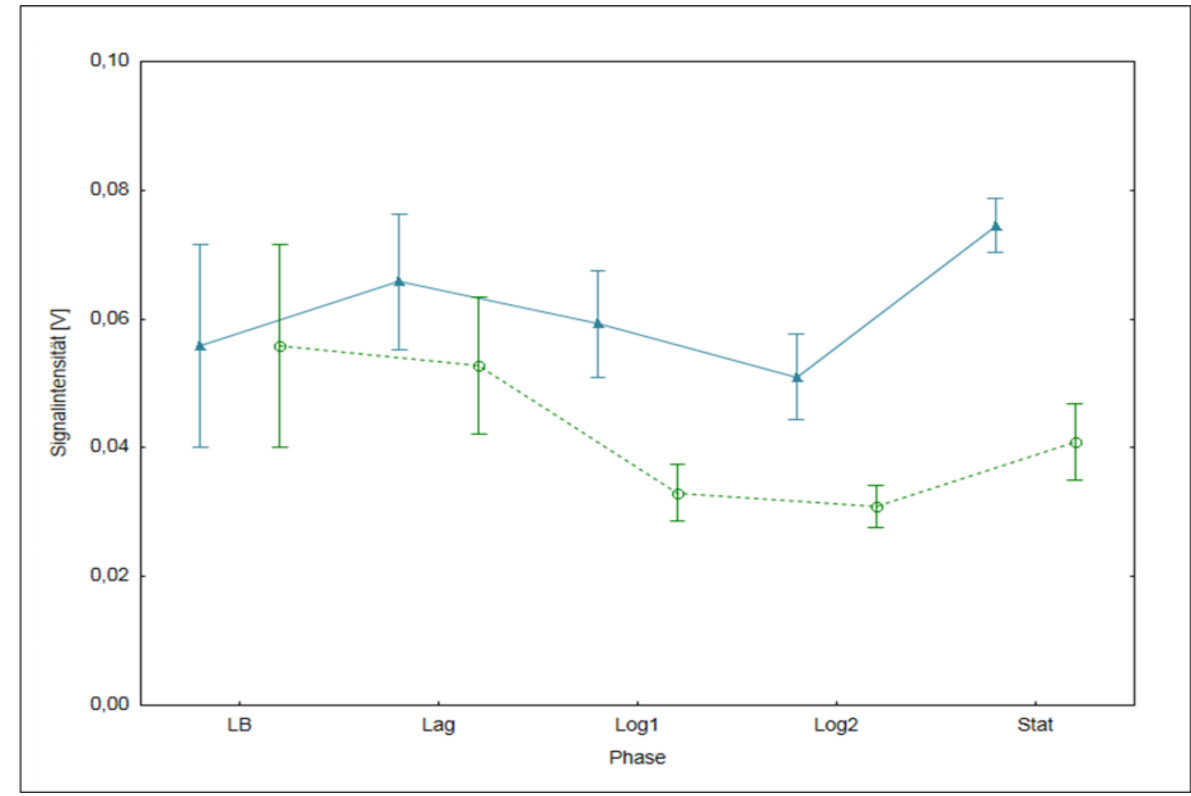

Abbildung 13. Aceton Messung von Aceton als VOC über dem Referenzstamm (blau) und den klinischen Isolaten (grün) von E. coli. 


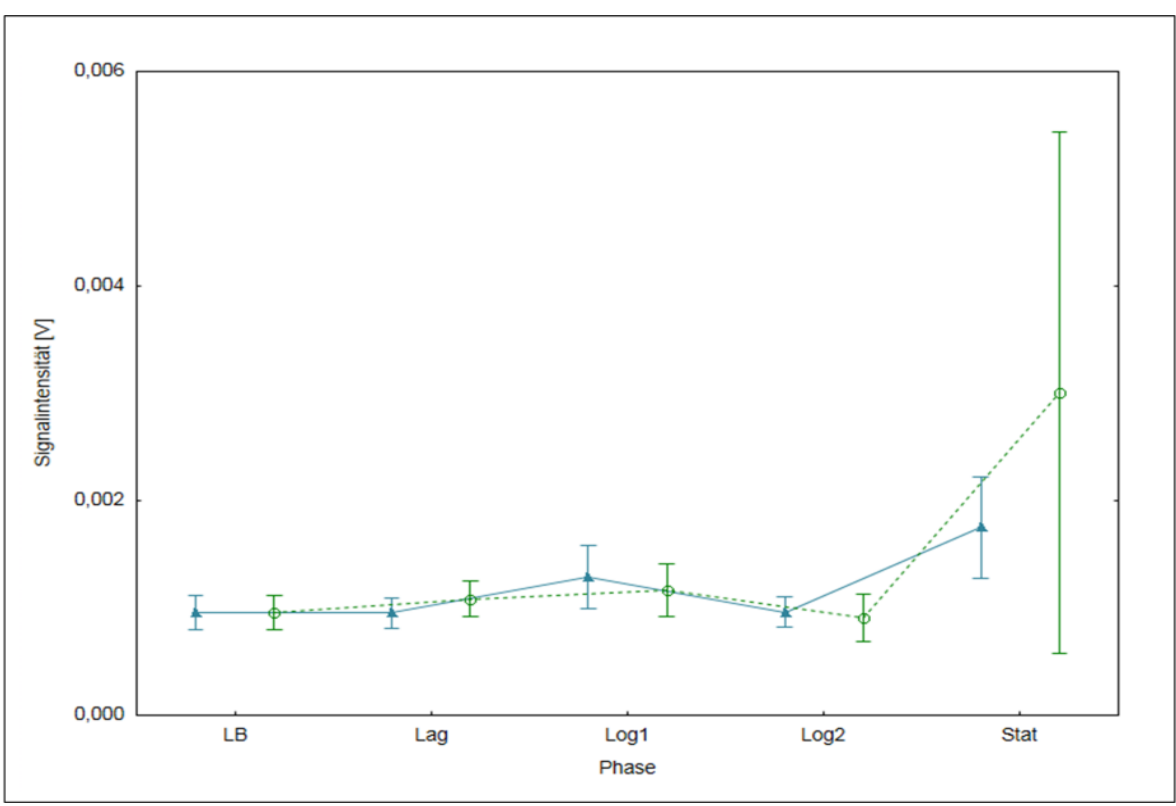

Abbildung 14. Ammoniak (Dimer) Messung von Ammoniak (Dimer) als VOC über dem Referenzstamm (blau) und den klinischen Isolaten (grün) von E. coli.

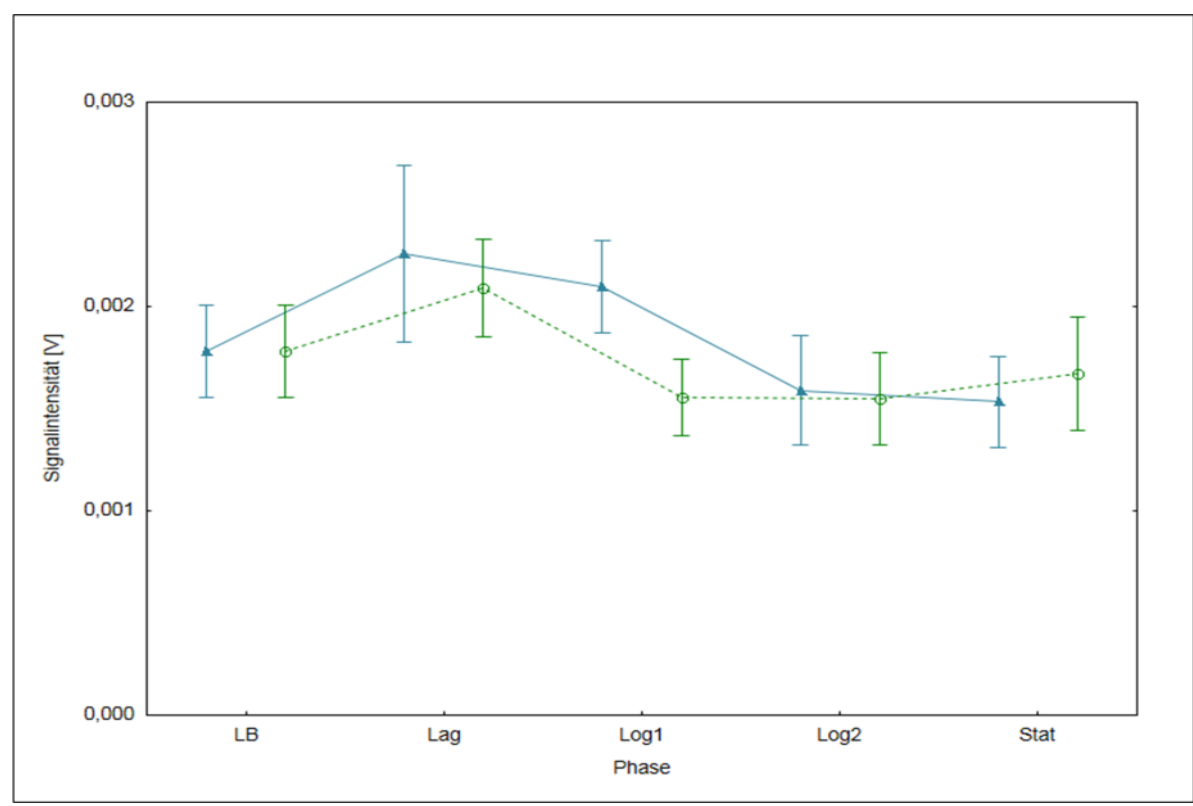

Abbildung 15. Dodecan Messung von Dodecan als VOC über dem Referenzstamm (blau) und den klinischen Isolaten (grün) von E. coli. 


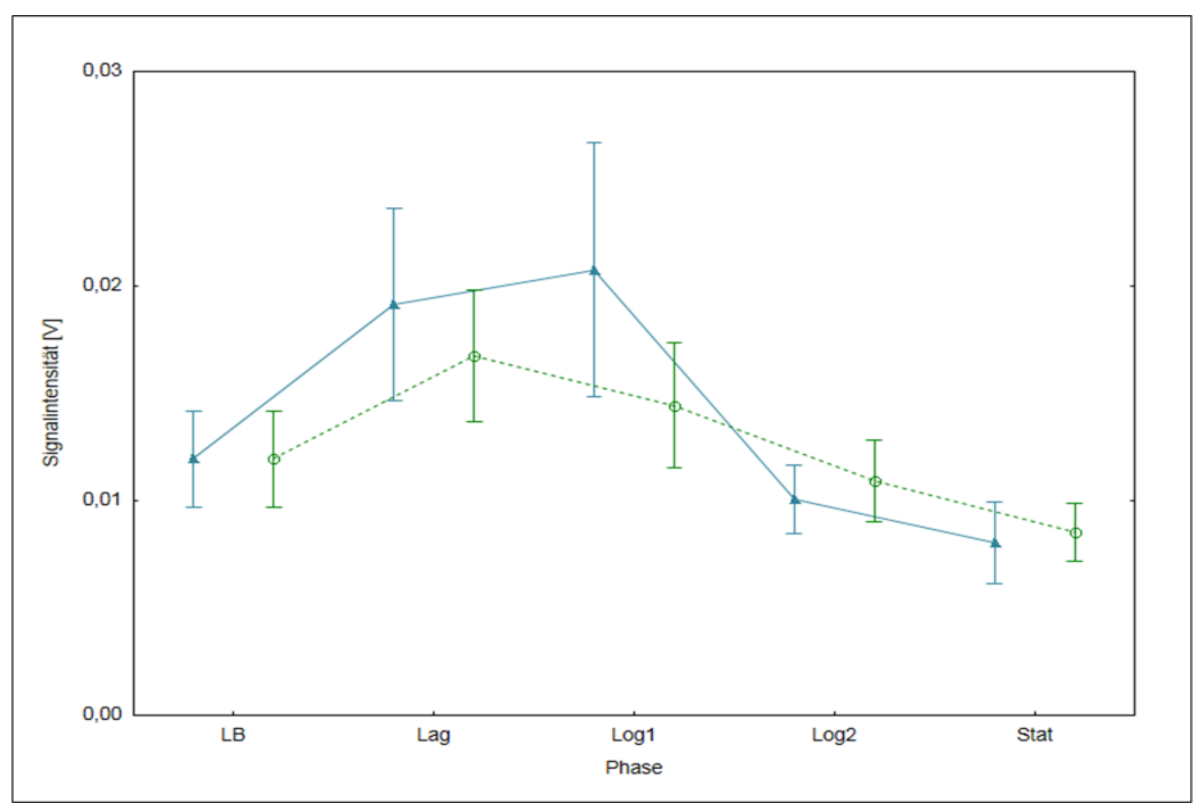

Abbildung 16. Nonanal Messung von Nonanal als VOC über dem Referenzstamm (blau) und den klinischen Isolaten (grün) von E. coli.

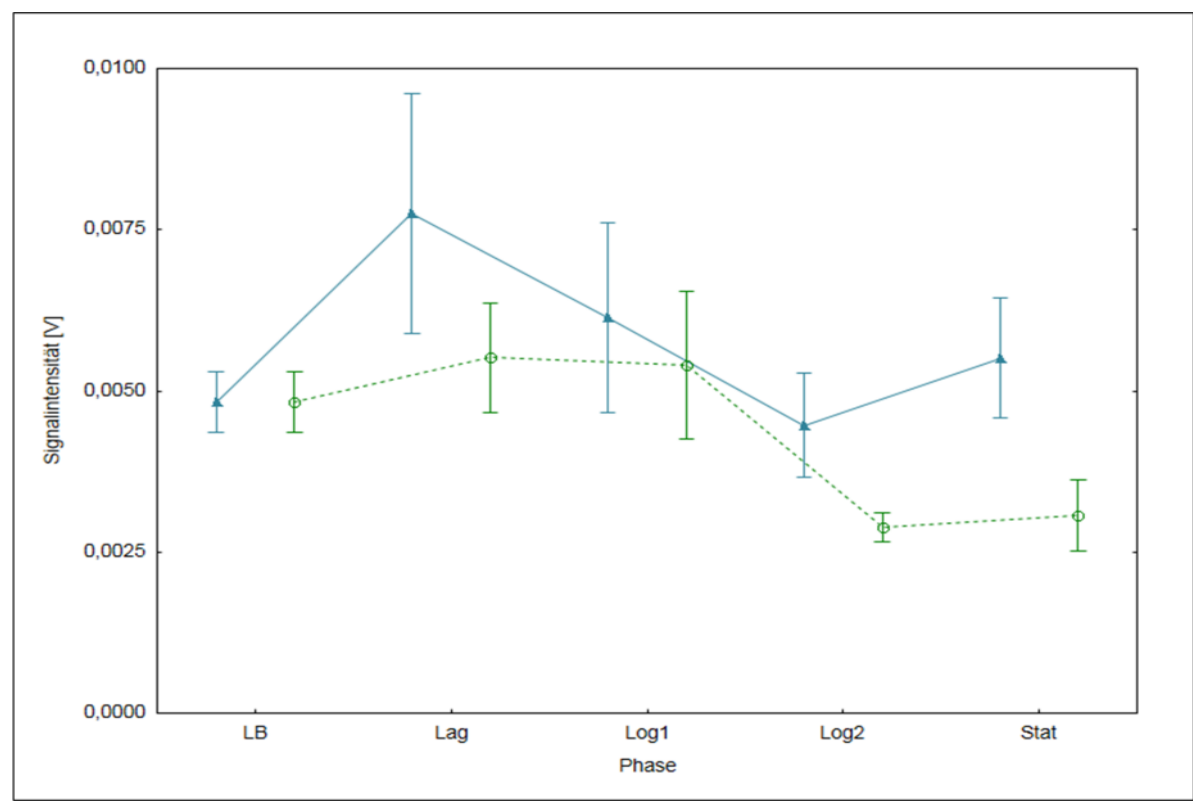

Abbildung 17. P_648_36 Messung von P_648_36 als VOC über dem Referenzstamm (blau) und den klinischen Isolaten (grün) von E. coli. 


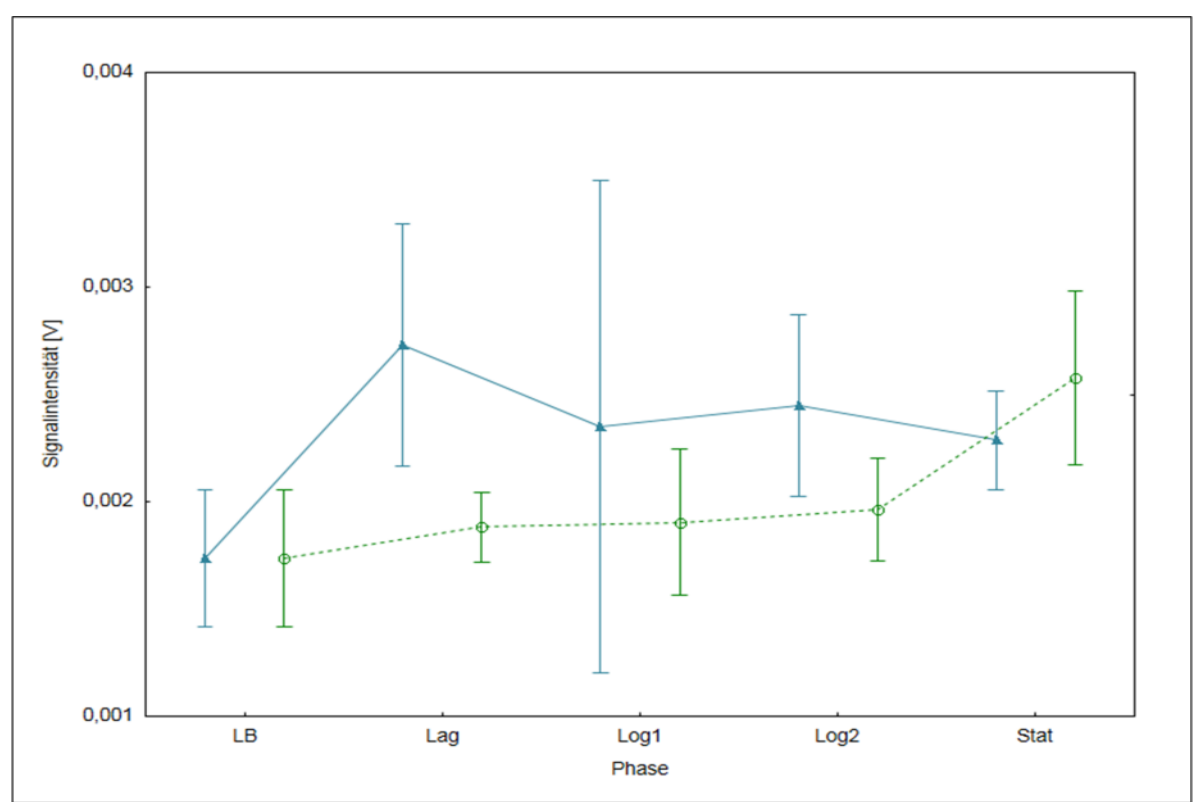

Abbildung 18. P_778_4 Messung von P_778_4 als VOC über dem Referenzstamm (blau) und den klinischen Isolaten (grün) von E. coli.

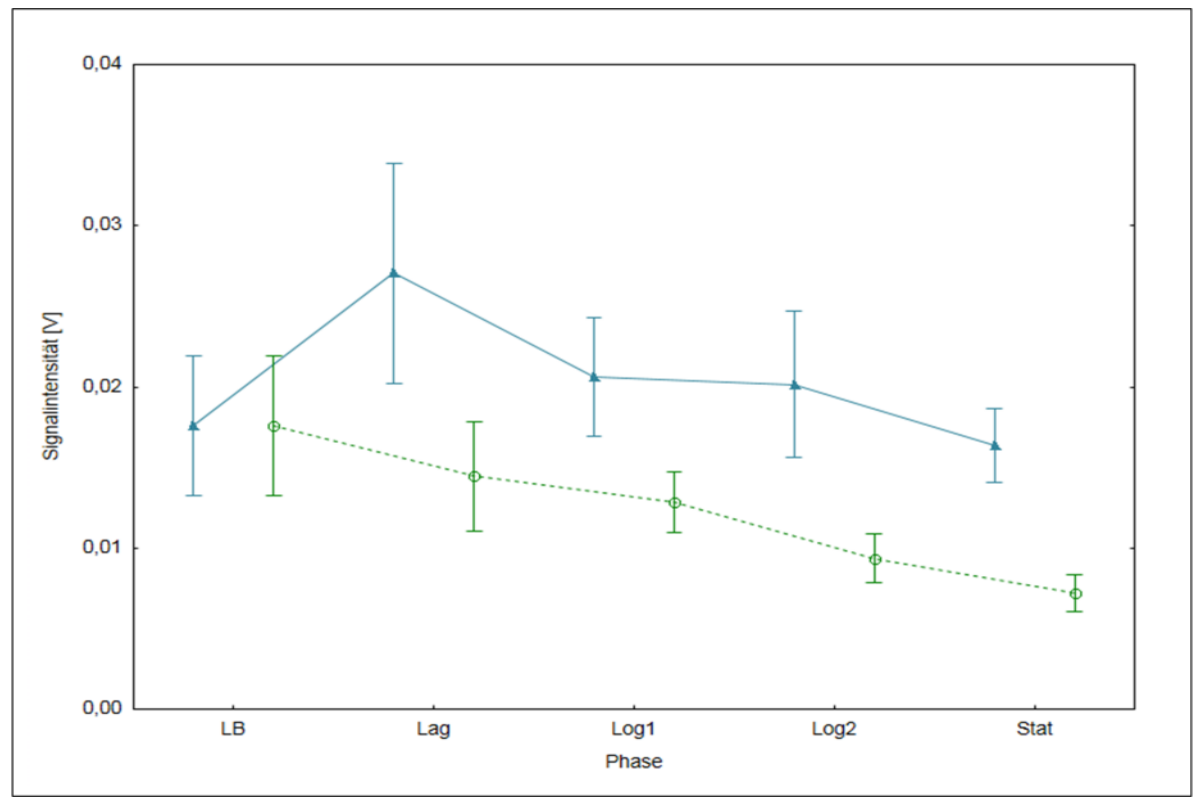

Abbildung 19. 2-Ethyl-1-Hexanol Messung von 2-Ethyl-1-Hexanol als VOC über dem Referenzstamm (blau) und den klinischen Isolaten (grün) von E. coli. 


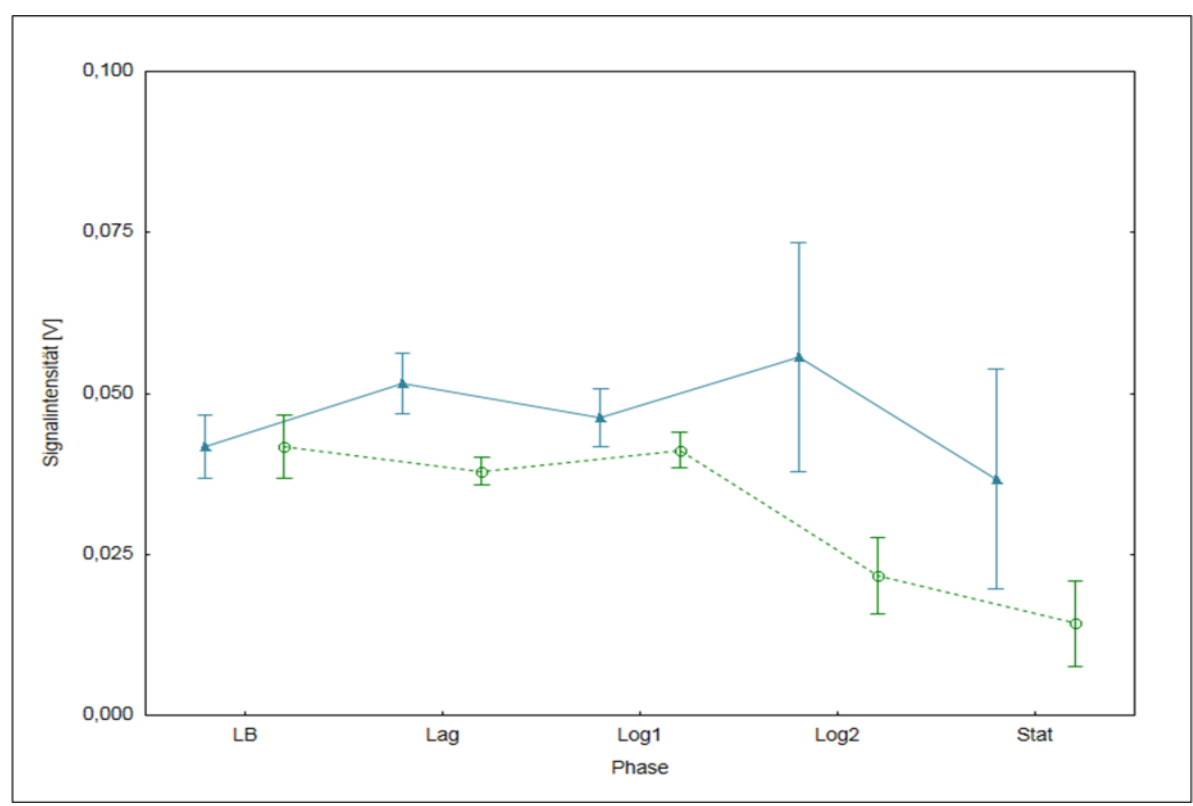

Abbildung 20. 5-Methyl-3-Heptanon Messung von 5-Methyl-3-Heptanon als VOC über dem Referenzstamm (blau) und den klinischen Isolaten (grün) von E. coli.

Ammoniak (Monomer), Decan-1-ol, Ethanol, Indol, 1-Octanol (Monomer und Dimer), P_603_25, P_642_48 und P_755_105 zeigten dagegen jeweils einen deutlichen Anstieg ihrer Signalintensitäten. Dieses Anwachsen der Signalintensität begann mit einzelnen Ausnahmen erst in der späten logarithmischen Phase und zeigte unterschiedliche Verläufe in der statischen Phase. Die Signalintensitäten von P_642_48 und P_755_105 nahmen bereits in der frühen logarithmischen Phase zu und die Maxima fanden sich in der Log1(P_642_48) bzw. in der Log2-Phase (P_755_105).

Diese Ergebnisse waren bei Referenzstamm und klinischen Isolaten im Wachstumsverlauf nahezu identisch. Lediglich bei der Substanz P_603_25 zeigen sich Unterschiede in der Geschwindigkeit des Anstiegs der Signalintensität. Beim Referenzstamm fand sich bereits im frühen Wachstum ein deutlicher Anstieg, der sich bei den klinischen Isolaten erst verzögert zeigte. 


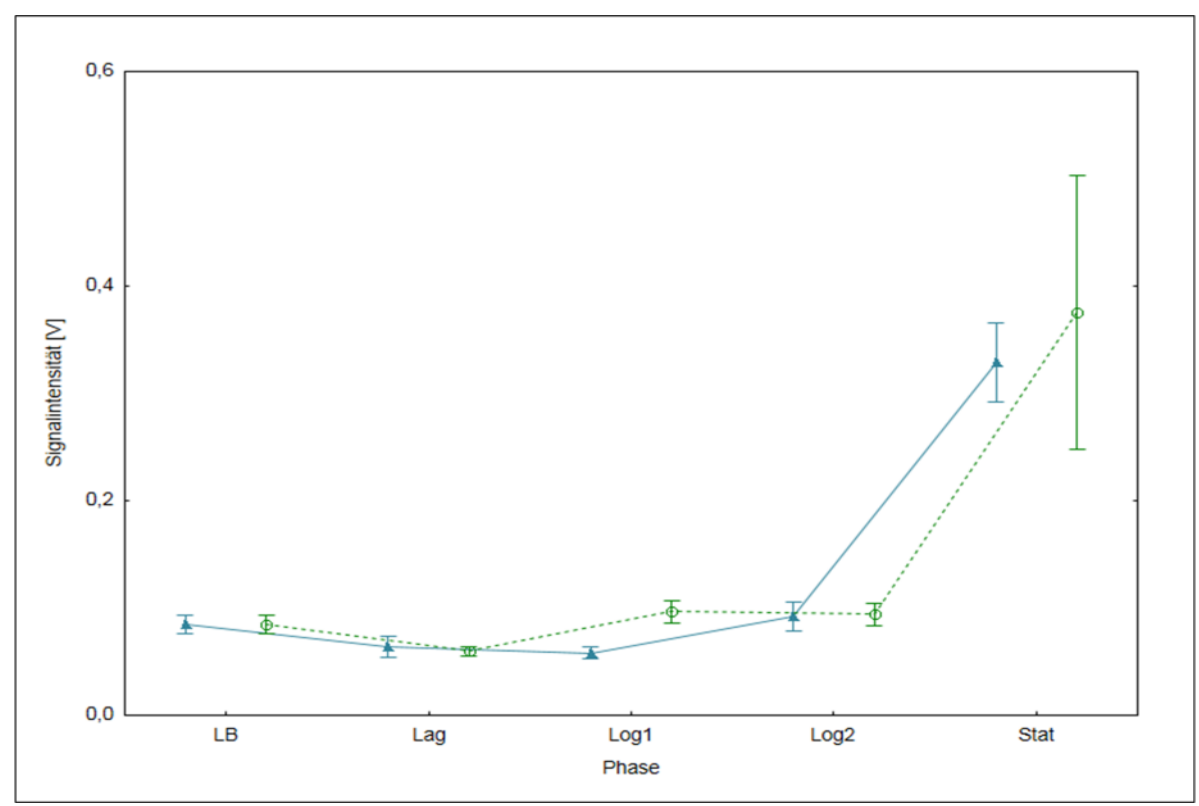

Abbildung 21. Ammoniak (Monomer) Messung von Ammoniak (Monomer) als VOC über dem Referenzstamm (blau) und den klinischen Isolaten (grün) von E. coli.

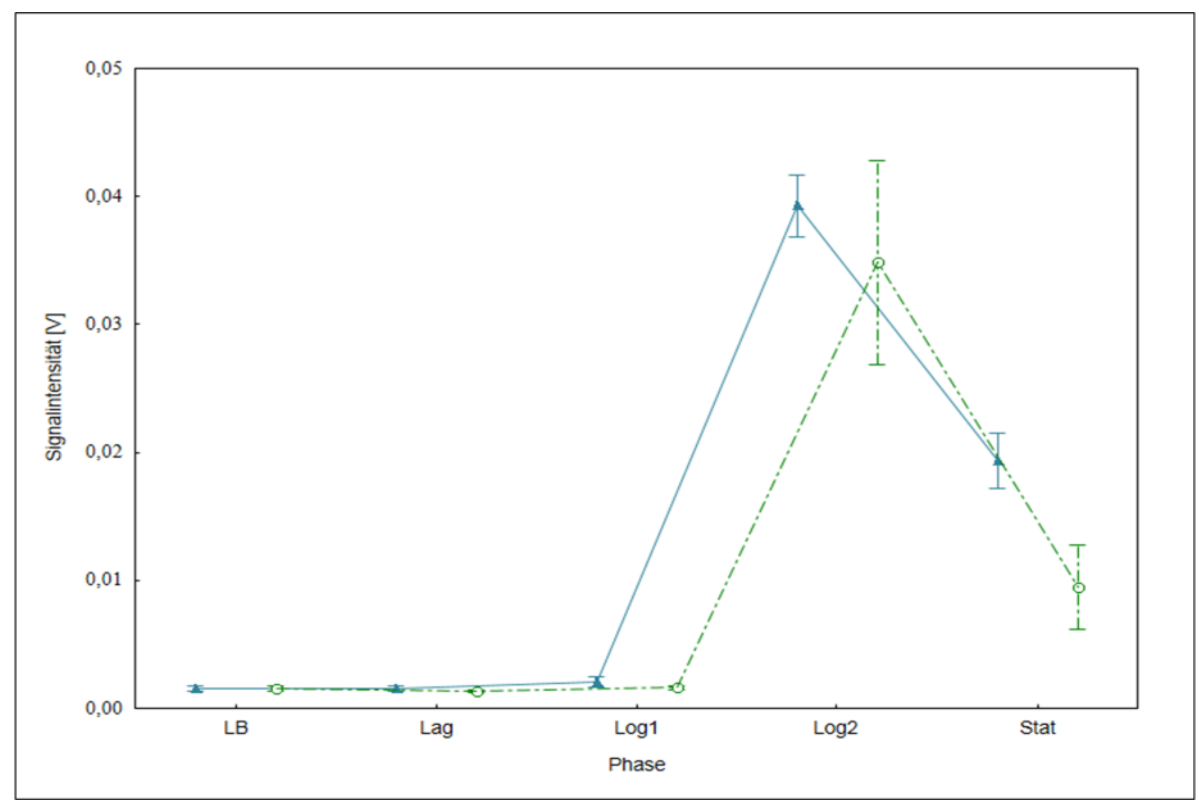

Abbildung 22. Decan-1-ol Messung von Decan-1-ol als VOC über dem Referenzstamm (blau) und den klinischen Isolaten (grün) von E. coli. 


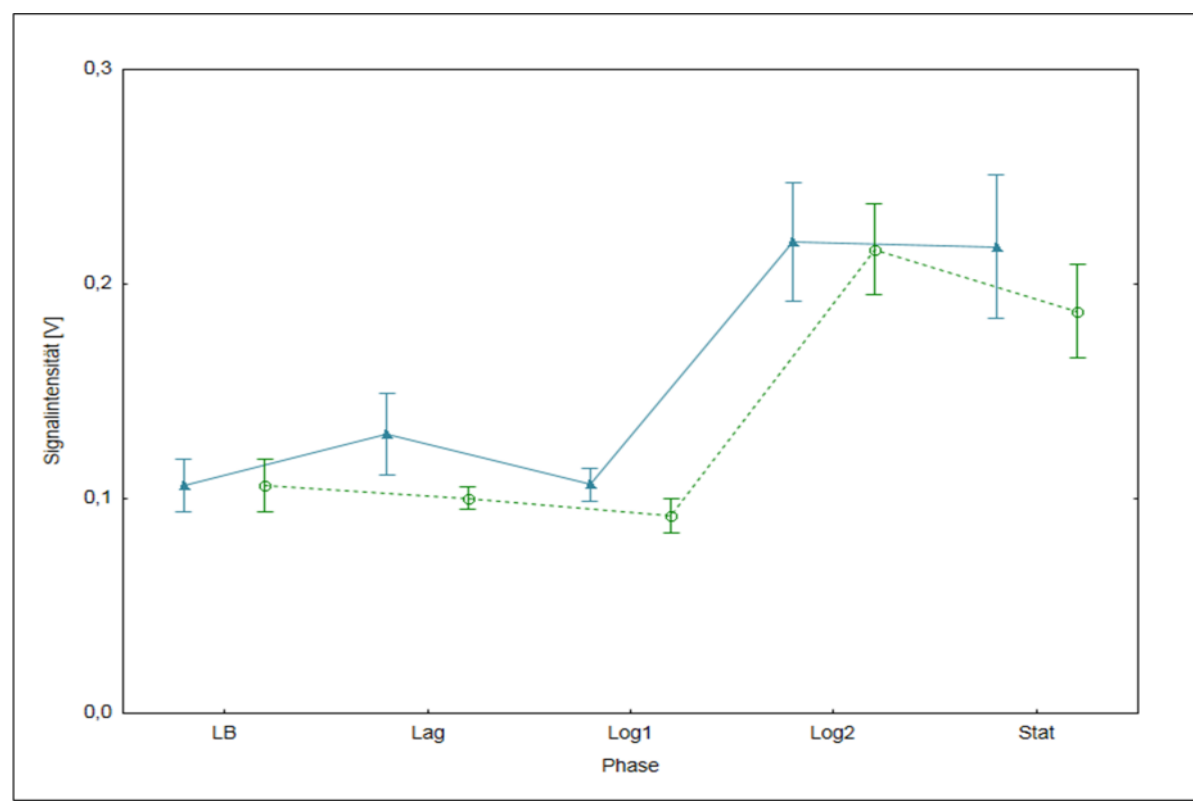

Abbildung 23. Ethanol Messung von Ethanol als VOC über dem Referenzstamm (blau) und den klinischen Isolaten (grün) von E. coli.

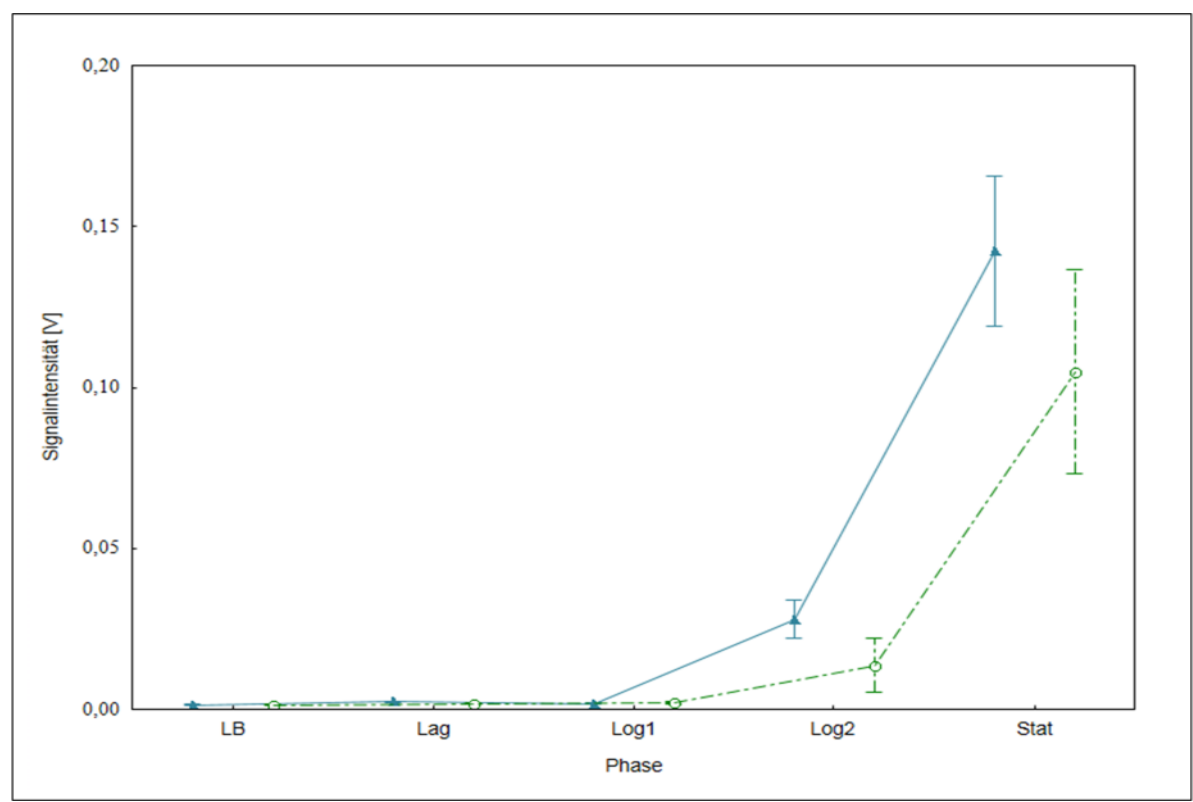

Abbildung 24. Indol Messung von Indol als VOC über dem Referenzstamm (blau) und den klinischen Isolaten (grün) von E. coli. 


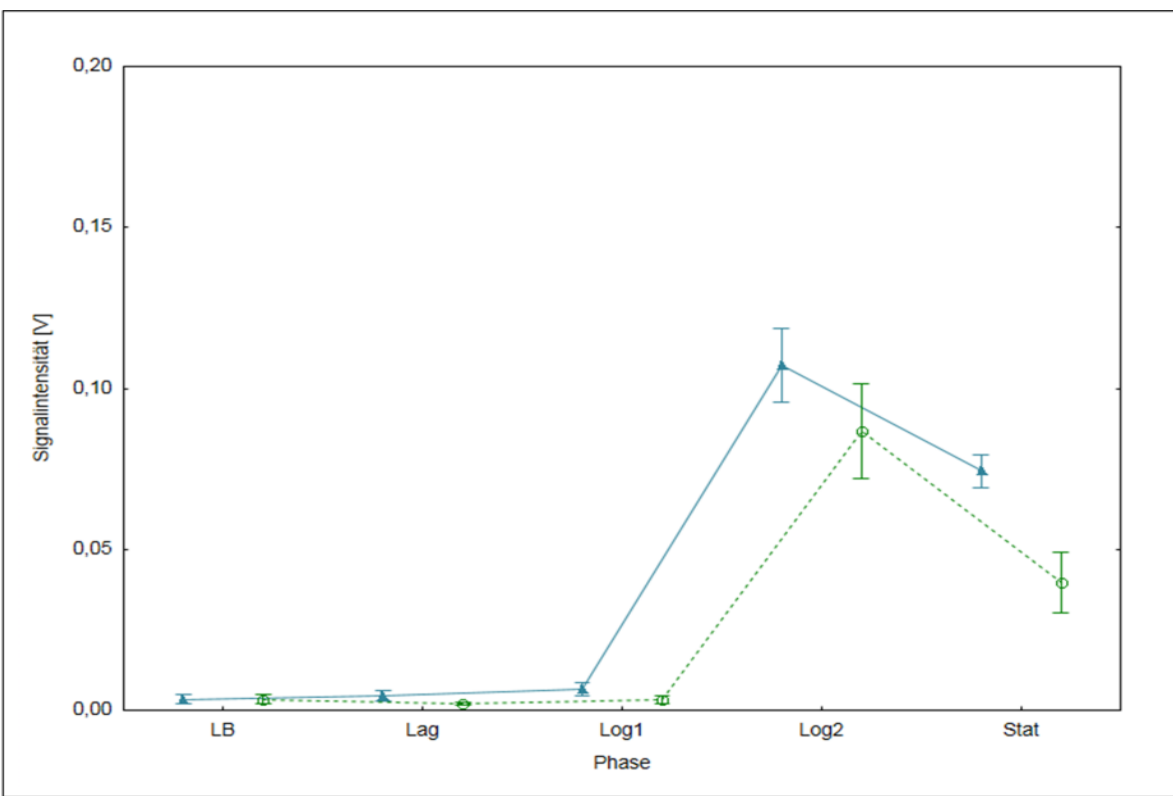

Abbildung 25. 1-Octanol (Monomer) Messung von 1-Octanol (Monomer) als VOC über dem Referenzstamm (blau) und den klinischen Isolaten (grün) von E. coli.

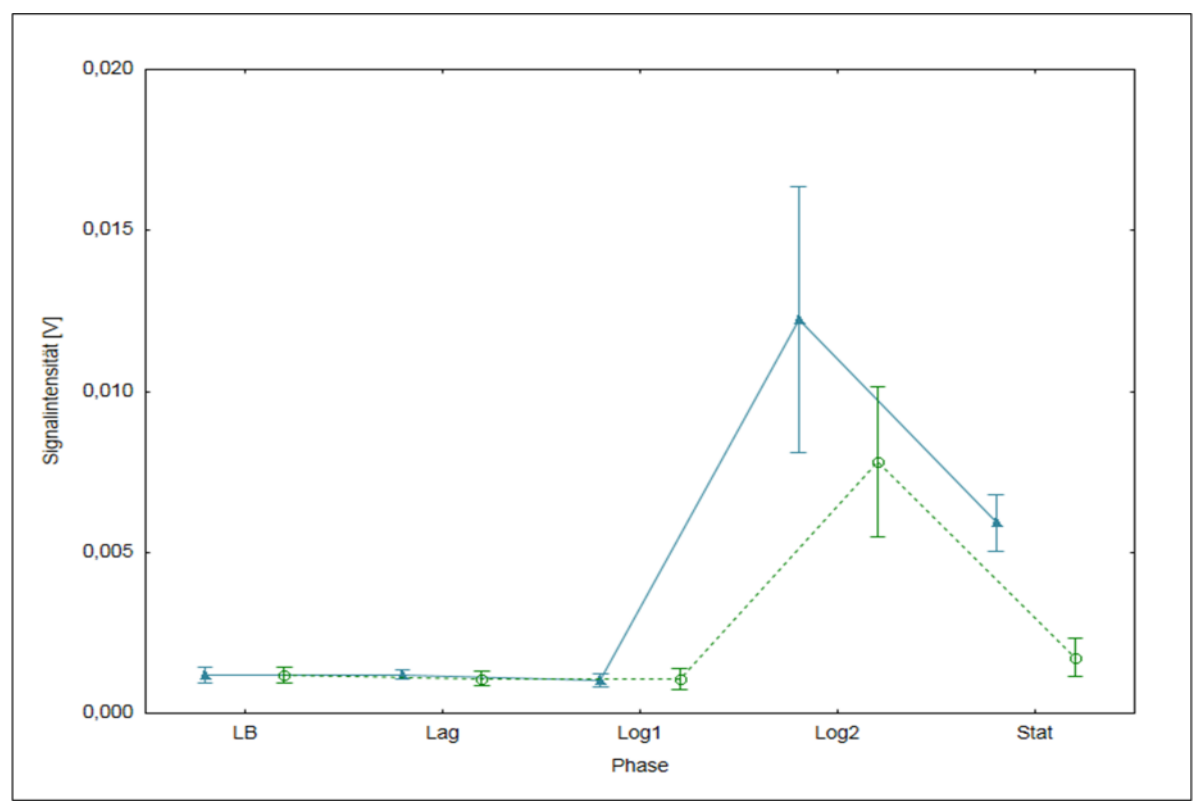

Abbildung 26. 1-Octanol (Dimer) Messung von 1-Octanol (Dimer) als VOC über dem Referenzstamm (blau) und den klinischen Isolaten (grün) von E. coli. 


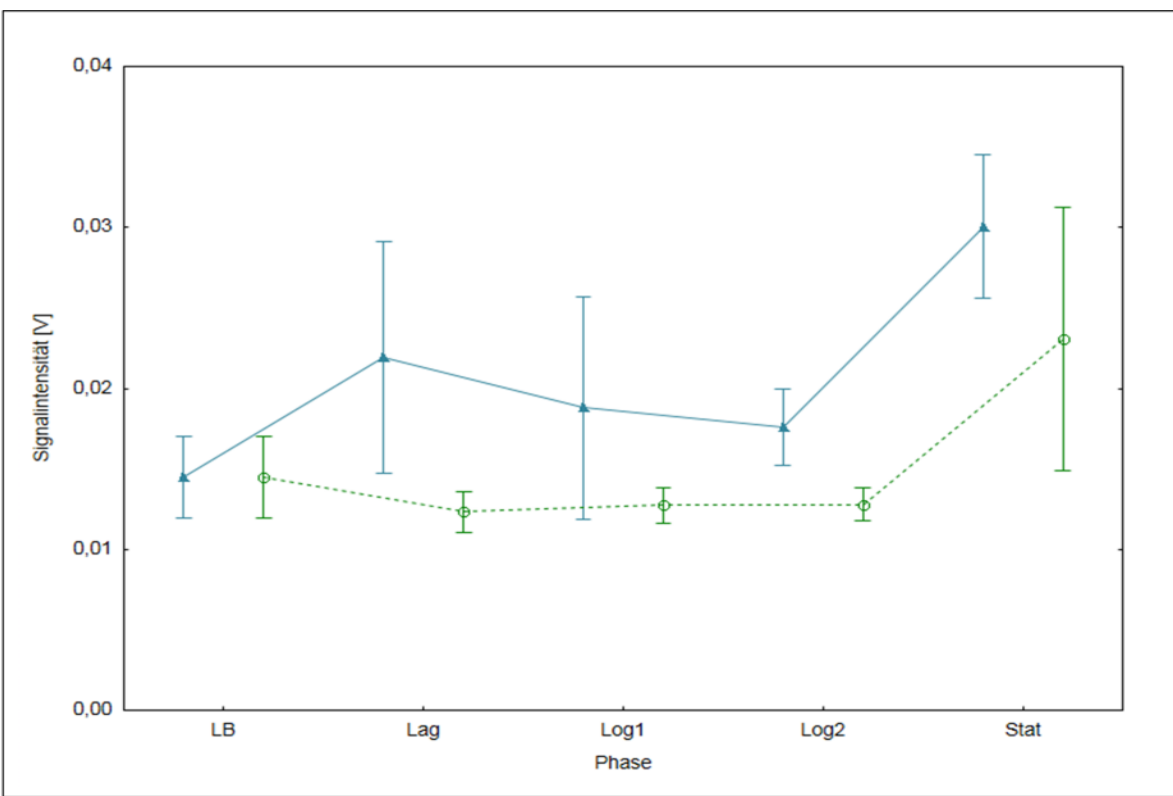

Abbildung 27. P_603_25 Messung von P_603_25 als VOC über dem Referenzstamm (blau) und den klinischen Isolaten (grün) von E. coli.

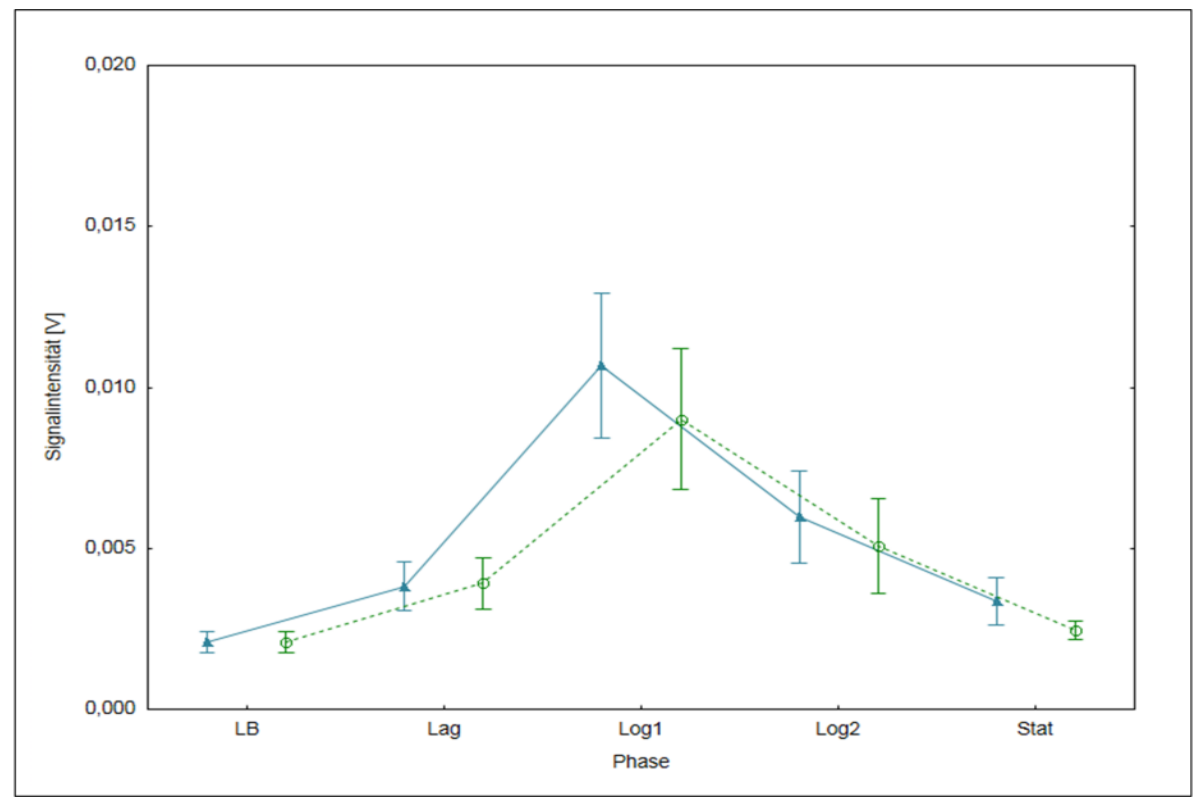

Abbildung 28. P_642_48 Messung von P_642_48 als VOC über dem Referenzstamm (blau) und den klinischen Isolaten (grün) von E. coli. 


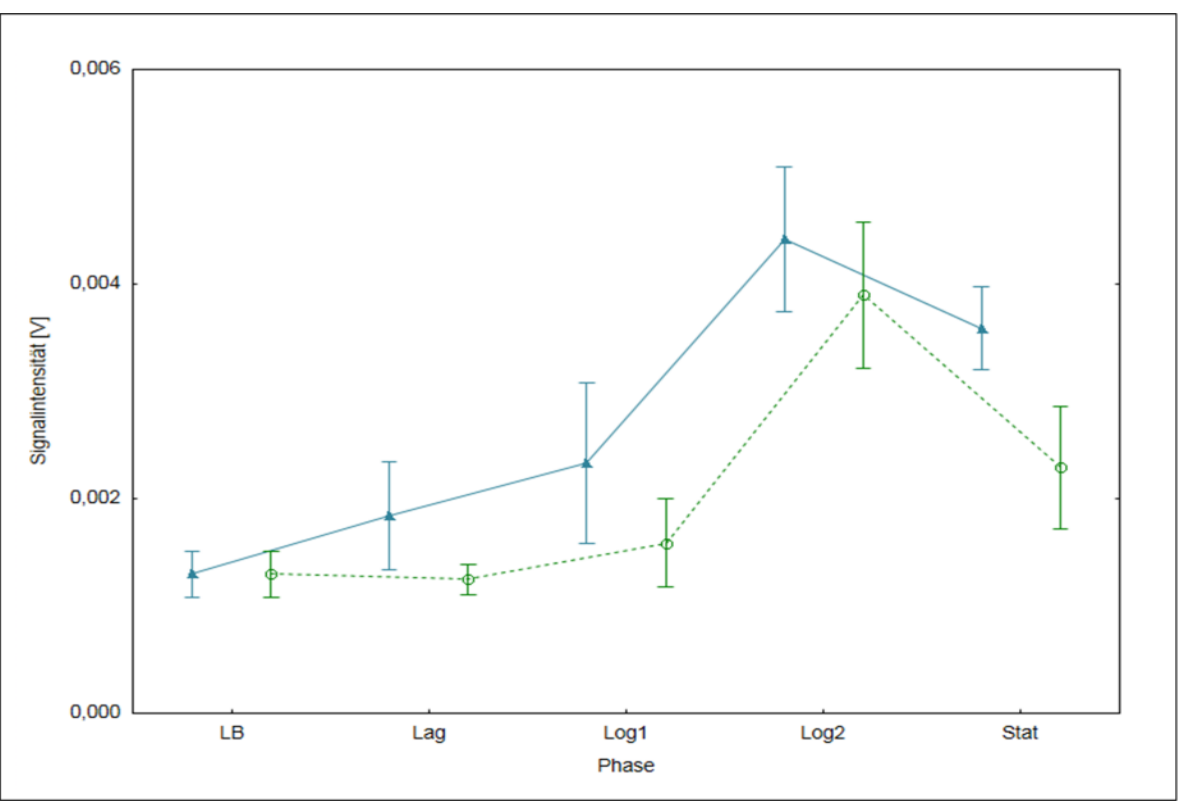

Abbildung 29. P_755_105 Messung von P_755_105 als VOC über dem Referenzstamm (blau) und den klinischen Isolaten (grün) von E. coli.

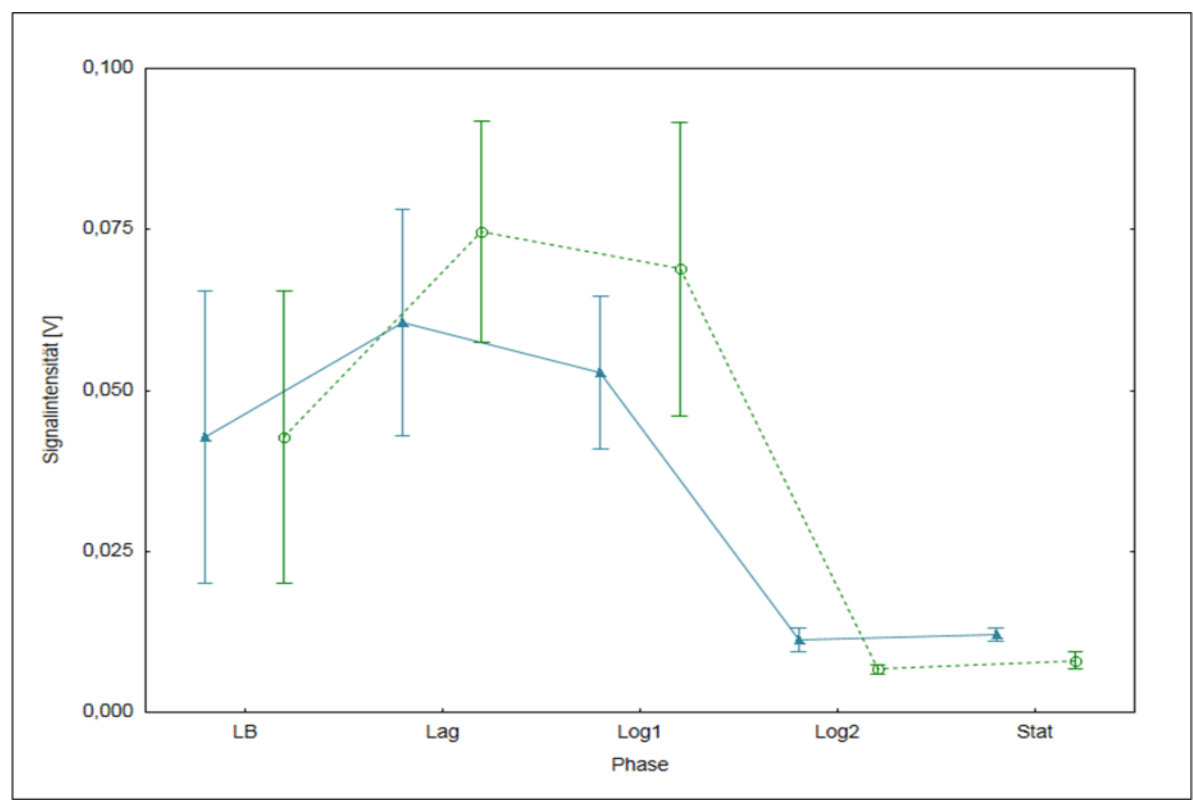

Abbildung 30. Phenylacetaldehyd Messung von Phenylacetaldehyd als VOC über dem Referenzstamm (blau) und den klinischen Isolaten (grün) von E. coli.

Einzig Phenylacetaldehyd (Abb. 30) zeigte im zweiten Teil der Wachstumsphase eine deutliche Abnahme der Signalintensität nach dem initialen Anstieg der Signalintensität in der ersten logarithmischen Phase. 


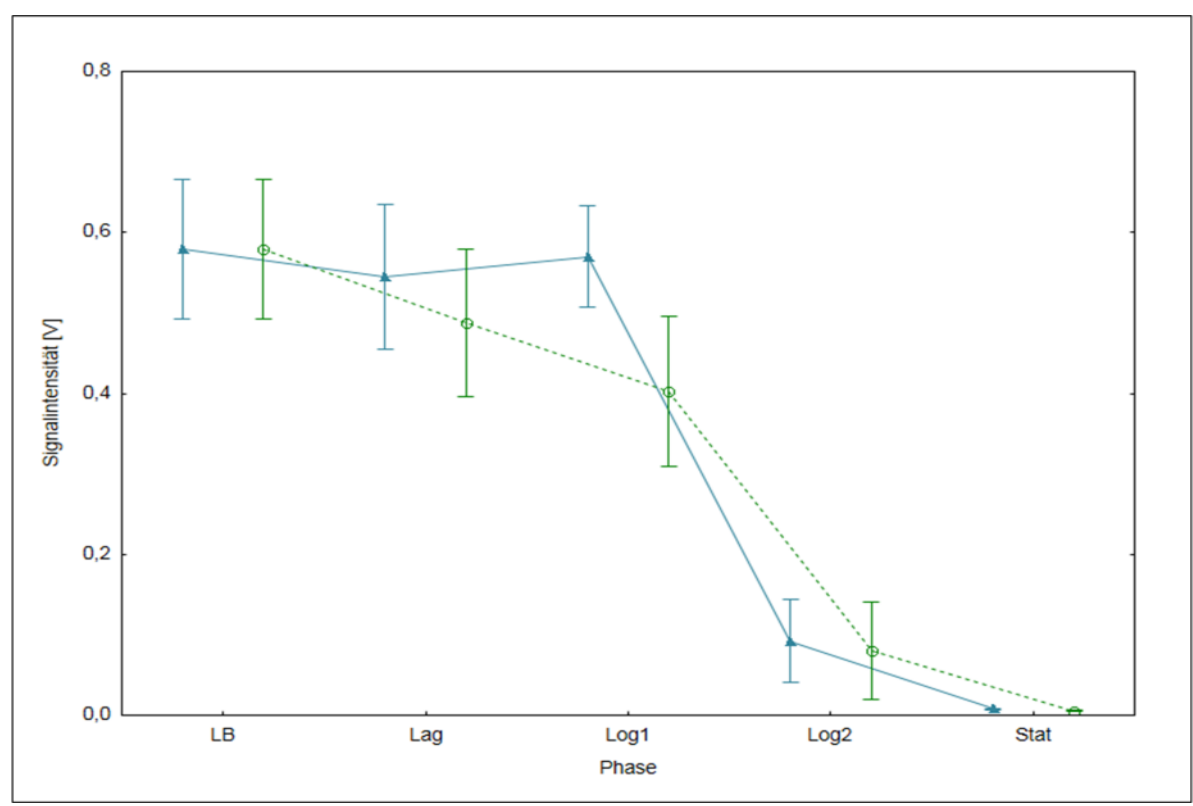

Abbildung 31. P_720_16 Messung von P_720_16 als VOC über dem Referenzstamm (blau) und den klinischen Isolaten (grün) von E. coli.

Die Substanz P_720_16 (Abb. 31) zeigte die höchste Signalintensität zu Beginn der Messungen und war in der statischen Phase kaum noch nachweisbar.

\subsubsection{P.-aeruginosa-Signale}

Insgesamt konnten in den Messungen über P. aeruginosa elf Signale detektiert werden, die sich im Wachstumsverlauf veränderten (Abb. 32-42). Diese lassen sich in zwei Gruppen einteilen: Einerseits Metaboliten, die während des Messzeitraumes an Quantität zunahmen, und solche, die im Verlauf abnahmen. Ähnlich wie bei E. coli war zu beobachten, dass die Zunahme der Signalintensitäten erst in der Log2-Phase begann. Dies war insbesondere für die folgenden Peakregionen zu beobachten: Ammoniak (Monomer), Ammoniak (Dimer), Dodecan, P_603_25, P_648_36 und P_778_4. Aceton folgte ebenfalls dem Trend einer zunehmenden Konzentration. Dieser begann jedoch schon in der frühen Wachstumsphase (Lag-Phase) und endete in der Log1-Phase.

Aceton und 5-Methyl-3-Heptanon wurden bei $P$. aeruginosa in der frühen Wachstumsphase detektiert. Im weiteren Verlauf fiel die Konzentration dieser Metaboliten jedoch unter den Ausgangswert der LB-Messung. 
2-Ethyl-1-Hexanol und P_720_16 zeigten über die gesamte Wachstumskurve abfallende Signalintensitäten.

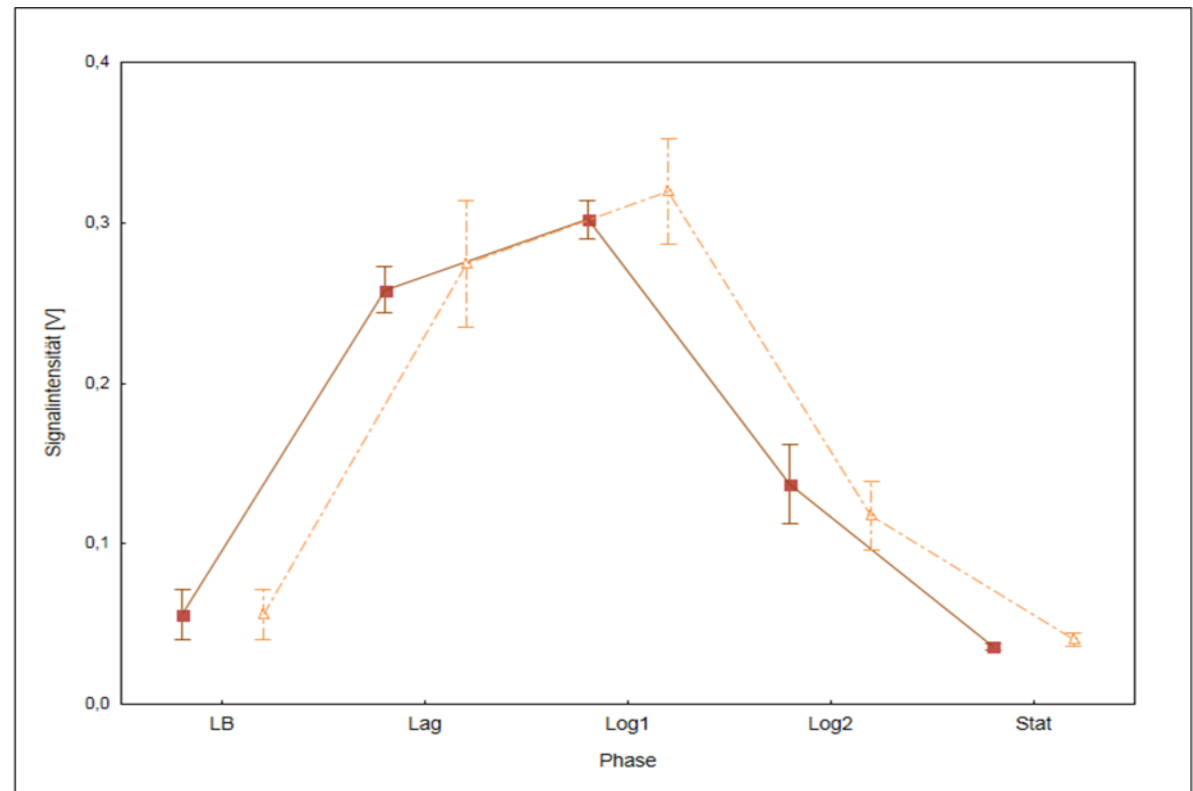

Abbildung 32. Aceton Messung von Aceton als VOC über dem Referenzstamm (rot) und den klinischen Isolaten (gelb) von P. aeruginosa.

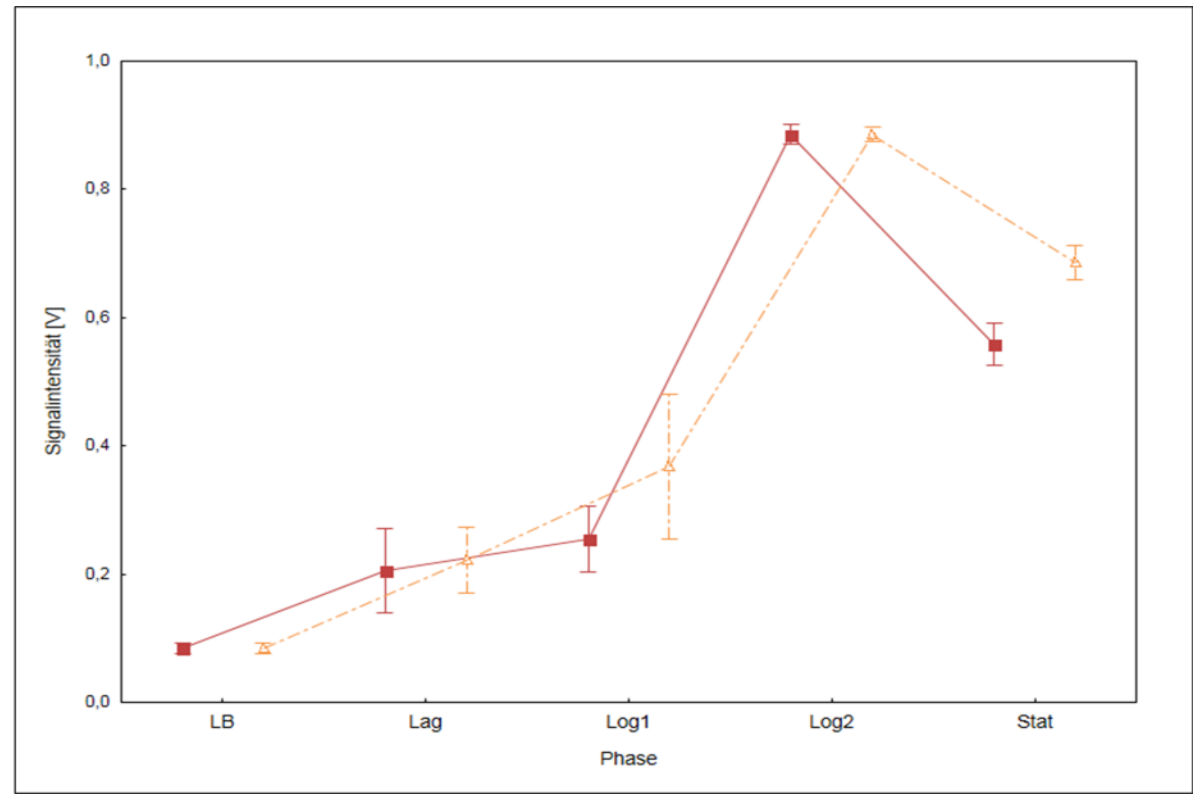

Abbildung 33. Ammoniak (Monomer) Messung von Ammoniak (Monomer) als VOC über dem Referenzstamm (rot) und den klinischen Isolaten (gelb) von P. aeruginosa. 


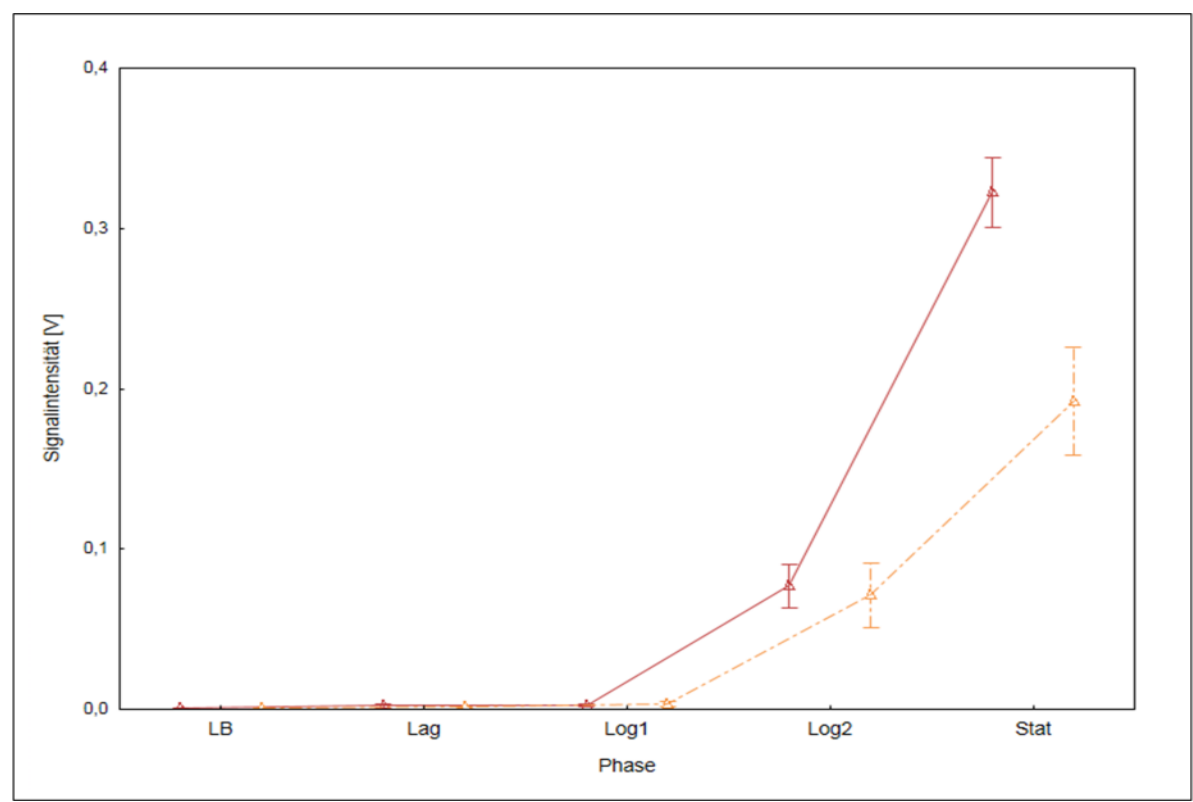

Abbildung 34. Ammoniak (Dimer) Messung von Ammoniak (Dimer) als VOC über dem Referenzstamm (rot) und den klinischen Isolaten (gelb) von P. aeruginosa.

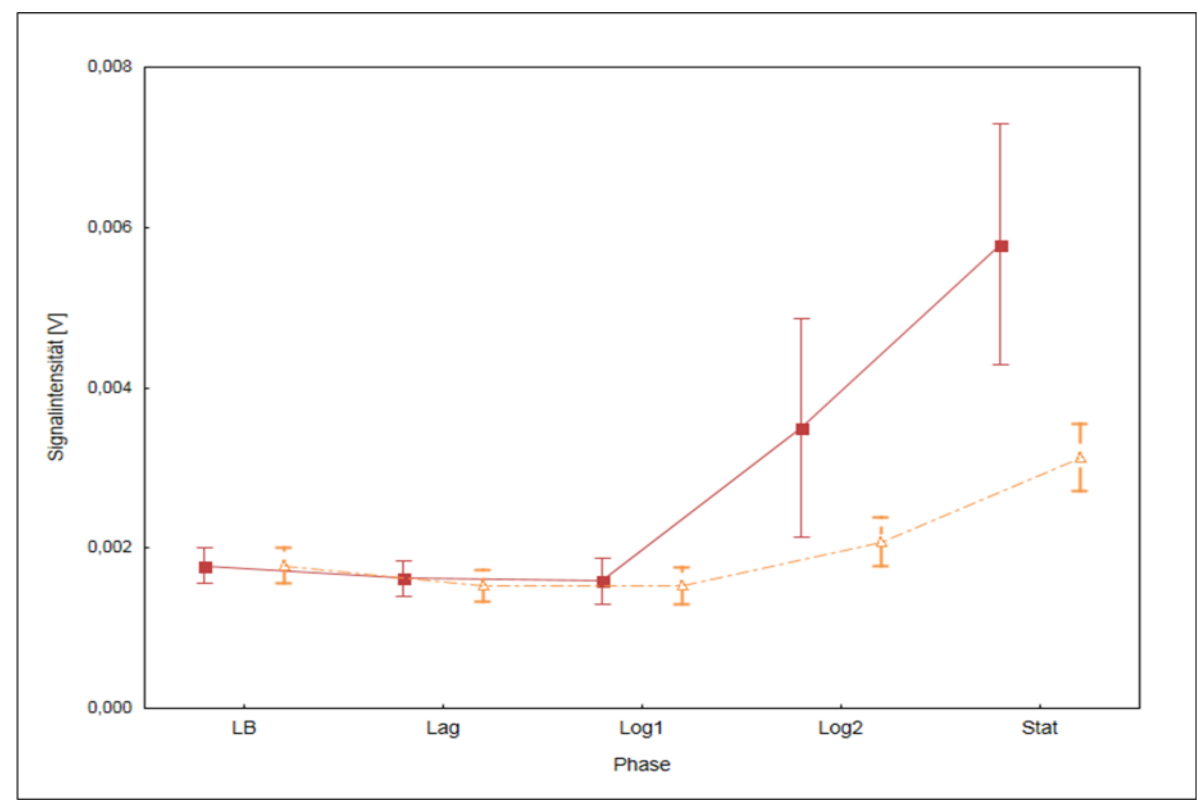

Abbildung 35. Dodecan Messung von Dodecan als VOC über dem Referenzstamm (rot) und den klinischen Isolaten (gelb) von P. aeruginosa. 


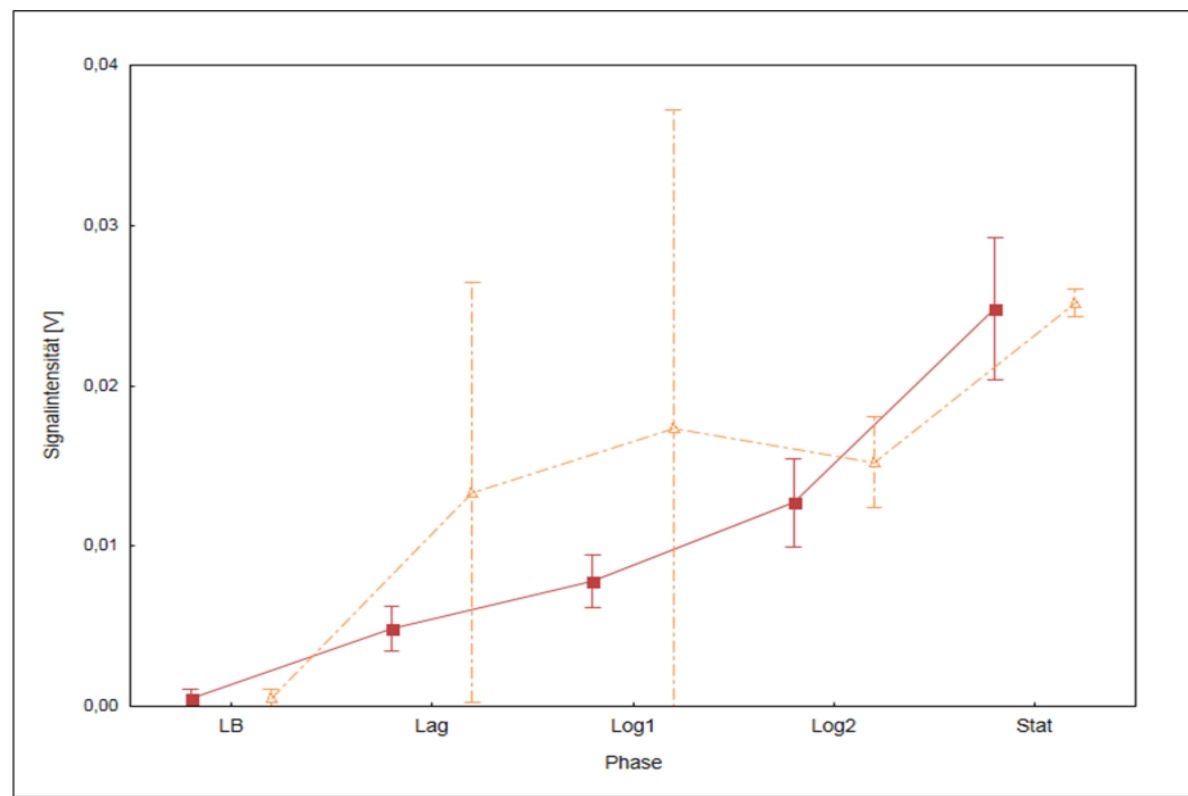

Abbildung 36. P_503_27 Messung von P_503_27 als VOC über dem Referenzstamm (rot) und den klinischen Isolaten (gelb) von P. aeruginosa.

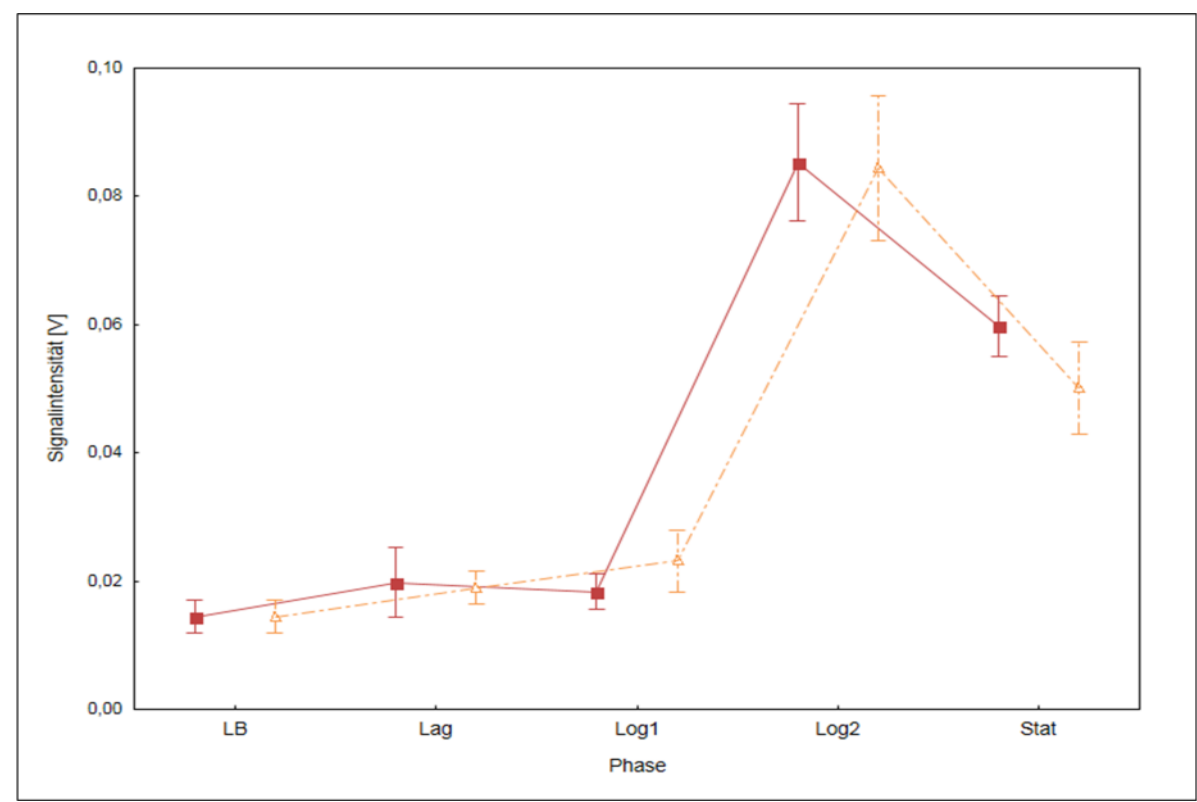

Abbildung 37. P_603_25 Messung von P_603_25 als VOC über dem Referenzstamm (rot) und den klinischen Isolaten (gelb) von P. aeruginosa. 


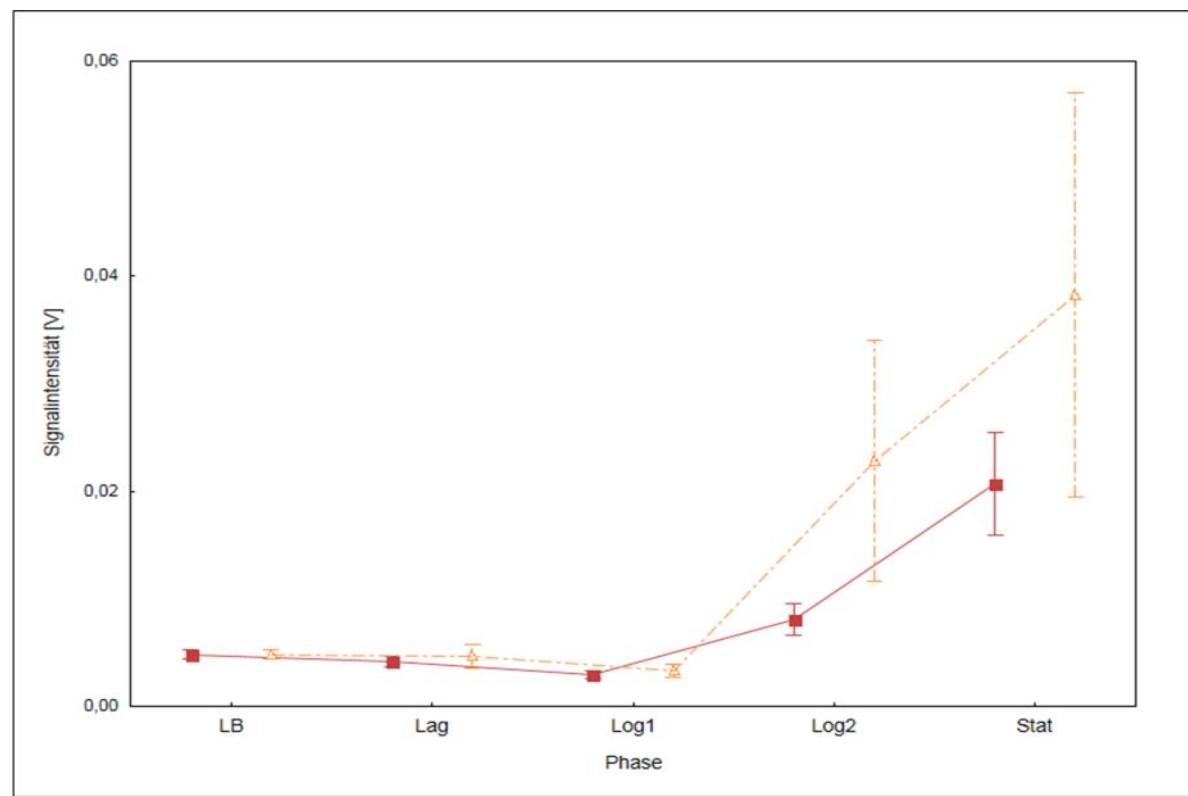

Abbildung 38. P_648_36 Messung von P_648_36 als VOC über dem Referenzstamm (rot) und den klinischen Isolaten (gelb) von P. aeruginosa.

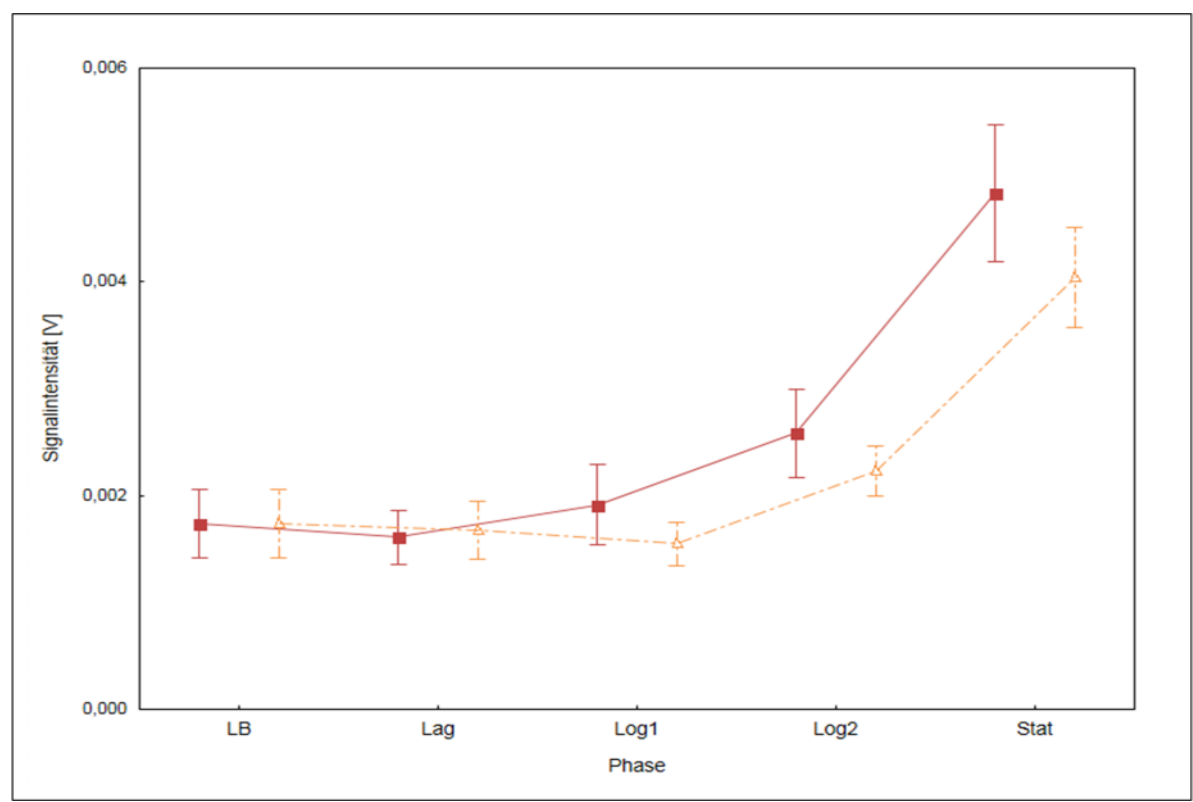

Abbildung 39. P_778_4 Messung von P_778_4 als VOC über dem Referenzstamm (rot) und den klinischen Isolaten (gelb) von P. aeruginosa. 


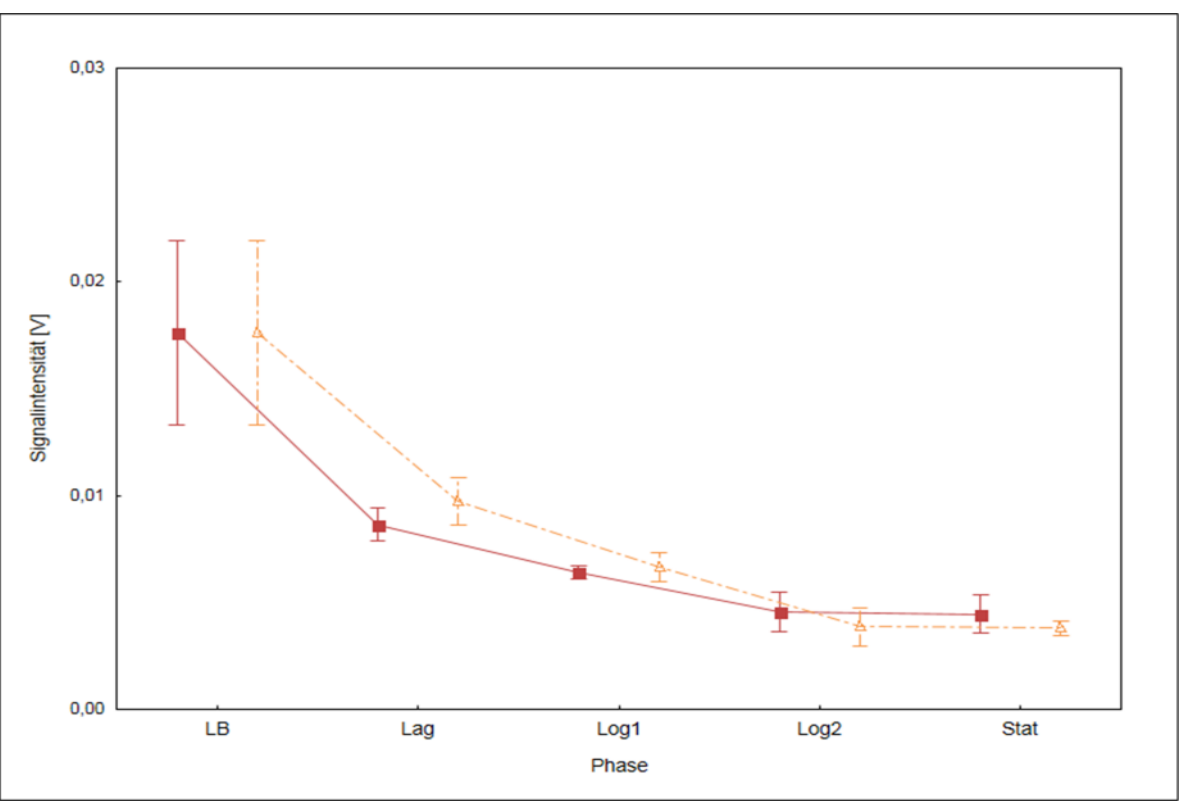

Abbildung 40. 2-Ethyl-1-Hexanol Messung von 2-Ethyl-1-Hexanol als VOC über dem Referenzstamm (rot) und den klinischen Isolaten (gelb) von P. aeruginosa.

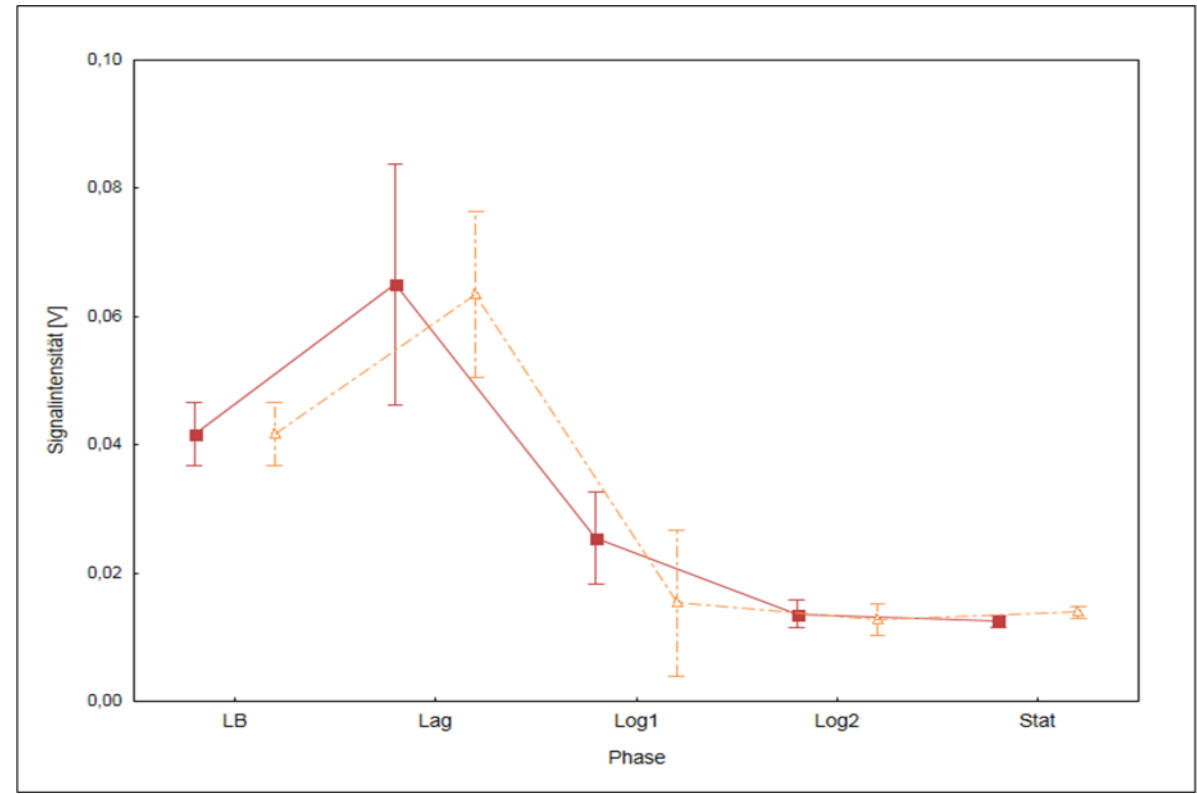

Abbildung 41. 5-Methyl-3-Heptanon Messung von 5-Methyl-3-Heptanon als VOC über dem Referenzstamm (rot) und den klinischen Isolaten (gelb) von P. aeruginosa. 


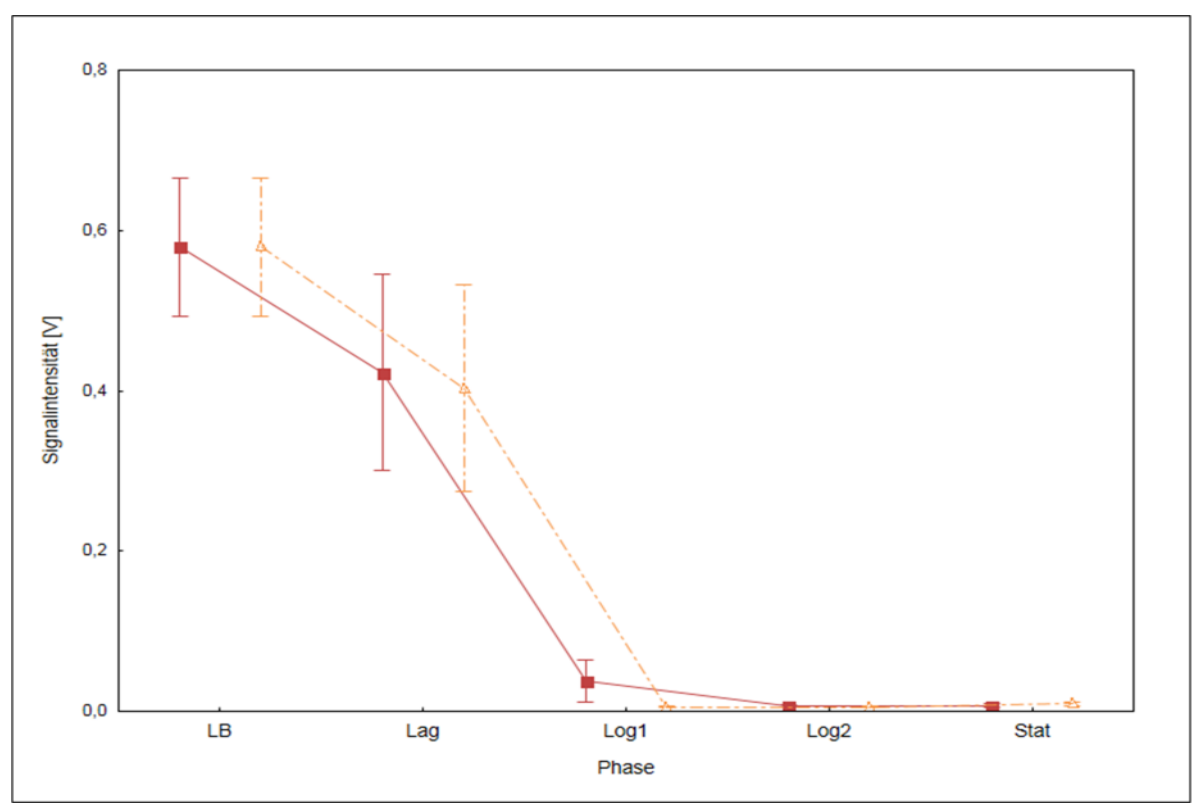

Abbildung 42. P_720_16 Messung von P_720_16 als VOC über dem Referenzstamm (rot) und den klinischen Isolaten (gelb) von P. aeruginosa.

P_503_27 zeigte, ähnlich wie bei P_603_25, im frühen Wachstumsbereich über den klinischen Isolaten der E.-coli-Kulturen größere Varianz der gemessenen Signalintensitäten. Es zeigte sich jedoch kein grundsätzlich voneinander abweichender Trend. Insgesamt war keine relevante Diskrepanz zwischen den Kulturen des Referenzstammes und der klinischen Isolate zu erkennen.

\subsection{Differenzierung anhand keimspezifischer VOCs}

Die folgenden Grafiken zeigen den Vergleich der VOCs beider Bakterienspezies. Dargestellt sind die Mittelwerte und 95 \%igen Konfidenzintervalle, die sich aus den Messungen der Referenzstämme und der klinischen Isolate des jeweiligen Bakteriums ergaben. Rechtsseitig ist in den Grafiken jeweils eine beispielhafte Region aus dem IMS-Topogramm abgebildet. Dafür wurde ein Peak des jeweiligen Referenzstammes, nämlich aus der fünften der zwölf Messungen, genutzt. 


\subsubsection{E.-coli-assoziierte VOCs}

Folgende VOCs zeigten ausschließlich über den E--coli-Kulturen eine relevante Zunahme ihrer Signalintensitäten: 1-Decanol, Ethanol, Indol, 1-Octanol (Monomer und Dimer) und P_755_105. Über den P.-aeruginosa-Kulturen zeigte sich in den entsprechenden Peakregionen keine Zunahme der Signalintensitäten.

1-Decanol, 1-Octanol (Monomer und Dimer), sowie P_755_105 hatten ähnliche Konzentrationsverläufe. In den späten exponentiellen Wachstumsphasennahmen die Signalintensitäten deutlich zu. In den statischen Wachstumsphasenfielen sie wieder moderat ab.

Allein Indol zeigte über den E-coli-Kulturen eine steigende Konzentration in der statischen Phase, während es über P.-aeruginosa-Kulturen nicht nachweisbar war.

Ethanol war im volatilen Hintergrund des Nährmediums bereits nachweisbar. Bei E. coli zeigte sich eine deutliche Zunahme der Signalintensität, während diese bei $P$. aeruginosa um etwa die Hälfte abfiel. 


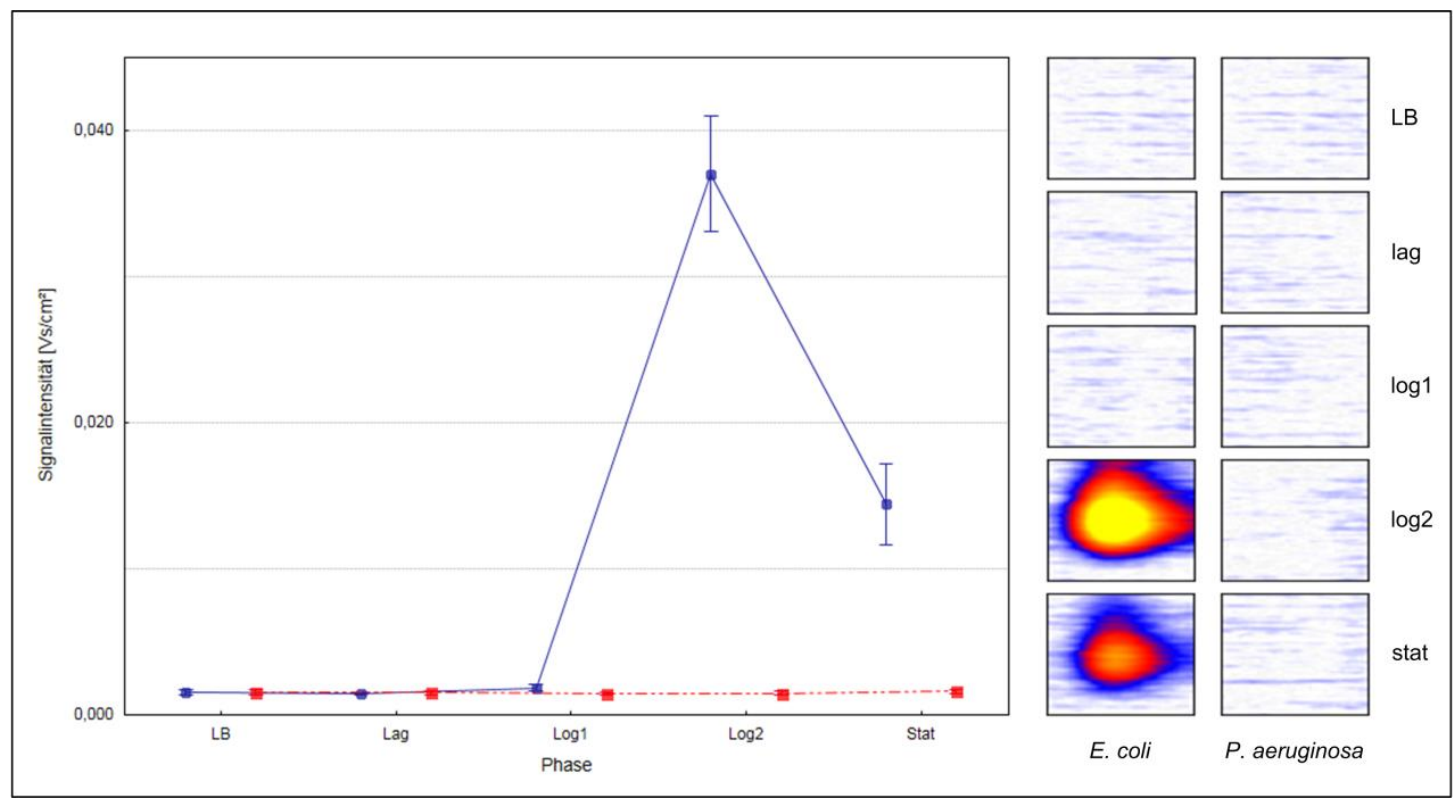

Abbildung 43. 1-Decanol Vergleich der Signalintensitäten von 1-Decanol über E. coli (blau) und $P$. aeruginosa (rot). Links: Darstellung der Signalintensität als Mittelwert und $95 \%$-KI. Rechts: Darstellung der Peakregionen aus der fünften Messreihe des Referenzstammes der jeweiligen Spezies.

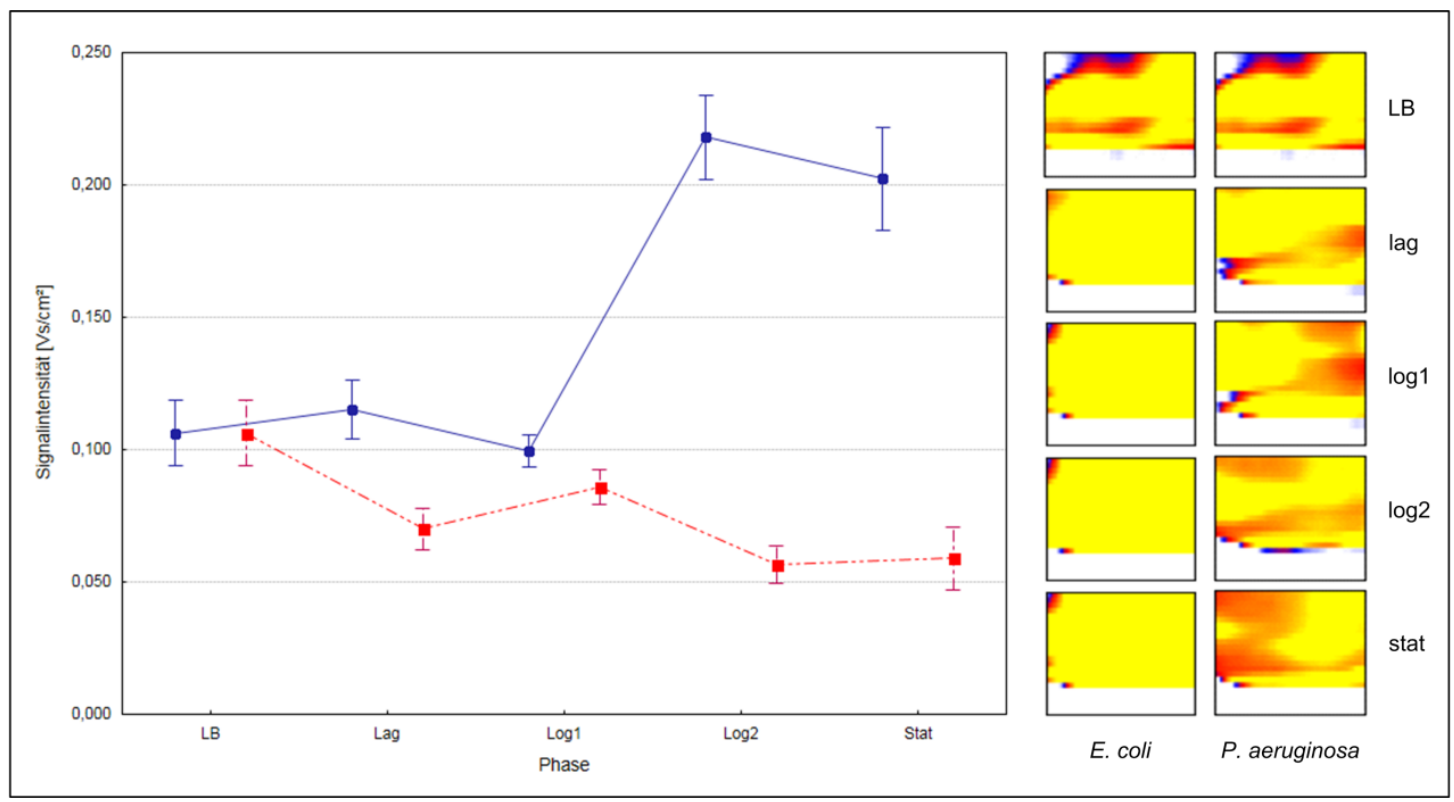

Abbildung 44. Ethanol Vergleich der Signalintensitäten von Ethanol über E. coli (blau) und $P$. aeruginosa (rot). Links: Darstellung der Signalintensität als Mittelwert und $95 \%$-KI. Rechts: Darstellung der Peakregionen aus der fünften Messreihe des Referenzstammes der jeweiligen Spezies. 


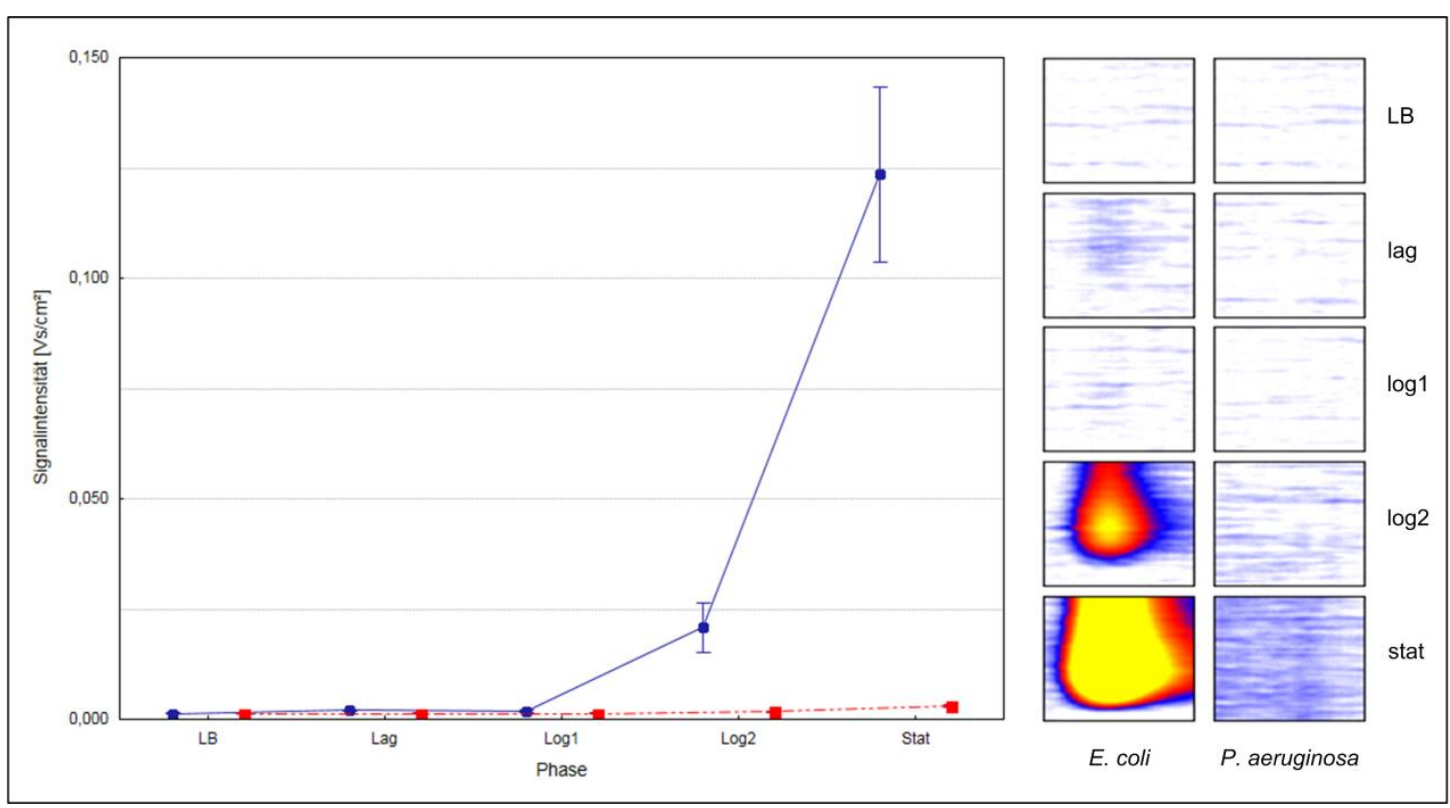

Abbildung 45. Indol Vergleich der Signalintensitäten von Indol über $E$. coli (blau) und $P$. aeruginosa (rot). Links: Darstellung der Signalintensität als Mittelwert und 95\%-KI. Rechts: Darstellung der Peakregionen aus der fünften Messreihe des Referenzstammes der jeweiligen Spezies.

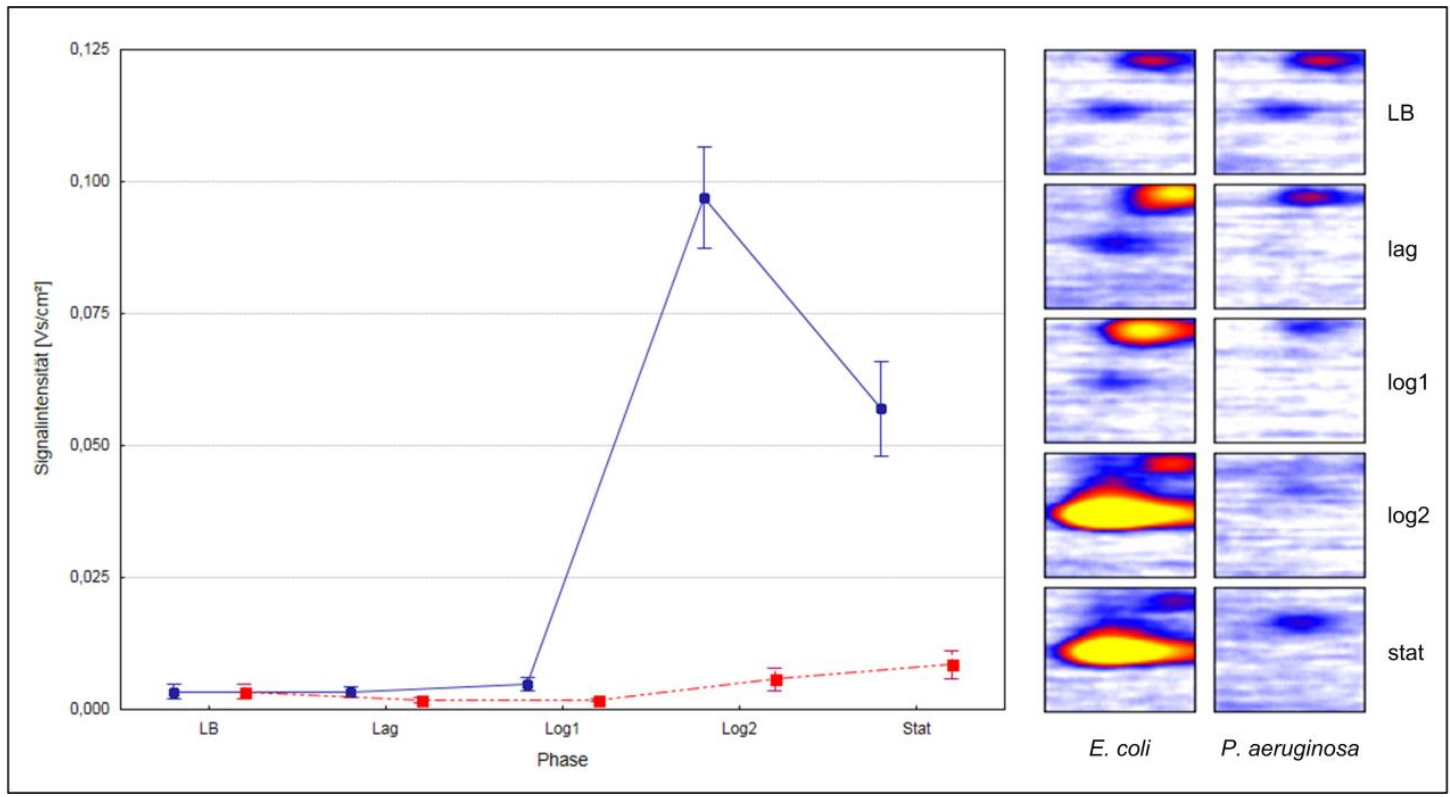

Abbildung 46. 1-0ctanol (Monomer) Vergleich der Signalintensitäten von 1-Octanol (Monomer) über E. coli (blau) und P. aeruginosa (rot). Links: Darstellung der Signalintensität als Mittelwert und 95 \%-KI. Rechts: Darstellung der Peakregionen aus der fünften Messreihe des Referenzstammes der jeweiligen Spezies. 


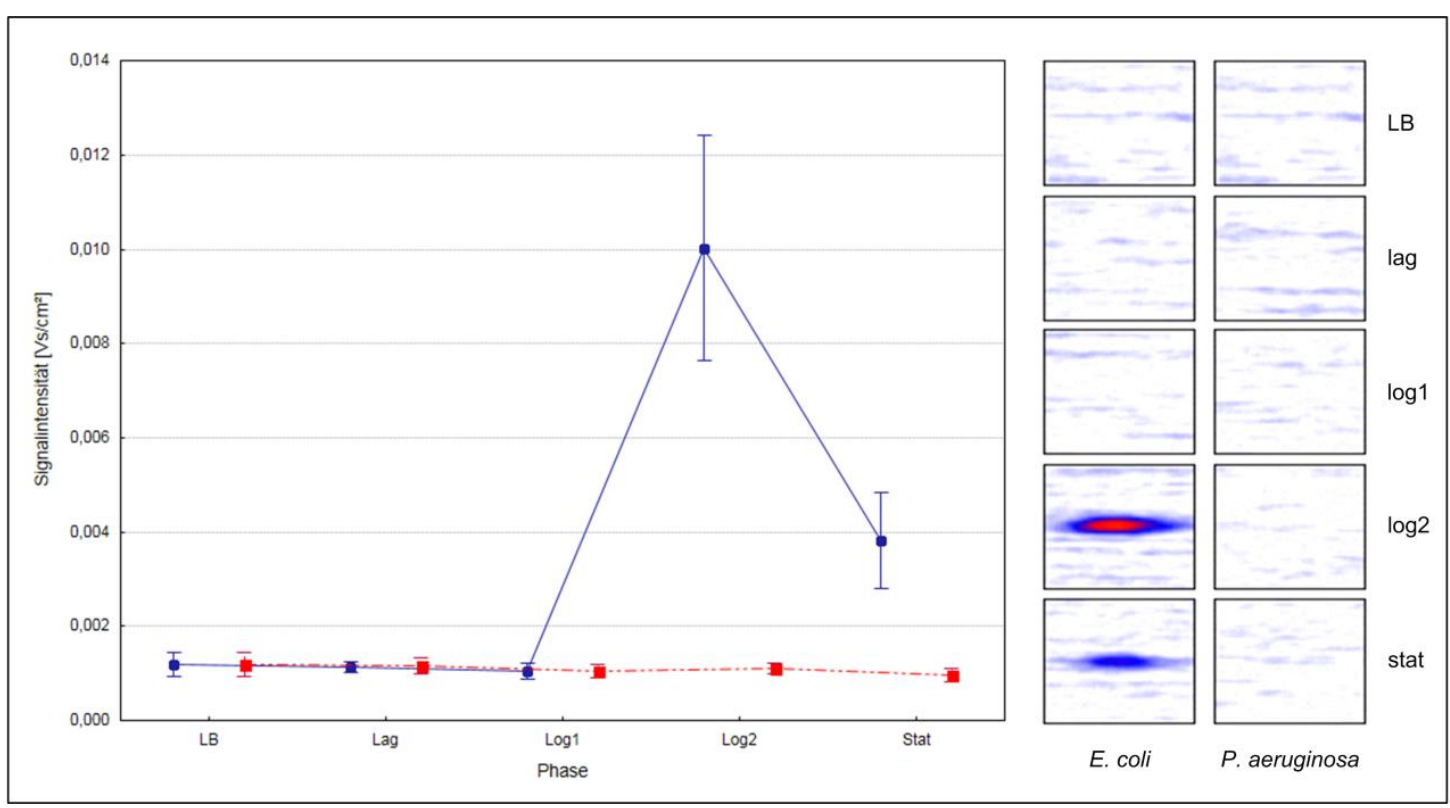

Abbildung 47. 1-Octanol (Dimer) Vergleich der Signalintensitäten von 1-Octanol (Dimer) über $E$. coli (blau) und P. aeruginosa (rot). Links: Darstellung der Signalintensität als Mittelwert und 95 \%KI. Rechts: Darstellung der Peakregionen aus der fünften Messreihe des Referenzstammes der jeweiligen Spezies.

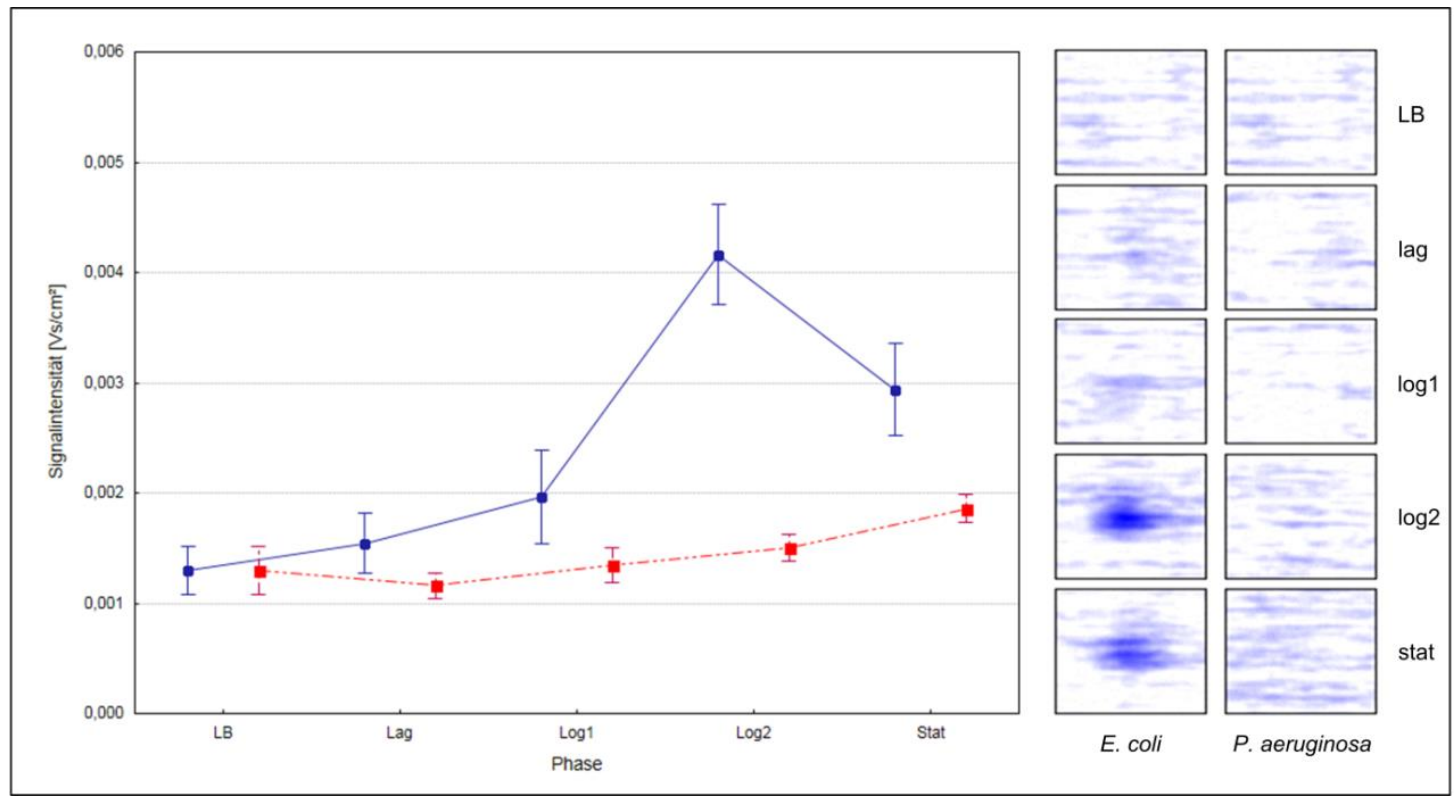

Abbildung 48. P_755_105 Vergleich der Signalintensitäten von P_755_105 über E. coli (blau) und P. aeruginosa (rot). Links: Darstellung der Signalintensität als Mittelwert und $95 \%$-KI. Rechts: Darstellung der Peakregionen aus der fünften Messreihe des Referenzstammes der jeweiligen Spezies. 


\subsubsection{P.-aeruginosa-assoziierte VOCs}

Sieben Peaks zeigten über den P.-aeruginosa-Kulturen Veränderungen, die über den E.-coli-Kulturen nicht auftraten. Hierzu gehörten Aceton, Ammoniak (Dimer), n-Dodecan, 2-Ethyl-1-Hexanol, P_603_25, P_648_36 und P_778_4. Die Signale zeigten in den verschiedenen Wachstumsphasen unterschiedliche Trends.

Aceton und P_603_25 erreichten die höchsten Signalintensitäten in der Log1 (Aceton) und Log2 Phase (P_603_25), und fielen dann ab.

Die Substanzen n-Dodecan, P_648_36 und P_778_4 zeigten steigende Signalintensitäten ab der späten exponentiellen Wachstumsphase mit Maxima in der statischen Phase. Da diese Peaks über den E-coli-Kulturen nicht gemessen werden konnten, wurden angenommen, dass sie mit dem Wachstum von P. aeruginosa assoziiert waren.

2-Ethyl-1-Hexanol war wie Ethanol bereits als Substrat im Nährmedium vorhanden. Über den Messzeitraum halbierte sich die Signalintensität während des P.-aeruginosaWachstums.

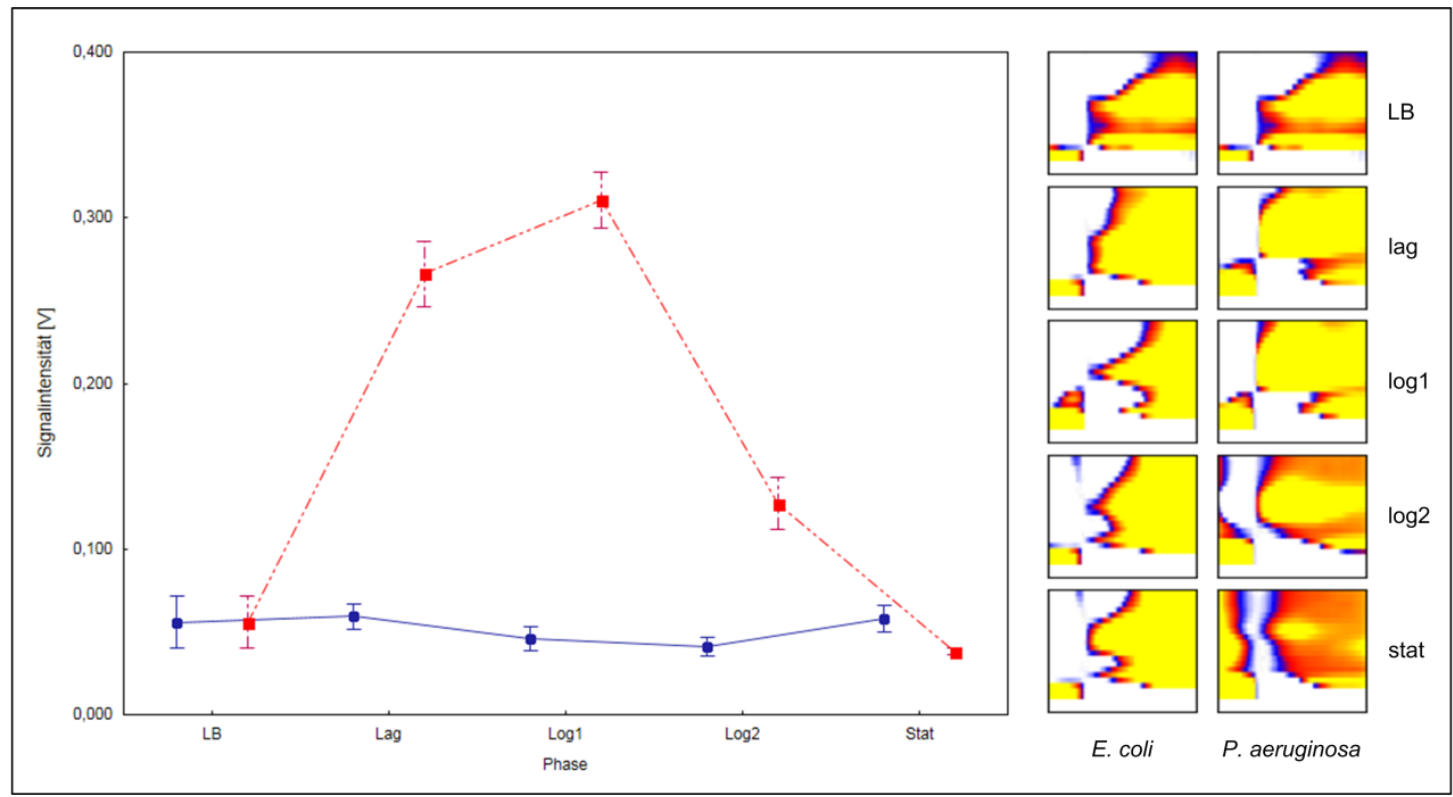

Abbildung 49. Aceton Vergleich der Signalintensitäten von Aceton über E. coli (blau) und $P$. aeruginosa (rot). Links: Darstellung der Signalintensität als Mittelwert und 95\%-KI. Rechts: Darstellung der Peakregionen aus der fünften Messreihe des Referenzstammes der jeweiligen Spezies. 


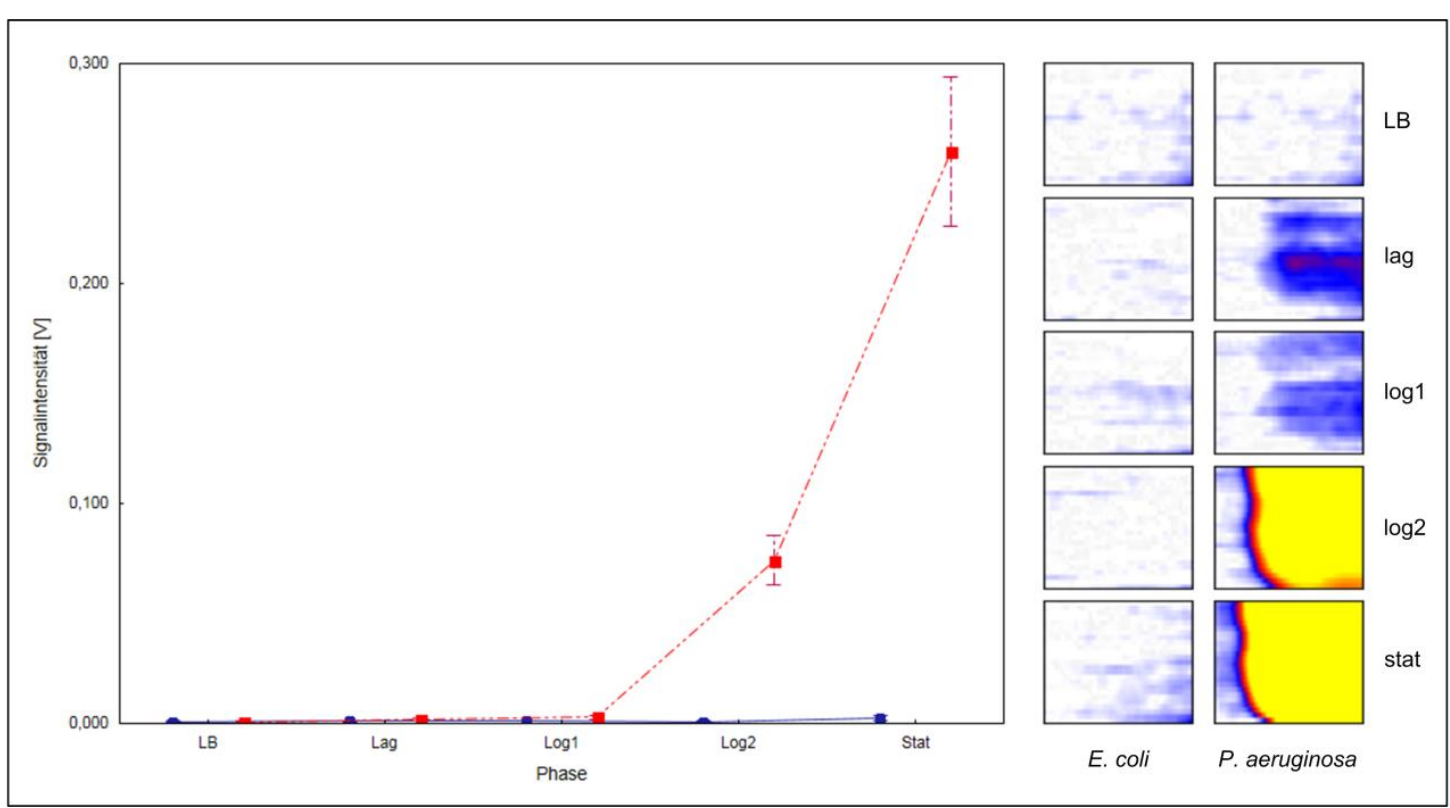

Abbildung 50. Ammoniak (Dimer) Vergleich der Signalintensitäten von Ammoniak (Dimer) über E. coli (blau) und P. aeruginosa (rot). Links: Darstellung der Signalintensität als Mittelwert und 95 \%-KI. Rechts: Darstellung der Peakregionen aus der fünften Messreihe des Referenzstammes der jeweiligen Spezies.

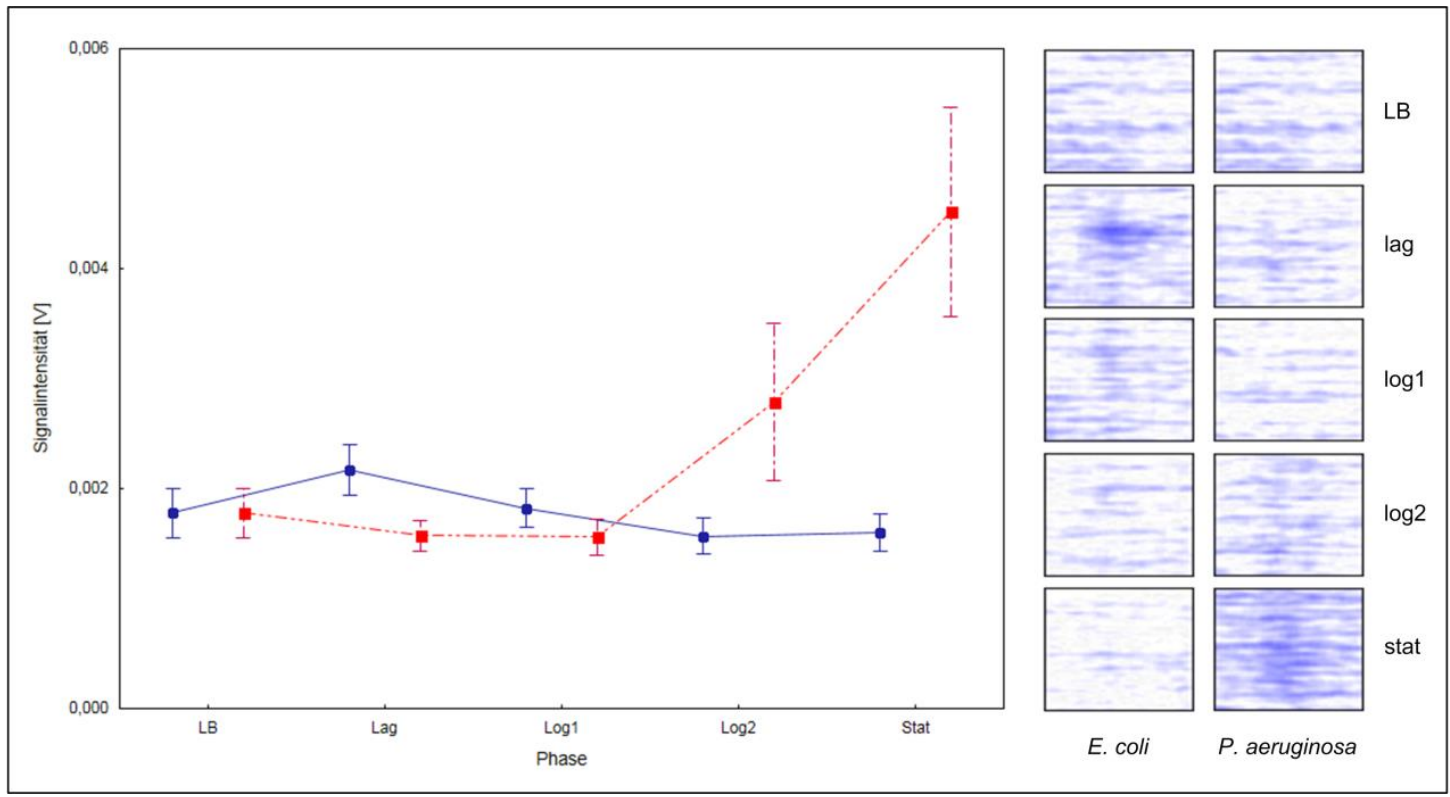

Abbildung 51. n-Dodecan Vergleich der Signalintensitäten von n-Dodecan über E. coli (blau) und P. aeruginosa (rot). Links: Darstellung der Signalintensität als Mittelwert und 95\%-KI. Rechts: Darstellung der Peakregionen aus der fünften Messreihe des Referenzstammes der jeweiligen Spezies. 


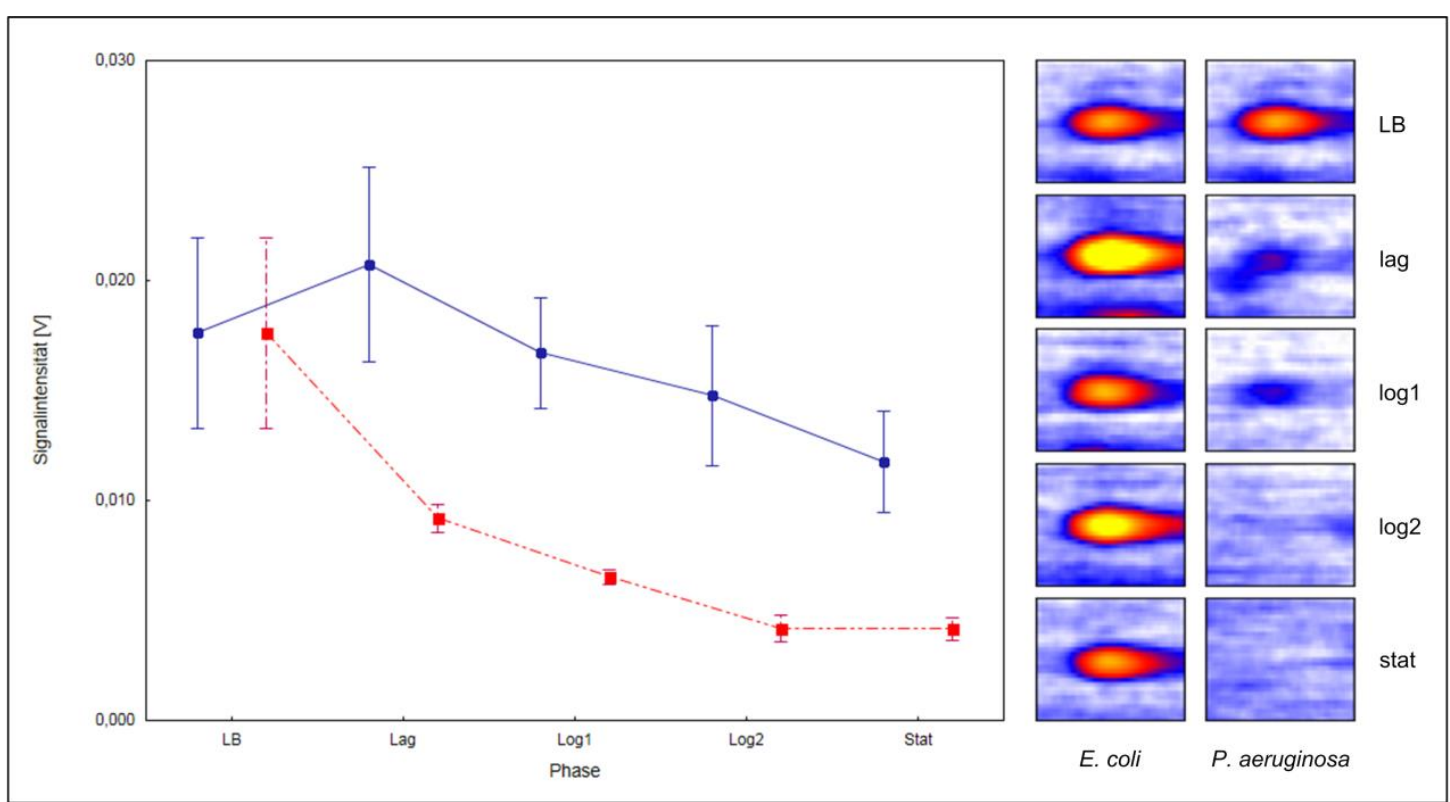

Abbildung 52. 2-Ethyl-1-Hexanol Vergleich der Signalintensitäten von 2-Ethyl-1-Hexanol über $E$. coli (blau) und P. aeruginosa (rot). Links: Darstellung der Signalintensität als Mittelwert und 95 \%KI. Rechts: Darstellung der Peakregionen aus der fünften Messreihe des Referenzstammes der jeweiligen Spezies.

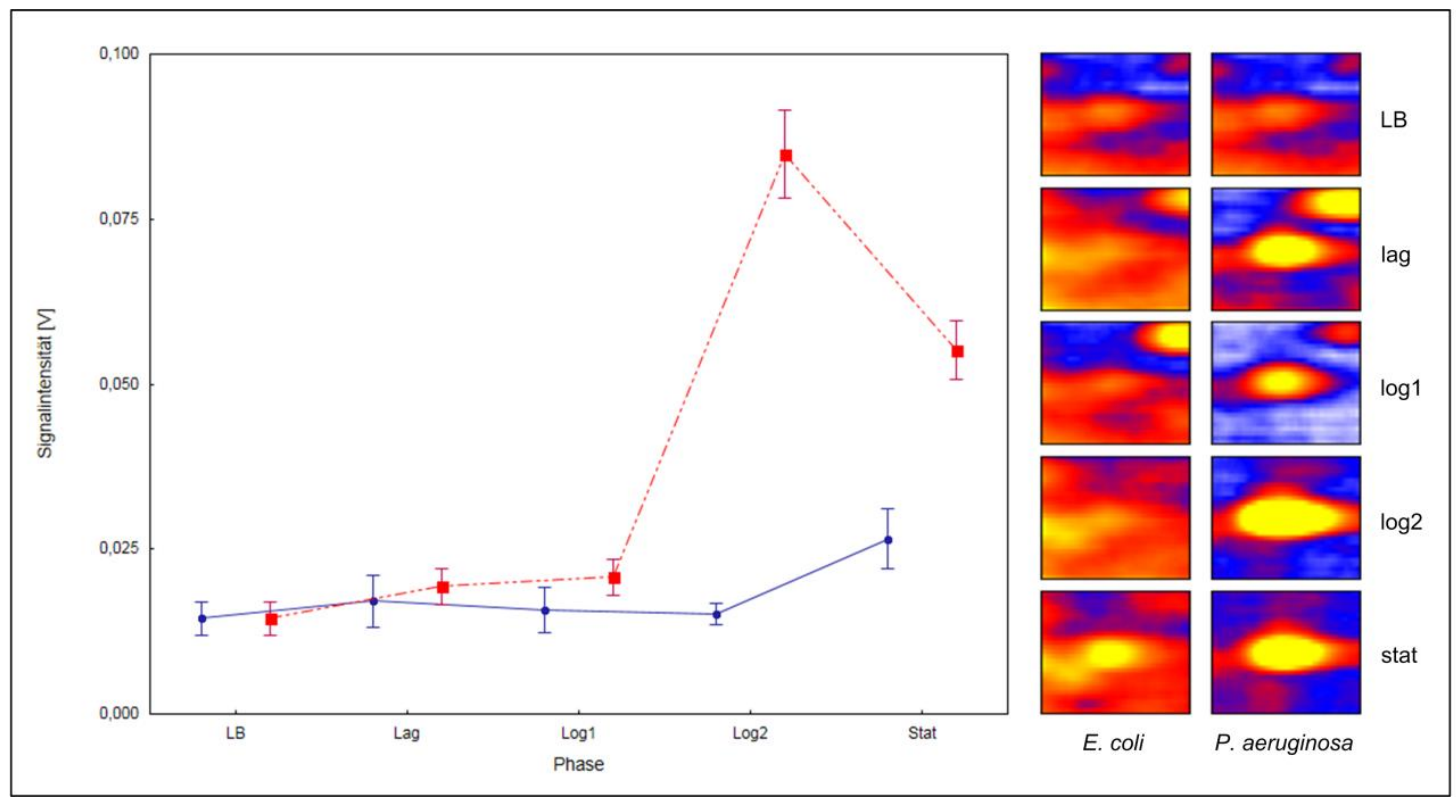

Abbildung 53. P_603_25 Vergleich der Signalintensitäten von P_603_25 über E. coli (blau) und $P$. aeruginosa (rot). Links: Darstellung der Signalintensität als Mittelwert und $95 \%$-KI. Rechts: Darstellung der Peakregionen aus der fünften Messreihe des Referenzstammes der jeweiligen Spezies. 


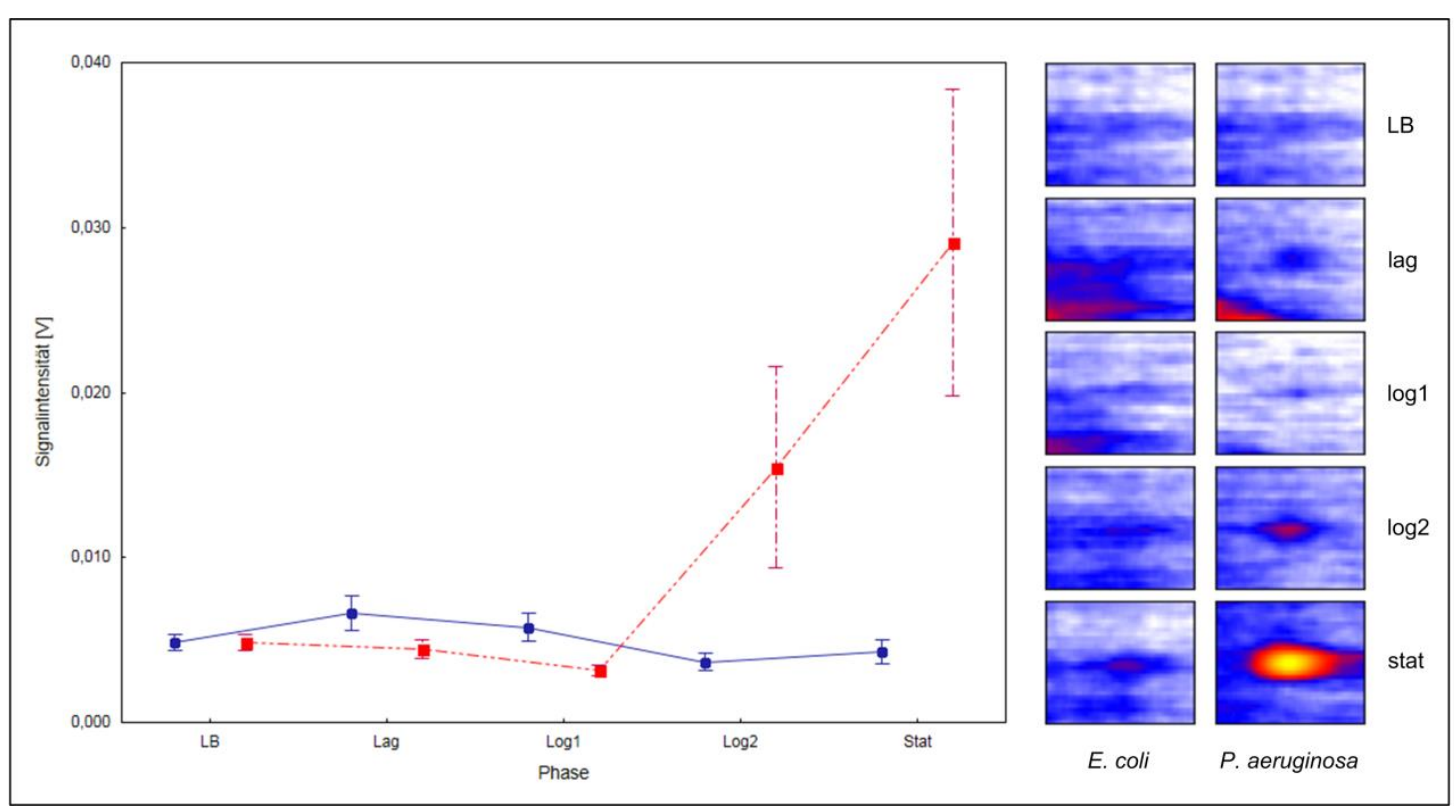

Abbildung 54. P_648_36 Vergleich der Signalintensitäten von P_648_36 über E. coli (blau) und $P$. aeruginosa (rot). Links: Darstellung der Signalintensität als Mittelwert und $95 \%$-KI. Rechts: Darstellung der Peakregionen aus der fünften Messreihe des Referenzstammes der jeweiligen Spezies.

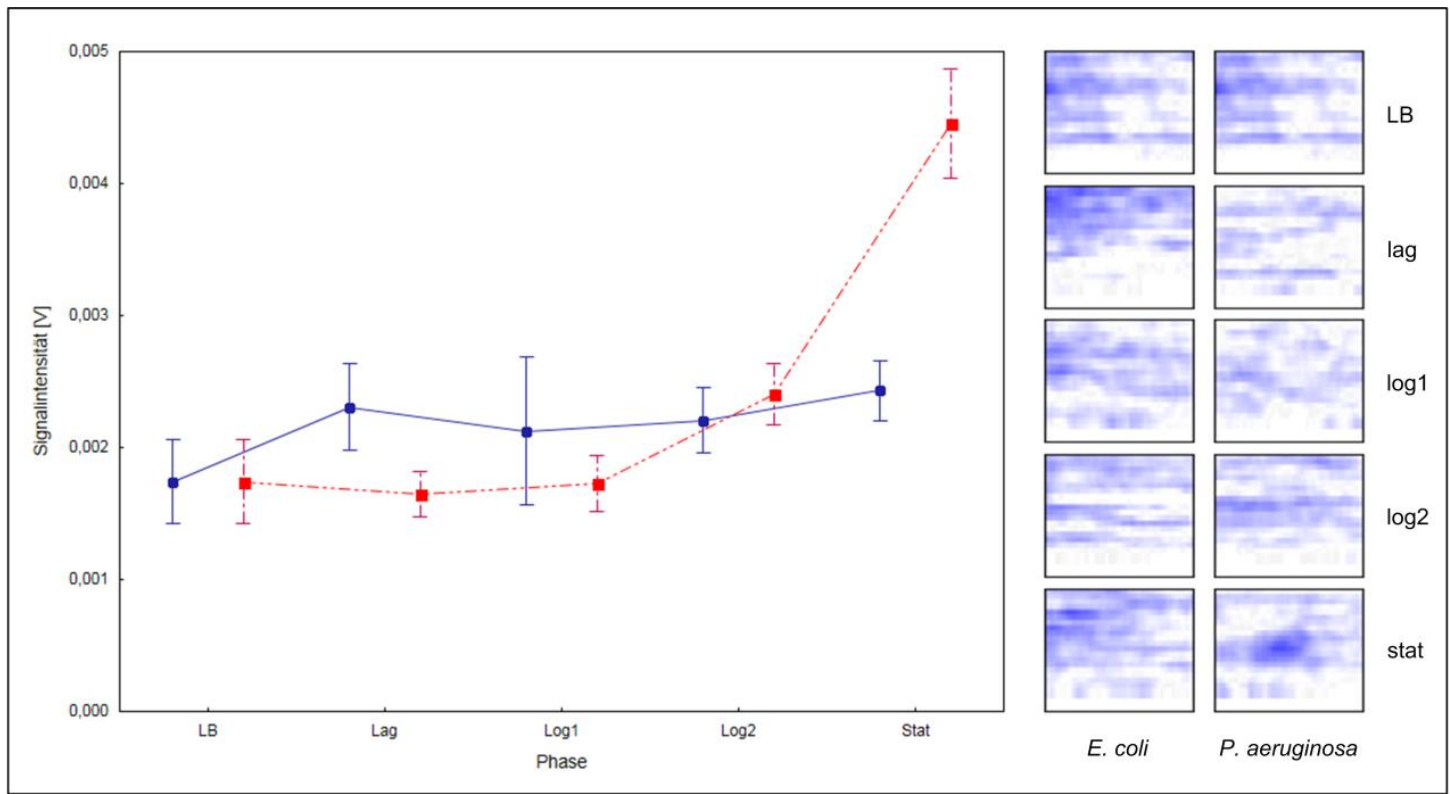

Abbildung 55. P_778_4 Vergleich der Signalintensitäten von P_778_4 über $E$. coli (blau) und $P$. aeruginosa (rot). Links: Darstellung der Signalintensität als Mittelwert und 95\%-KI. Rechts: Darstellung der Peakregionen aus der fünften Messreihe des Referenzstammes der jeweiligen Spezies. 


\subsubsection{VOCs ohne Keimassoziation}

Es gab Substanzen, die über beiden Spezies auftraten, sich aber nicht deutlich in ihrer Signalintensitätsverlauf voneinander unterscheiden. Dazu zählten: Ammoniak (Monomer), Nonanal, Phenylacetaldehyd, 5-Methyl-3-Heptanon, P_642_48 und P_720_16. Lediglich P_642_48 zeigte bei E. coli einen frühen und ausgeprägten Anstieg bis in die Log1-Phase und danach einen erneuten Abfall der Signalintensität. Im Gegensatz dazu war ein kontinuierlicher Anstieg bei P. aeruginosa zu sehen (Abb. 56).

Ammoniak (Monomer) ist in dieser Arbeit der Metabolit, mit der stärksten in den IMSMessungen registrierten Signalintensität $(>0,8 \mathrm{~V})$ und damit der höchsten Konzentration. Diese Substanz wird von P. aeruginosa bis in die späte exponentielle Wachstumsphase gebildet und nimmt danach ab, während bei $E$. coli die Konzentration erst in der statischen Phase ansteigt. Dieses gegenläufige Verhalten ist jedoch für eine Differenzierung der beiden Spezies voneinander nicht förderlich, da wie bereits vorher erwähnt, unter klinischen Bedingungen keine Aussage über die Wachstumsphasen in vivo getroffen werden können.

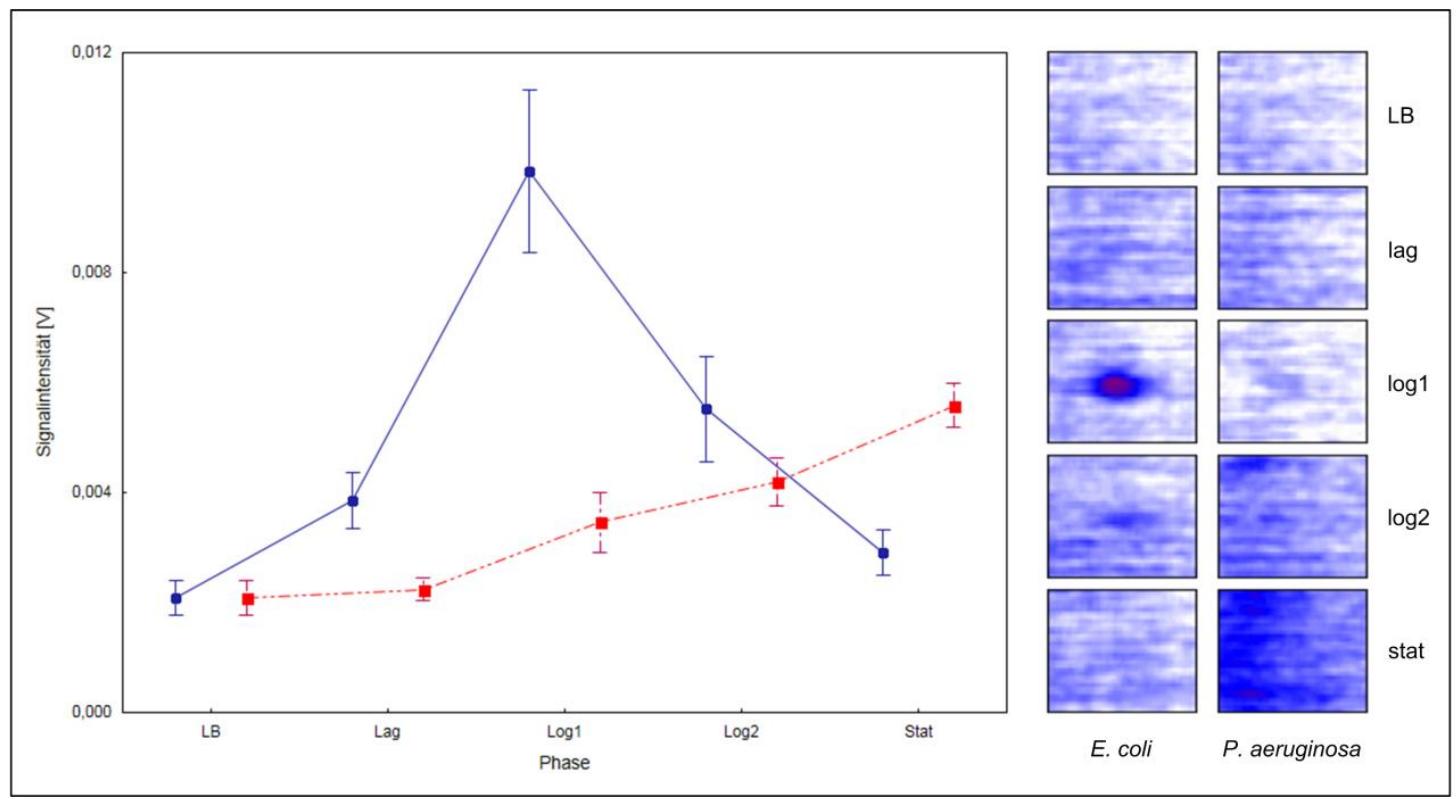

Abbildung 56. P_642_48 Vergleich der Signalintensitäten von P_642_48 über $E$. coli (blau) und $P$. aeruginosa (rot). Links: Darstellung der Signalintensität als Mittelwert und $95 \%$-KI. Rechts: Darstellung der Peakregionen aus der fünften Messreihe des Referenzstammes der jeweiligen Spezies. 


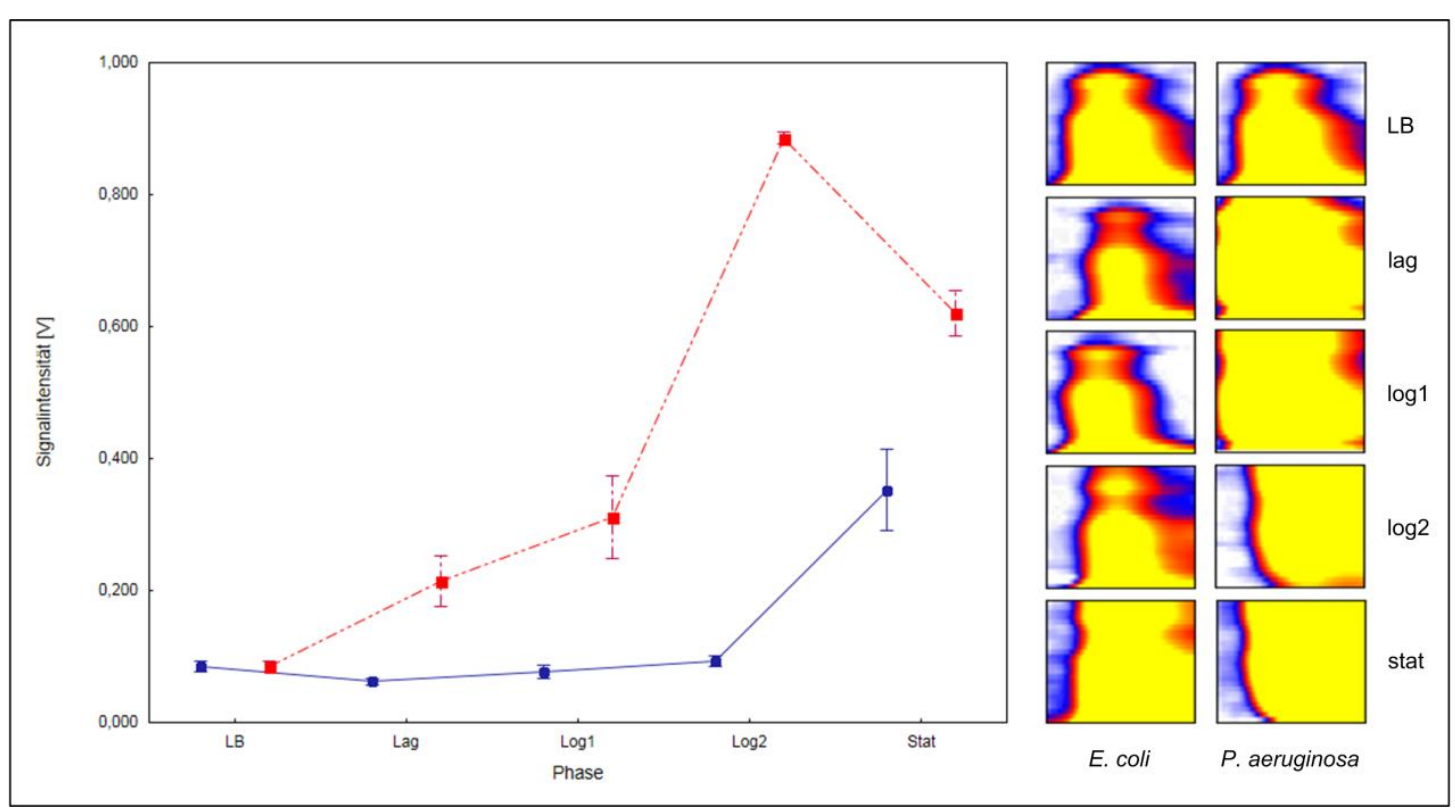

Abbildung 57. Ammoniak (Monomer) Vergleich der Signalintensitäten von Ammoniak (Monomer) über E. coli (blau) und P. aeruginosa (rot). Links: Darstellung der Signalintensität als Mittelwert und $95 \%$-KI. Rechts: Darstellung der Peakregionen aus der fünften Messreihe des Referenzstammes der jeweiligen Spezies.

Ein fallender Trend der Signalintensität ist bei Nonanal, Phenyacetaldehyd, 5-Methyl-3Heptanon und P_720_16 zu beobachten. Sie sind jeweils zu Beginn im LB-Medium nachweisbar und dienen wahrscheinlich als Substrat für das bakterielle Wachstum der beiden Spezies. 


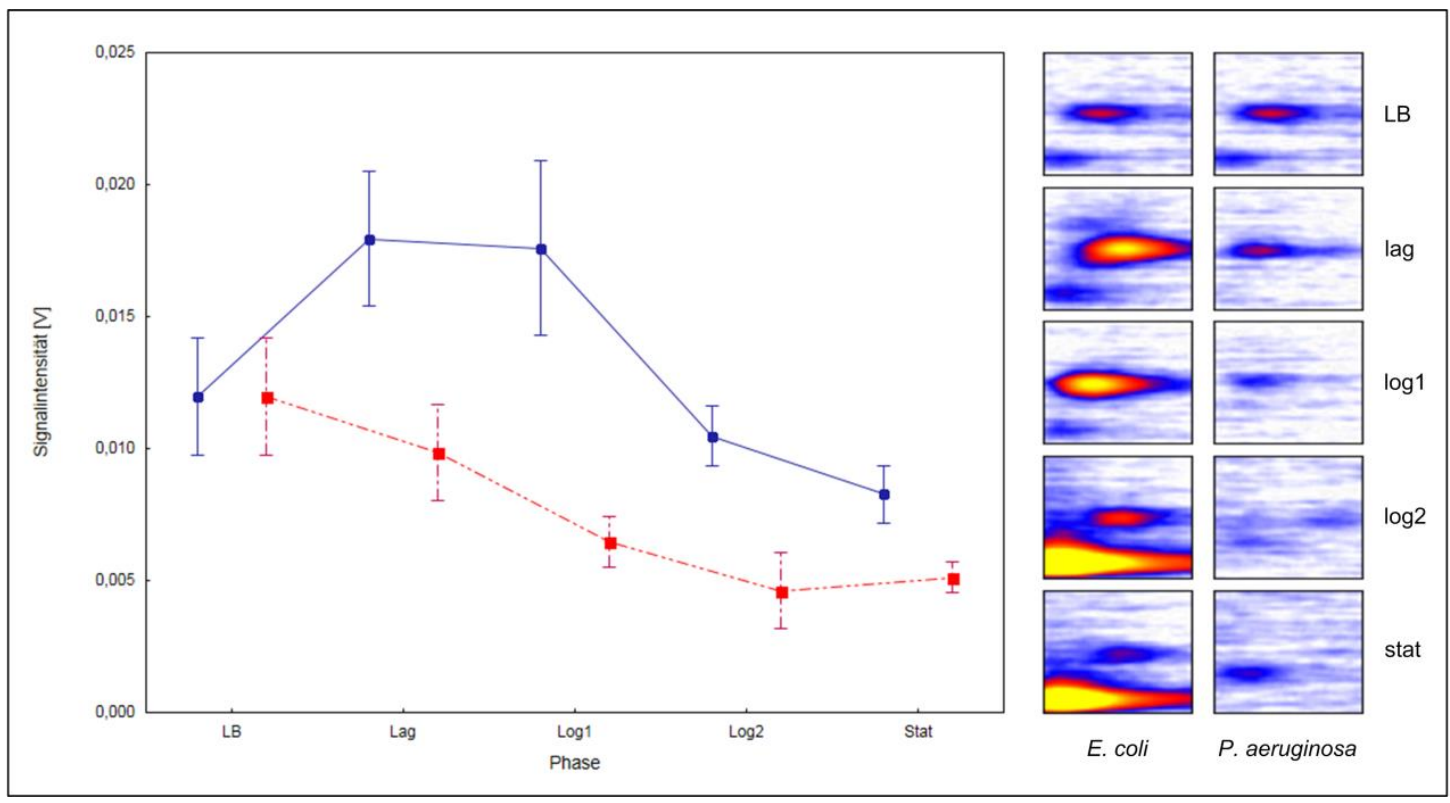

Abbildung 58. Nonanal Vergleich der Signalintensitäten von Nonanal über E. coli (blau) und $P$. aeruginosa (rot). Links: Darstellung der Signalintensität als Mittelwert und 95\%-KI. Rechts: Darstellung der Peakregionen aus der fünften Messreihe des Referenzstammes der jeweiligen Spezies.

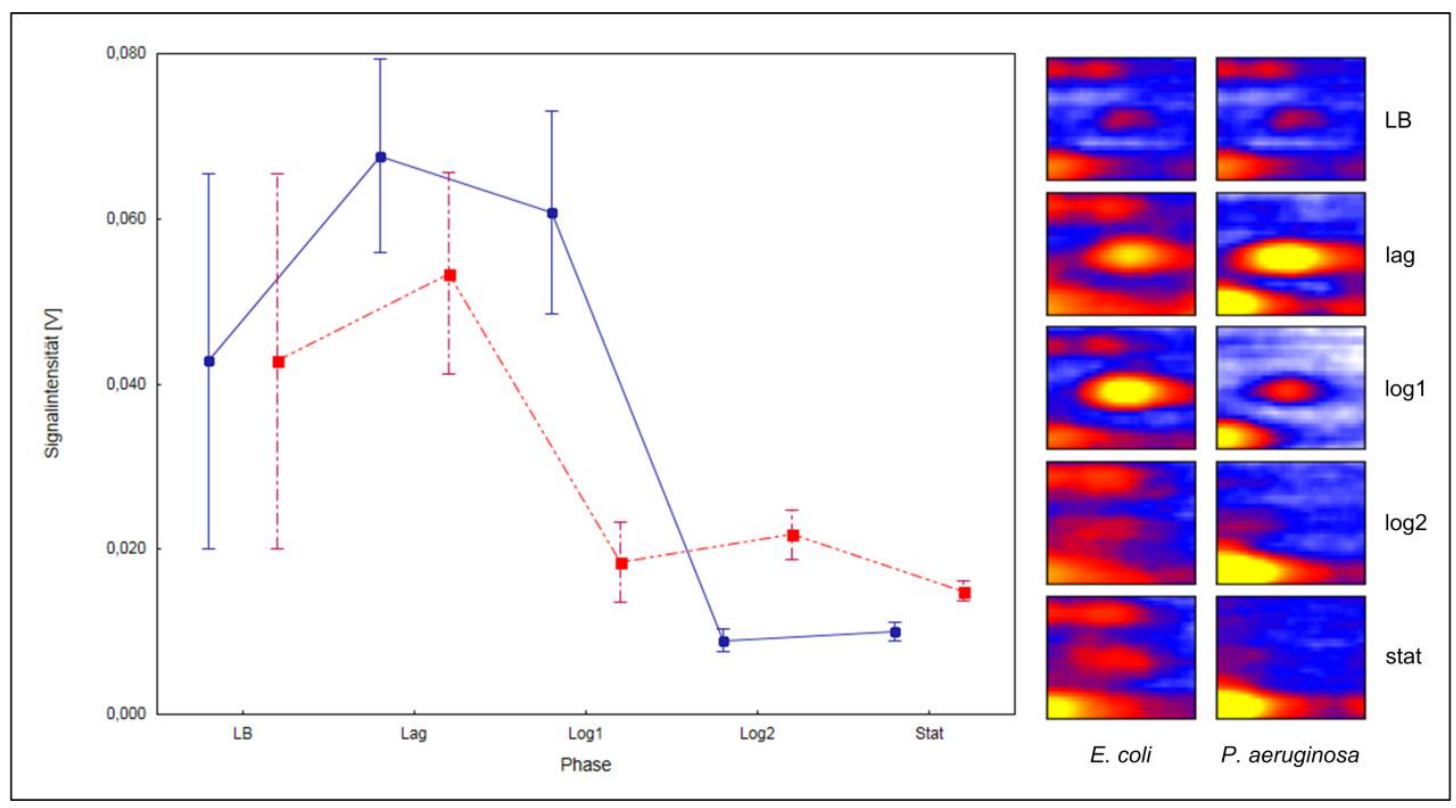

Abbildung 59. Phenylacetaldehyd Vergleich der Signalintensitäten von Phenylacetaldehyd über E. coli (blau) und P. aeruginosa (rot). Links: Darstellung der Signalintensität als Mittelwert und 95 \%-KI. Rechts: Darstellung der Peakregionen aus der fünften Messreihe des Referenzstammes der jeweiligen Spezies. 


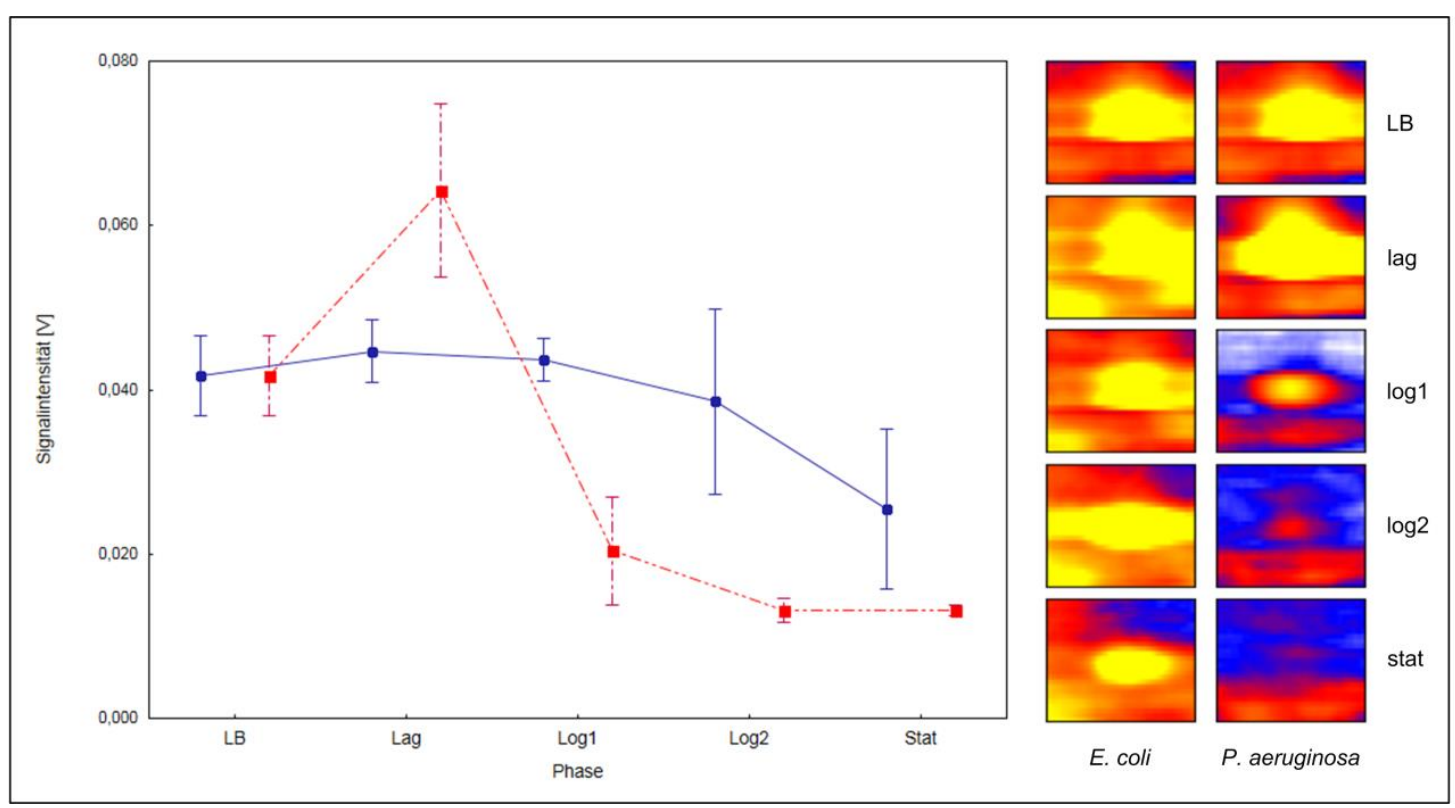

Abbildung 60. 5-Methyl-3-Heptanon Vergleich der Signalintensitäten von 5-Methyl-3-Heptanon über E. coli (blau) und P. aeruginosa (rot). Links: Darstellung der Signalintensität als Mittelwert und 95 \%-KI. Rechts: Darstellung der Peakregionen aus der fünften Messreihe des Referenzstammes der jeweiligen Spezies.

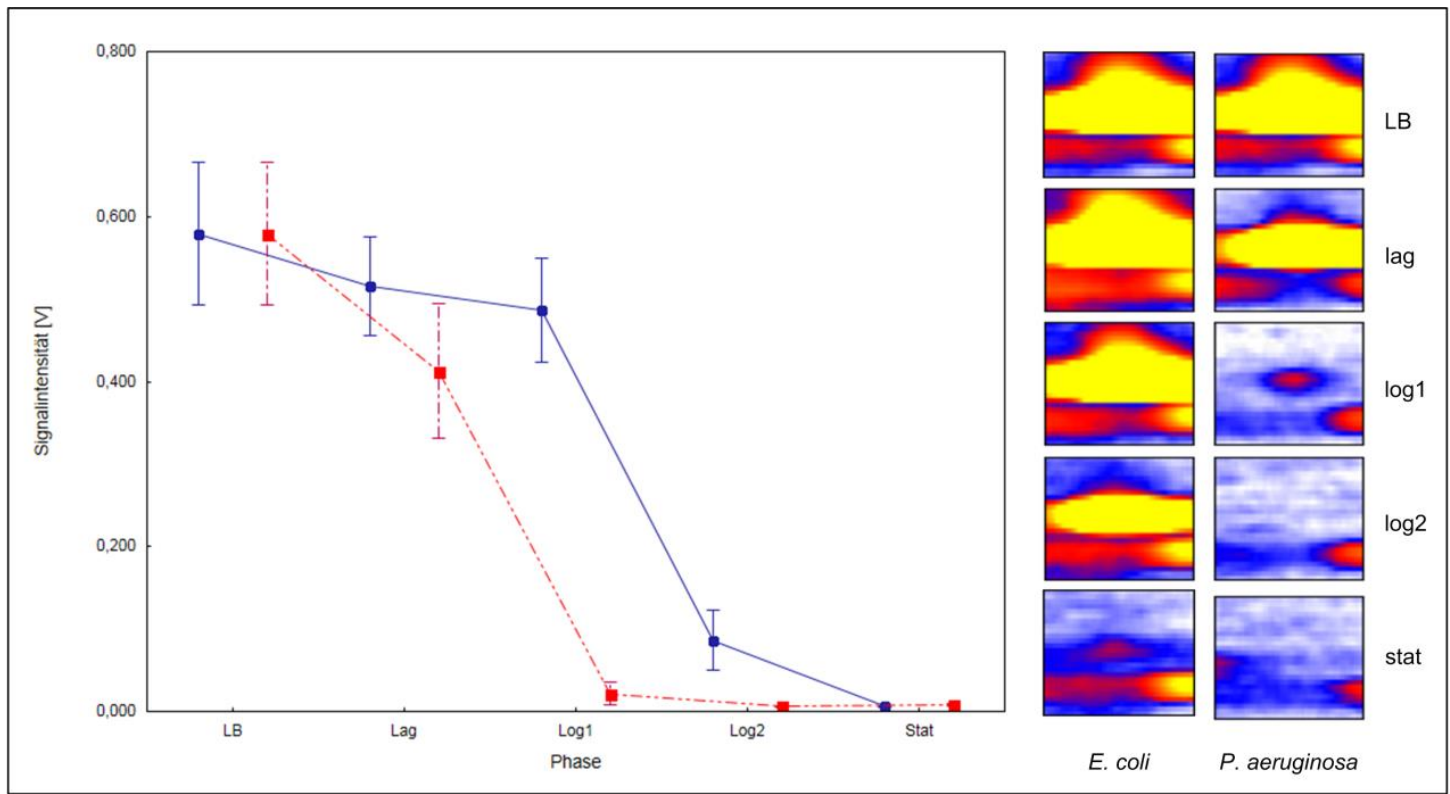

Abbildung 61. P_720_16 Vergleich der Signalintensitäten von P_720_16 über E. coli (blau) und $P$. aeruginosa (rot). Links: Darstellung der Signalintensität als Mittelwert und $95 \%$-KI. Rechts: Darstellung der Peakregionen aus der fünften Messreihe des Referenzstammes der jeweiligen Spezies. 
Die nachfolgende Tabelle zeigt abschließend einen Überblick der detektierten VOCs und die Assoziation zu den analysierten bakteriellen Erregern E. coli und P. aeruginosa.

Tabelle 6. Auflistung der VOCs mit Angabe der spezifischen reduzierten Ionenmobilität $\left(1 / K_{0}\right)$ und der Retentionszeit (RT), sowie Assoziation zu E. coli oder $P$. aeruginosa.

\begin{tabular}{|c|c|c|c|c|}
\hline Peak-Nr. & VOC-Name & $1 / K_{0}\left[\mathrm{Vs} / \mathrm{cm}^{2}\right]$ & RT [s] & Assoziation \\
\hline 1 & Aceton & 0,493 & 3,9 & P. aeruginosa \\
\hline 2 & Ammoniak (Monomer) & 0,448 & 10,5 & - \\
\hline 3 & Ammoniak (Dimer) & 0,413 & 10,5 & P. aeruginosa \\
\hline 4 & 1-Decanol & 0,788 & 256,6 & E. coli \\
\hline 5 & n-Dodecan & 0,692 & 140,0 & P. aeruginosa \\
\hline 6 & Ethanol & 0,509 & 3,7 & E. coli \\
\hline 7 & 2-Ethyl-1-Hexanol & 0,696 & 31,0 & P. aeruginosa \\
\hline 8 & Indol & 0,567 & 247,2 & E. coli \\
\hline 9 & 5-Methyl-3-Heptanon & 0,629 & 16,0 & - \\
\hline 10 & Nonanal & 0,732 & 53,5 & - \\
\hline 11 & 1-Octanol (Monomer) & 0,722 & 44,3 & E. coli \\
\hline 12 & 1-Octanol (Dimer) & 0,929 & 44,3 & P. aeruginosa \\
\hline 13 & Phenylacetaldehyd & 0,616 & 30,4 & - \\
\hline 14 & P_603_25 & 0,603 & 25,0 & P. aeruginosa \\
\hline 15 & P_642_48 & 0,642 & 48,3 & - \\
\hline 16 & P_648_36 & 0,648 & 36,0 & P. aeruginosa \\
\hline 17 & P_720_16 & 0,720 & 16,0 & - \\
\hline 18 & P_755_105 & 0,755 & 106,0 & E. coli \\
\hline 19 & P_778_4 & 0,778 & 4,0 & P. aeruginosa \\
\hline
\end{tabular}




\section{DISKUSSION}

In der vorliegenden Arbeit wurden mittels Multikapillarsäulen-gekoppelter Ionenmobilitäts- spektrometrie (MCC-IMS) quantitative Änderungen von flüchtigen organischen Verbindungen (volatile organic compounds) im Headspace über zwei humanpathogenen Bakterien während deren Wachstum im Nährmedium LB gemessen und dargestellt.

Bereits in der Vergangenheit haben sich einzelne Arbeiten mit der VOC-Produktion von Bakterien beschäftigt. Jedoch besteht weiterhin eine dünne Datenlage zur Abhängigkeit der VOC-Produktion von der Quantität der jeweiligen bakteriellen Population. Zu den wenigen Publikationen, die sich dieser Fragestellung widmeten, gehören die Studien von O'Hara und Mayhew (2009), von Maddula et al. (2009) und von Küntzel et al. (2016). Die Suche nach gesicherten Informationen darüber, ab welchem Wachstumsstadium Bakterien über ihre VOC-Emissionen identifizierbar sind, erschien deshalb als wissenschaftlich interessant. Ebenso wurde überprüft, ob zwei ausgewählte Bakterienspezies anhand der von ihnen emittierten VOC-Profile differenziert werden können.

Darüber hinaus wurde in dieser Arbeit untersucht, ob sich die gemessenen VOCVerteilungsmuster eines Bakteriums auf andere Stämme der gleichen Spezies übertragen lassen. Dazu wurden entsprechende klinische Isolate untersucht. In der Literatur wurden bisher nur die VOCs einzelner Bakterienstämme und die Unterschiede zu den VOC-Profilen anderer Spezies untersucht (Maddula et al. 2009; Jünger et al. 2012).

Schwere Infektionen, insbesondere Septitiden, haben in der Intensivmedizin einen stark negativen Einfluss auf Morbidität und Mortalität, wie in der Arbeit der SepNet Critical Care Trials Group (2016) dargestellt wird. Hohe Mortalitätsraten von bis zu 40 \% bei SepsisPatienten verdeutlichen, wie dringend der Forschungsbedarf in der innovativen Erregerdiagnostik einzustufen ist (SepNet Critical Care Trials Group 2016). Der frühe Beginn einer adäquaten antimikrobiellen Therapie hat wesentlichen Einfluss auf die Prognose der Patienten. Kumar et al. sahen eine etwa fünffach erhöhte Mortalitätsrate bei Patienten mit einem septischen Schock, bei denen dies initial nicht der Fall war (Kumar et al. 2009). Neben der schnellen klinischen Diagnosestellung ist die zeitnahe und sichere Erregeridentifizierung Garant für eine adäquate Antibiotikatherapie. Bis heute erfolgt die 
Identifizierung der Erreger mittels konventioneller mikrobiologischer Verfahren deren Ergebnisse in der Regel erst nach 48 Stunden oder mehr vorliegen (Maurer et al. 2017).

Innovative Methoden für eine schnelle und zuverlässige Erregerdiagnostik stehen daher im Fokus des wissenschaftlichen und klinischen Interesses. In der vorliegenden Arbeit kam dafür die Multikapillarsäulen-gekoppelte Ionenmobilitätsspektrometrie (MCC-IMS) zur Anwendung. Durch die Nutzung dieser Technologie ist der Nachweis volatiler Substanzen in komplexen, feuchten Gasgemischen in geringsten Konzentrationen möglich. Vorarbeiten von Perl et al. (2011) und Jünger et al. (2012) konnten zeigen, dass die Methodik eine Differenzierung verschiedener bakterieller und mykotischer Spezies erlaubt nachdem diese mehr als 24 Stunden auf Agarplatten angezüchtet wurden.

In der vorliegenden Arbeit wurde untersucht, ob sich zwei ausgewählte Bakterienspezies über die von ihnen gebildeten VOC-Profile identifizieren und von anderen Spezies differenzieren lassen. Da es sich um die Analyse dynamischer Prozesse handelt, war es für die vorliegende Untersuchung unerlässlich, zunächst die Wachstumskurven von E. coli und P. aeruginosa zu betrachten. Aus deren Verlauf ließen sich geeignete Messzeitpunkte ableiten, die einen phasenbezogenen, und damit sinnvollen Vergleich der Ergebnisse der beiden Bakterienspezies ermöglichten, obwohl die zeitlichen Verläufe ihrer Wachstumsphasen abwichen. Bisher finden sich in der Literatur keine Hinweise auf Arbeiten mit einem ähnlichen Vorgehen.

Die Wachstumskurven für die hier untersuchten Bakterienspezies wurden anhand der optischen Dichte der im flüssigen Nährmedium wachsenden Bakterienpopulation über einen definierten Zeitraum erstellt und in vier Phasen eingeteilt. Diese vier Phasen sind aus der Mikrobiologie bekannt und können auf jedes Bakterium angewendet werden. In der Latenzphase (Lag-Phase), auch Anlaufphase genannt, bereitet sich das Bakterium anhand der vorgefundenen Nährstoffe auf seine jeweiligen Stoffwechselprozesse vor. Darauf folgt die logarithmische Wachstumsphase (Log-Phase). Diese wurde für die vorliegende Arbeit in zwei Abschnitte unterteilt, um die VOC-Bildung in diesem exponentiellen Wachstumsstadium präziser analysieren und beschreiben zu können (Log1- und Log2-Phase). Während der stationären Phase (Stat-Phase) pendelt sich ein Gleichgewicht zwischen der Vermehrung und dem Absterben von Bakterien aufgrund der geringeren Nährstoffkapazität ein.

Auf die Betrachtung der Absterbe-Phase wurde hier verzichtet, da es im Hinblick auf die medizinische Zielsetzung, pathogene Keime möglichst frühzeitig bekämpfen zu können, wenig sinnvoll erschien, die VOC-Charakteristiken einer absterbenden Population zu 
messen. Dies könnte in Folgeuntersuchungen in Hinblick auf die Sensibilität gegenüber Antibiotika jedoch von Interesse sein.

In den Abbildungen 10 und 11 sind die Wachstumskurven grafisch dargestellt. Sie waren bei beiden Bakterienspezies sowohl für die Referenzstämme als auch für die klinischen Isolate reproduzierbar. Relevante Abweichungen des Wachstums zwischen dem Referenzstamm eines Bakteriums und den klinischen Isolaten anderer unbekannter Stämme des Bakteriums zeigten sich nicht.

Bei P. aeruginosa wurde die statische Phase ca. 700 Minuten nach Ansetzen der Kultur erreicht. Damit wies diese Spezies ein langsameres Wachstum auf als das E.-coliBakterium, das ab ca. 220 Minuten in die Stat-Phase überging. Aufgrund dieser unterschiedlichen Verlaufszeiten kommt der Wahl der Messzeitpunkte eine hohe Bedeutung zu. Sie wurden anhand der Phasen für die einzelnen Spezies festgelegt. Auf diese Weise ließen sich in der vorliegenden Arbeit Trend-Profile für einzelne Substanzen erstellen, die eine Vergleichbarkeit der beiden Spezies miteinander ermöglichten. Der Log2-Messpunkt für E. coli lag mit 225 Minuten den Ergebnissen zufolge offenbar bereits am Übergang von der Log- in die Stat-Phase und sollte in eventuellen Folgearbeiten etwas früher gewählt werden.

Werden die Ergebnisse der vorliegenden Arbeit mit anderen Studien verglichen, die ebenfalls VOC-Profile dieser Bakterienspeziesmittels MCC-IMS untersucht haben, so finden sich Übereinstimmungen. In dieser Arbeit waren sechs Substanzen (Decan-1-ol, Ethanol, Indol, Octan-1-ol (Monomer und Dimer), P_755_105) spezifisch für das Wachstum von E. coli. Diese Ergebnisse bestätigen teilweise die von Jünger et al., die die Gasphase über mehreren Bakterienkulturen, u. a. bei E. coli und P. aeruginosa, untersucht hatten. Dabei erfolgte eine 24-stündige Inkubation vor den MCC-IMS-Messungen, sodass keine weiteren Informationen über den zeitlichen Verlauf des Auftretens und der Konzentration der entsprechenden VOCs in der Arbeit erfasst wurden (Jünger et al. 2012). Diese Arbeit konnte deshalb lediglich ein „Vorhandensein“ einer Substanz nachweisen. Die Ergebnisse der Arbeit von Jünger et al. (2012) geben daher am ehesten Informationen aus der statischen Wachstumsphase wieder.

Sowohl in der vorliegenden Untersuchung als auch in der Arbeit von Jünger et al. wurden Ethanol und Indol über E.-coli-Kulturen nachgewiesen (Jünger et al. 2012). In der Driftregion des IMS bewegen sich Ionen durch ein angelegtes elektrisches Feld, das je nach Wahl der Messmethode positiv oder negativ geladen sein kann. Die MCC-IMS-Messungen in dieser Arbeit wurden nur im positiven Ionenmodus des MCC-IMS durchgeführt. Jünger 
et al. konnten in diesem Messmodus vier Substanzen nachweisen: Ethanol, Indol, P_711_3 und P_774_4. Zusätzlich gelang es in jener Untersuchung im negativen Ionenmodus sieben weitere Substanzen zu detektieren. Hierzu zählt unter anderem ein Dimer von Indol (Jünger et al. 2012).

Interessant ist zudem, dass Jünger et al. ihre mit MCC-IMS erfassten Ergebnisse als Referenzmethode zur Substanzidentifizierung ebenfalls mittels GC/MS untersucht haben. Für E. coli konnten mit Hilfe der GC/MS-Messungen 22 VOCs gegenüber den nur elf zuvor mittels MCC-IMS erfassten VOCs nachgewiesen werden. Daraus resultiert die Frage, ob mit der in dieser Arbeit verwendeten Methodik tatsächlich alle vorhandenen VOCs detektiert werden konnten, die mit den erhobenen Daten aber nicht beantwortet werden kann.

Während Jünger et al. lediglich eine Momentaufnahme der vorhandenen VOCs zu einem späten Zeitpunkt der Wachstumsphasen erhoben haben, hat die hier vorliegende Untersuchung den zeitlichen Verlauf über die Wachstumsphasen hinweg analysiert. Eine Messung nur zu einem Zeitpunkt lässt möglicherweise wichtige Informationen außer Acht oder verführt zur potenziellen Fehleinschätzung, dass ein zum gewählten, singulären Mess-Zeitpunkt nachgewiesener Metabolit unabhängig von der Wachstumsphase zu jedem anderen Zeitpunkt auch vorhanden sein müsste (Jünger et al. 2012; Perl et al. 2011).

Auch Maddula et al. beobachteten den zeitlichen Verlauf von VOC-Emissionen über E.-coliKulturen. Sie konnten vier verschiedene, während des Wachstums neu auftretende, Metaboliten über den Kulturen nachweisen und beobachteten Veränderungen der gemessenen Signalstärken als Funktion des Koloniewachstums. Dabei wurde nach zwei Stunden lediglich ein Signal gefunden. Nach sechs Stunden konnten Maddula et al. sechs Signale erfassen, und zwar für Ethanol, Aceton, Heptan-2-one (3x) und Nonan-2-one (Maddula et al. 2009). Im Vergleich der Arbeit von Maddula et al. mit der vorliegenden Untersuchung, konnte hier nur eine Übereinstimmung bei Ethanol erfasst werden. Hierbei ist zu berücksichtigen, dass in beiden Arbeiten unterschiedliche Nährmedien verwendet wurden. In Übereinstimmung mit dieser Untersuchung haben Maddula et al. aber ebenfalls eine Korrelation zwischen der zeitlichen Änderung der bakteriellen Biomasse und der VOC-Konzentration hergestellt. Bei dem von Maddula et al. verwendeten E--coli-Stamm handelte es sich um einen nicht pathogenen Industriestamm, wie er zur Herstellung verschiedener Produktkomponenten verwendet werden kann. Dieser apathogene Stamm wurde in einem spezifisch auf sein Wachstum zugeschnittenem Nährmedium inkubiert. Diese Umstände könnten erklären, weshalb sich hier nur wenige VOCs fanden und u. a. auch kein Indol nachweisbar war. 
Zhu et al. haben ebenfalls Ethanol und Indol, sowie Acetonitril über E. coli nachgewiesen. Auch diese Arbeitsgruppe nutzte ein anderes Messverfahren, nämlich Secondary Electrospray Ionization-Mass Spectrometry (SESI-MS) und führte ebenfalls nur eine Messung nach 24-stündiger Inkubationszeit durch (Zhu et al. 2010).

In der vorliegen Arbeit waren sieben VOCs spezifisch für das Wachstum von P. aeruginosa. Dies waren Aceton, Ammoniak (Dimer), n-Dodecan, 2-Ethyl-1-Hexanol, P_603_25, P_648_36 und P_778_4.

Sechs dieser VOCs zeigten ansteigende Signalintensitäten, vor allem in den späteren Wachstumsphasen.

In der Arbeit von Jünger et al. wurden mit Ethanol und P_711_3 im positiven Ionenmodus zwei neu auftretende Substanzen nachgewiesen, die aber in der vorliegenden Untersuchung beide über $P$. aeruginosa keine ansteigende Signalintensität zeigten. Auch die sieben VOCs die in den mit GC/MS durchgeführten Kontrollmessungen von Jünger et al. auftraten, zeigten keine Korrelation mit den Ergebnissen dieser Arbeit (Jünger et al. 2012).

Trotz geringfügiger Unterschiede der Messergebnisse geht die vorliegende Arbeit davon aus, dass es sich bei der hier gefundenen Substanz P_778_4 und bei P_774_4 in der Arbeit von Jünger et al. um den gleichen Metaboliten handelt. Die entsprechende Signalintensität stieg über $P$. aeruginosa in der späten logarithmischen und in der statischen Wachstumsphase an.

Verglichen mit den Kontrollmessungen über dem reinen Nährmedium wurde in dieser Untersuchung für P_778_4 auch eine geringfügig höhere Signalintensität über E. coli registriert.

Zhu et al. haben $P$. aeruginosa in vier verschiedenen Nährmedien kultiviert. Nach $24 \mathrm{~h}$ Inkubationszeit konnten keine erheblichen Unterschiede in der VOC-Produktion zwischen den einzelnen Metaboliten und deren Intensitäten festgestellt werden. Insgesamt wurden von $\mathrm{Zhu}$ et al. neun VOCs identifiziert, die spezifisch sind. Identisch mit unseren Ergebnissen war lediglich Aceton (Zhu et al. 2010).

Einen Nachweis über ortho-Aminoacetophenon welches für den spezifischen Geruch von P. aeruginosa verantwortlich ist, konnte in dieser Arbeit nicht erbracht werden (Mann 1966). Jedoch konnten Zhu et al. dieses VOC nachweisen, und sehen es als spezifisch für P. aeruginosa (Zhu et al. 2010). Letztlich zeigte die Arbeit von Zhu et al. ebenfalls, dass eine 
Differenzierung zu anderen Bakterien-Spezies möglich ist.

Wie bereits betont, enthalten Nährmedien selbst flüchtige organische Metaboliten, wobei die Zusammensetzung spezifisch für das jeweilige Medium ist. Hieraus ergeben sich zwei Folgerungen: Zum einen müssen die vom reinen Nährmedium abgegebenen VOCs untersucht und gemessen werden, um die über den Wachstumskulturen der Bakterienspezies erfassten VOC-Profile entsprechend abgrenzen zu können. Dies ist für die vorliegende Arbeit geschehen. Die VOCs des LB-Mediums wurden identifiziert und als „volatiler Hintergrund“ in der Analyse der Daten berücksichtigt.

Zum anderen hat das Nährmedium Einfluss auf die Entstehung der entlang der Wachstumskurven gemessenen VOC-Profile. Aufgrund abweichender Inhaltsstoffe in den verschiedenen Nährmedien vollziehen die Bakterienkulturen unterschiedliche Stoffwechselprozesse, was zu abweichenden VOC-Charakteristiken für ein und dieselbe Bakterienspezies führt. Es ist daher von besonderer Bedeutung für die Interpretation der genannten Arbeiten, dass unterschiedliche Nährmedien für die Anzucht der Bakterien genutzt wurden. In welcher Art und Weise die verwendeten Nährmedien Einfluss auf die von einer Bakterienspezies emittierten VOC-Profile haben, wird in der Literatur teilweise kontrovers diskutiert.

O'Hara und Mayhew haben VOC-Profile über Kulturen eines Staphylococcus-aureusStammes bei deren Wachstum über drei verschiedenen Nährmedien beobachtet. Sie stellten zwar grundsätzlich fest, dass das Nährmedium einen gewissen Einfluss auf die zu detektierenden VOC-Profile über Bakterienkulturen hat, aber sie fanden über allen drei Medien die gleichen emittierten Metaboliten. Lediglich die zeitlichen Charakteristiken der VOC-Profile und die jeweiligen Intensitäten der gemessenen Signale unterschieden sich, je nach verwendetem Nährmedium (O’Hara und Mayhew 2009).

Küntzel et al. (2016) haben biologische und methodische Faktoren bei der VOC-Emission über Kulturen von Mycobacterium avium ssp. paratuberculosis analysiert. Dabei wurden Messungen über fünf verschiedenen Medien evaluiert. Aufgrund ihrer Daten unterstützen Küntzel et al. die Hypothese, dass Bakterien auf verschiedenen Nährmedien unterschiedliche Metaboliten emittieren (Küntzel et al. 2016). Diese Annahme wird auch durch die Arbeit von Ratiu et al. unterstützt. Sie kultivierten E. coli in drei unterschiedlichen Nährmedien und konnten verschiedene organische Gruppen den einzelnen Medien zuordnen (Ratiu et al. 2017). Die Verwendung unterschiedlicher Nährmedien bei dieser und den hier zum Ergebnisvergleich zitierten Arbeiten (Jünger et al. 2012; Maddula et al. 2009; O'Hara und Mayhew 2009; Ratiu et al. 2017; Zhu et al. 2010) 
lässt Diskrepanzen in den gemessenen VOC-Profilen nachvollziehbarer erscheinen, da unterschiedliche Medien mit ihren Substraten gegebenenfalls wirklich andere Stoffwechselwege induzieren, wodurch andere VOCs entstehen.

Maddula et. al benutzten als Nährmedium für E. coli Neidhardt minimal salt medium, das 1974 speziell für das Wachstum von Enterobakterien entwickelt wurde (Neidhardt et al. 1974). Um einen möglichst minimalen volatilen Hintergrund und damit potentiell interferierende Signale so gering wie möglich zu halten, war das genutzte Medium auf die sehr geringen metabolischen Anforderungen von E-coli-Bakterien optimiert worden (Maddula et. al 2009).

Bakterien sind anpassungsfähig, und solche maßgeschneiderten Nährmedien sind in der Umwelt meistens nicht gegeben. Zudem sind individuelle, auf ein einzelnes Bakterium zugeschnittene Nährmedien für diagnostische Zwecke nur bedingt geeignet. Dies gilt vor allem, weil es in der medizinischen Praxis das Ziel sein muss, die Differenzierung bzw. Identifikation verschiedener Bakterien in einem nicht bekannten Probenmaterial zu erreichen. Aus diesem Grund haben wir mit Lysogeny Broth (LB) ein komplexes Medium zur Anzucht verwendet, das universell und im klinischen Umfeld weit verbreitet ist.

Jünger et. al verwendeten in ihrer Arbeit Columbia Sheep Blood Agar als Nährmedium. Wie in der vorliegenden Arbeit konnten u. a. Indol und Ethanol identifiziert werden. Zur Evaluation ihrer Ergebnisse haben auch Jünger et al. die vom Nährmedium abgegebenen VOCs identifiziert und nicht weiter einbezogen (Jünger et al. 2012). Wir haben ein flüssiges Nährmedium gegenüber einem festen Nährmedium (z. B. Agar) vorgezogen, weil die Wachstumsphasen damit besser nachvollziehbar sind.

Zwischen den Referenzstämmen und den klinischen Isolaten zeigten sich keine relevanten Abweichungen hinsichtlich des Wachstums oder der detektierten VOCs.

Frühere Studien, die IMS-Messungen für den Nachweis von Mikroben nutzten, untersuchten nur jeweils die VOC-Profile eines Stamms eines bestimmten Bakteriums, und nahmen an, dass die Ergebnisse auf andere Stämme derselben Spezies übertragbar wären (Maddula et al. 2009; Jünger et al. 2012; Perl et al. 2011). Die Überprüfung dieser Hypothese war Teil der vorliegenden Arbeit.

Der Vergleich der gemessenen VOC-Profile der zwölf gemessenen ReferenzstammKulturen mit denen der zufällig ausgewählten zwölf klinischen Isolate unterschiedlicher Herkunft bestätigte die Hypothese, dass das Metabolom eines Bakterienstammes auf andere Stämme derselben Spezies übertragbar sind, wenn diese ähnliche Eigenschaften 
(wie z. B. humanpathogene Merkmale) haben. Im Hinblick auf eine mögliche klinischediagnostische Nutzung des MCC-IMS-Messverfahrens ist dies von Bedeutung.

Die Übertragbarkeit der Resultate zwischen verschiedenen Stämmen der gleichen Bakterienspezies wurde zwischenzeitlich auch von Küntzel et al. bestätigt, in deren Untersuchung drei verschiedene MAP-Stämme (Mycobacterium avium ssp. paratuberculosis) sehr ähnliche VOC-Charakteristiken zeigen (Küntzel et al. 2016).

Dennoch sollten weitere Untersuchungen folgen, mit denen die Übertragbarkeit auch bei anderen humanpathogenen Bakterienüberprüft werden kann.

Im Hinblick auf die Arbeit von Schulz und Dickschat über VOC-Emissionen durch Bakterienpopulationen ist festzustellen, dass die meisten der in dieser Arbeit identifizierten VOCs als Anhaltspunkte für das Wachstum bei mehreren Bakterien bekannt sind. Diese umfassen beispielsweise aromatische Komponenten (Indol, 2-Phenylacetaldehyde), Fettsäurederivate (Decan-1-ol, Nonanal, Octan-1-ol), Ketone (2-Propanone [Aceton]) und Azane (Ammoniak) (Schulz und Dickschat 2007).

Weiterhin wurde in der vorliegenden Untersuchung die Bildung von Dimeren beobachtet. Borsdorf und Eiceman haben beschrieben, dass die Ionisierung einer Substanz durch eine Ni63-Quelle zur Bildung sowohl von Monomeren, als auch von Dimeren oder sogar Trimeren führen kann (Borsdorf und Eiceman 2006). Die vorliegende Untersuchung detektierte Dimer-Bildungen bei Ammoniak und Octan-1-ol. Octan-1-ol trat nur bei E. coli auf, während Ammoniak bei beiden Spezies nachgewiesen wurde. Das Ammoniak-Dimer konnte ausschließlich über $P$. aeruginosa in den späten Wachstumsphasen gefunden werden, was ebenfalls als Kriterium zur Differenzierung der beiden Spezies herangezogen werden kann.

Die Ergebnisse der vorliegenden Arbeit legen nahe, dass es mit Hilfe der MCC-IMS-Technik möglich sein könnte verschiedene intensivmedizinisch relevante Bakterien innerhalb weniger Stunden zu differenzieren. Für eine tatsächliche Nutzung als diagnostische Methode ist allerdings eine Reihe weitere Vorarbeiten notwendig.

Unter Verwendung einer reproduzierbaren Methodik sollten die Metabolome möglichst vieler humanpathogener Bakterienspezies untersucht werden.

Die vorliegende Arbeit zeigte die Notwendigkeit mit den Headspace-Messungen verschiedene Wachstumsphasen $\mathrm{zu}$ erfassen, um detaillierte Informationen zum 
Metabolom eines Bakteriums anhand des VOC-Profils zu generieren. Dies bringt jedoch besondere Herausforderungen für einen möglichen klinischen Einsatz mit sich.

So wäre beispielsweise bei Atemluftanalysen eines beatmeten Pneumonie-Patienten initial nicht bekannt, welche Erreger die Infektion verursachten. Demnach ist initial unklar in welcher Wachstumsphase die Messungen stattfinden. Für einen klinischen Einsatz müssen die Anwender sichere diagnostische Schlüsse anhand der Messergebnisse ableiten können. Dafür muss eine Reihe weiterer in-vitro- und in-vivo-Untersuchungen erfolgen, die die Methode und ihre Leistungsfähigkeit im Hinblick auf die Differenzierung aller im Kontext relevanten Mikroorganismen überprüfen.

In zukünftigen Studien sollten die MCC-IMS-Messungen daher im positiven und negativen Ionenmodus durchgeführt werden. Gegebenenfalls sollten auch Messungen mit alternativen Nährmedien erfolgen, da der konkrete Einfluss eines Nährmediums auf die VOC-Charakteristiken nicht abschließend geklärt ist.

Ziel dieser Arbeiten muss es sein, erregerspezifische VOC-Muster herauszuarbeiten, die medien-unabhängig die Identifizierung von Bakterienspezies mit ausreichender Sicherheit ermöglichen. Messungen verschiedener Stämme einer Bakterienspezies erscheinen nach den Ergebnissen der vorliegenden Arbeit für nicht-multiresistente Stämme von E. coli und P. aeruginosa nicht nötig. Die Hypothese sollte jedoch für jede relevante Spezies untersucht werden. 


\section{ZUSAMMENFASSUNG}

Eine schnelle und sichere Alternative zur konventionellen mikrobiologischen Diagnostik könnte die Erregeridentifikation durch die Detektion und Zuordnung von flüchtigen organischen Verbindungen, mittels Multikapillarsäulen-gekoppelter Ionenmobilitätsspektrometrie (MCC-IMS) sein. In der Literatur werden Möglichkeiten des Verfahrens zur Differenzierung von Bakterien und Pilzen beschrieben, jedoch liegen keine Informationen zu Wachstumsverläufen und den damit verbunden Zeitpunkten vor, wann eine Differenzierung möglich ist. Diese Arbeit untersucht das Auftreten von flüchtigen organischen Verbindungen entlang der Wachstumskurven von zwei ausgewählten Bakterienspezies. Hierfür wurden Escherichia (E.) coli und Pseudomonas (P.) aeruginosa in einem flüssigen Nährmedium kultiviert und jeweils in den einzelnen Wachstumsphasen eine Headspace-Analyse mittels MCC-IMS durchgeführt. Um die Relevanz für einen klinischen Nutzen zu beurteilen, wurden ebenfalls zwölf zufällig ausgewählte klinische Isolate dieser Bakterienspezies analysiert.

Die erhobenen Ergebnisse belegen, dass eine Differenzierung der Bakterienspezies E. coli und $P$. aeruginosa in Wachstumskulturen anhand ihres Metaboloms insbesondere während der späten logarithmischen (Log2) und der statischen Wachstumsphase (Stat) möglich ist. Zur Identifikation von E. coli eignen sich nach den hier gemessenen Daten 1-Decanol, Ethanol, Indol, 1-Octanol (Monomer) und P_755_105. Für die Identifikation von P. aeruginosa empfehlen sich Aceton, Ammoniak (Dimer), n-Dodecan, 2-Ethyl-1-Hexanol, 1- Octanol (Dimer), P_603_25, P_648_36 und P_778_4.

Die Evaluation zeigt weiterhin, dass bei den gemessenen VOC-Profilen keine signifikanten Unterschiede zwischen verschiedenen Stämmen einer Bakterienspezies zu erkennen sind. 


\section{LITERATURVERZEICHNIS}

Aldrige C, Jones PW, Gibson S, Lanham J, Meyer M, Vannest R, Charles R (1977): Automated microbiological detection/identification system. J Clin Microbiol 6, 406-413

Anhalt JP, Fenselau C (1975): Identification of bacteria using mass spectrometry. Anal Chem $47,219-225$

Baumbach JI (2009): Ion mobility spectrometry coupled with multi-capillary columns for metabolic profiling of human breath. J Breath Res $\underline{3}, 1-16$

Baumbach JI, Eiceman GA, Klockow D, Sielemann S, von Irmer A (1997): Exploration of a multicapillary column for use in elevated speed gas chromatography. Int J Environ Anal Chem $\underline{66}, 225-239$

Baumgärtel T: Neue Ergebnisse der Coliforschung. In: von Pfaundler M, Schittenhelm A (Hrsg.): Ergebnisse in der Inneren Medizin und Kinderheilkunde. Springer, Berlin 1945, 445-503

Bertani G (1951): Studies on lysogenesis I: The mode of phage liberation by lysogenic Escherichia coli. J Bacteriol 62, 293-300

Borsdorf H, Eiceman GA (2006): Ion mobility spectrometry: Principles and applications. Appl Spectrosc Rev 41, 323-375

Burak S, Gehrt A (2010): Verkürzte Analysezeit bei höherer Genauigkeit. MALDI-TOF Massenspektrometrie zur Identifizierung klinisch relevanter Mikroorganismen. Wien klin $\operatorname{Mag} \underline{13}, 22-26$

Burkhardt F, Neumeister B, Geiss HK, Braun R, Kimmig P (Hrsg.): Mikrobiologische Diagnostik. 2. Auflage; Georg-Thieme, Stuttgart 2009

Carr TW (1979): Comparison of the negative reactant ions formed in the plasma chromatograph by nitrogen, air, and sulfur hexafluoride as the drift gas with air as the carrier gas. Anal Chem $\underline{51}, 705-711$ 
Carstens ETH (2010): Quantifizierung von Propofol in der Atemluft mittels endtidaler Ionenmobilitätsspektrometrie. Med. Diss. Göttingen 2010

Carroll DI, Dzidic I, Stillwell RN, Horning EC (1975): Identification of positive reactant ions observed for nitrogen carrier gas in plasma chromatograph mobility studies. Anal Chem 47, 1956-1959

Dierkes C, Ehrenstein B, Siebig S, Linde HJ, Reischl U, Salzberger B (2009): Clinical impact of a commercially available multiplex PCR system for rapid detection of pathogens in patients with presumed sepsis. BMC Infect Dis $\underline{9}, 126$

Eiceman GA, Karpas Z: Ion mobility spectrometry. 2. Edition; CRC Press, Boca Raton 2005 Eiceman GA, Leasure CS, Vandiver VJ (1985): Flow characteristics in a segmented closetube design for ion mobility spectrometry. Anal Chim Acta $\underline{175}, 135-145$

Engel C, Brunkhorst FM, Bone HG, Brunkhorst R, Gerlach H, Gruendling M, Huhle G, Jaschinski U, John S (2007): Epidemiology of sepsis in Germany: results from a national prospective multicenter study. Intensive Care Med $\underline{3}$,606-618

European Centre for Disease Prevention and Control: Healthcare-associated infections acquires in intensive care units. Annual epidemiological report for 2017. ECDC, Stockholm 2019

Fenollar F, Gonçalves A, Esterni B, Azza A, Habib G, Borg JP, Raoult D (2006): A serum protein signature with high diagnostic value in bacterial endocarditis: Results from a study based on surface-enhanced laser desorption/ionization time-of-flight mass spectrometry. J Infect Dis $\underline{194}$, 1356-1366

Funke G, Monnet D, de Bernardis C, von Graevenitz A, Freney J (1998): Evaluation of the VITEK2 system for rapid identification of medically relevant gram-negative rods. J Clin Microbiol 36, 1948-1952

GBD 2016 Causes of Death Collaborators (2017): Global, regional, and national age-sex specific mortality for 264 causes of death, 1980-2016: A systematic analysis for the global burden of disease study 2016. Lancet 390 , 1151-1210

Good A, Durden A, Kerarke P (1970): Ion-molecule reactions in pure nitrogen and nitrogen containing traces of water at total pressures 0.5-4 torr. Kinetics of clustering reactions fforming $\mathrm{H}+(\mathrm{H} 2 \mathrm{O})$. J Chem Phys $\underline{52}, 212-221$ 
Gram HC (1884): Über die isolierte Färbung der Schizomyceten in Schnitt- und Trockenpräparaten. Fortschr Med 2, 185-189

Guamán AV, Carreras A, Calvo D, Agudo I, Navajas D, Pardo A, Marco S, Farré R (2012): Rapid detection of sepsis in rats through volatile organic compounds in breath. J Chromatogr B 881-882, 76-82

He Y, Li H, Lu X, Stratten CW, Tang YW (2010): Mass spectrometry biotyper system identifies enteric bacterial pathogens directly from colonies grown on selective stool culture media. J Clin Microbiol 48, 3888-3892

Hill HH Jr, Siems WF, St Louis RH, McMinn DG (1990): Ion mobility spectrometry. Anal Chem $\underline{62}, 1201 \mathrm{~A}-1209 \mathrm{~A}$

Houck PM, Bratzler DW, Nsa W, Ma A, Bartlett JG (2004): Timing of antibiotic administration and outcome for medicare patients hospitalized with community-acquired pneumonia. Arch Intern Med 164, 637-644

Huber D, Voith von Voithenberg L, Kaigala DV (2018): Fluorescence-in-situ-hybridization (FISH): History, limitations and what to expect from micro-scale FISH? Micro and Nano Engeneering $\underline{1}, 15-24$

Isailovic D. Kurulugama RT, Plasencia MD, Stokes ST, Kyselova Z, Goldman R, Mechref Y, Novotny MV, Clemmer DE (2008): Profiling of human serum glycans associated with liver cancer and cirrhosis by IMS-MS. J Proteome Res $\underline{7}, 1109-1117$

Jünger M, Vautz W, Kuhns M, Hofmann L, Ulbricht S, Baumbach JI, Quintel M, Perl T (2012): Ion mobility spectrometry for microbial volatile organic compounds: A new identification tool for human pathogenic bacteria. Appl Microbiol Biotechnol 93, 2603-2614

Kai M, Haustein M, Molina F, Petri A, Scholz B, Piechulla B (2009): Bacterial volatiles and their action potential. Appl Microbiol Biotechnol 81, 1001-1012

Karasek FW (1974): Plasma chromatography. Anal Chem $\underline{46}$, 710A-720A

Karasek FW, Keller RA (1972): Gas chromatograph/plasma chromatograph interface and its performance in the detection of musk ambrette. J Chromatogr Sci 10, 626-628

Kumar A, Ellis P, Arabi Y, Roberts D, Light B, Parrillo JE, Dodek P, Wood G, Kumar A, Simon D (2009): Initiation of inappropriate antimicrobial therapy results in a fivefold reduction of survival in human septic shock. Chest $\underline{136}, 1237-1244$ 
Küntzel A, Fischer S, Bergmann A, Oertel P, Steffens M, Trefz P, Miekisch W, Schubert JK, Reinhold P, Köhler H (2016): Effects of biological and methodological factors on volatile organic compound patterns during cultural growth of Mycobacterium avium ssp. paratuberculosis. J Breath Res 10, 037103

Kunze N, Moerer O, Steinmetz N, Schulze MH, Quintel M, Perl T (2015): Point-of-care multiplex PCR promises short turnaround times for microbial testing in hospital acquiredpneumonia - an observational pilot study in critical ill patients. Ann Clin Microbiol Antimicrob 14,33

Laupland KB, Lee H, Gregson DB, Manns BJ (2006): Cost of intensive care unit-acquired bloodstream infections. J Hosp Infect $\underline{63}, 124-132$

Lehmann LE, Hunfeld KP, Emrich T, Haberhausen G, Wissing H, Hoeft A, Stüber F (2008): A multiplex real-time PCR assay for rapid detection and differentiation of 25 bacterial and fungal pathogens from whole blood samples. Med Microbiol Immunol 197 313-324

Leverstein- van Hall MA, Fluit AC, Paauw A, Box ATA, Brisse S, Verhoef J (2002): Evaluation of the Etest ESBL and the BD Phoenix, VITEK1, and VITEK2 automated instruments of detection of extended-spectrum beta-lactamases in multiresistant Escheriachia coli and Klebsiella spp. J Clin Microbiol 40, 3703-3711

Ling TK, Tam PC, Liu ZK, Cheng AF (2001): Evaluation of VITEK2 rapid identification and susceptibility testing system against gram-negative clinical isolates. J Clin Microbiol $\underline{39}$ 2964-2966

Lodes U, Lippert H, Meyer F (2011): Molekularbiologische Sepsisdiagnostik mittels Multiplex-PCR in der chirurgischen Intensivmedizin als geeignete Alternative zur konventionell-mikrobiellen Kultur - ein repräsentativer Überblick. Zentralbl Chir 136 , 135-142

Maddula S, Blank LM, Schmid A, Baumbach JI (2009): Detection of volatile metabolites of Escherichia coli by multi capillary column coupled ion mobility spectrometry. Anal Bioanal Chem $\underline{394}, 791-800$

Mann S (1966): Über den Geruchsstoff von Pseudomonas aeruginosa. Arch Microbiol $\underline{54}$ 184-190 
Mann PH, Gandelman AI (1965): An evaluation of reagent-impregnated paper strips for use in the process of identifying certain species of clinically important bacteria. II. Testing for the production of indole. Curr Ther Res Clin Exp 7, 510-512

Marx G, SeptNet Critical Care Trials Group (2018): Incidence of severe sepsis and septic shock in german intensive care units: The prospective, multicentre INSEP study. Intensive Care Med $\underline{44}$ 153-156

Maurer FP, Hentschke M, Rohde H (2017): Neue mikrobiologische Diagnostikverfahren. Wien klin Mag 20, 190-194

Mercer J, Shakleya D, Bell S (2006): Applications of ion mobility spectrometry (IMS) to the analysis of gamma-hydroxybutyrate and gamma-hydroxyvalerate in toxicological matrices. J Anal Toxicol 30, 539-544

Micek ST, Lloyd AE, Ritchie DJ, Reichley RM, Fraser VJ, Kollef MH (2005): Pseudomonas aeruginosa bloodstream infection: importance of appropriate initial antimicrobial treatment. Antimicrob Agents Chemother $\underline{49}$, 1306-1311

Moussaoui W, Jaulhac B, Hoffmann AM, Ludes B, Kostrzewa M, Riegel P, Prévost G (2010): Matrix-assisted laser desorption ionization time-of-flight mass spectrometry identifies $90 \%$ of bacteria directly from blood culture vials. Clin Microbiol Infect 16, 1631-1638

Müller H-J, Prange DR (2016): PCR - Polymerase-Kettenreaktion. 2. Auflage; Springer, Berlin 2016

Nagassar RP, Christian N, Gorton R, Willey BM, Mazzulli T (2013): Agreement and cost comparison of VITEK2 Compact, VITEK2 60, VITEK MS Systems and API 20E/NE using clinical gram-negative bacilli isolates from Jamaica. Posterpräsentation im Rahmen der 53rd Interscience Conference on Antimicrobial Agents and Chemotherapy (ICAAC), Denver, 10.-13.9.2013

Neidhardt FC, Bloch PL, Smith DF (1974): Culture medium for enterobacteria. J Bacteriol $\underline{119}, 736-747$

O'Hara CM (2005): Manual and automated instrumentation for identification of enterobacteriaceae and other aerobic gram-negative bacilli. Clin Microbiol Rev $\underline{18}$, 147162 
O'Hara M, Mayhew CA (2009): A preliminary comparison of volatile organic compounds in the headspace of cultures of Staphylococcus aureus grown in nutrient, dextrose and brain heart bovine measured using a proton transfer reaction mass spectrometer. J Breath Res $\underline{3}$, 027001

Pellizzari ED (1974): Electron capture detection in gas-chromatography. J Chromatogr 98 , 323-361

Perl T, Bödeker B, Jünger M, Nolte J, Vautz W (2010): Alignment of retention time obtained from multicapillary column gas chromatography used for VOC analysis with ion mobility spectrometry. Anal Bioanal Chem $\underline{397}$ 2385-2394

Perl T, Jünger M, Vautz W, Nolte J, Kuhns M, Borg-von Zepelin M, Quintel M (2011): Detection of characteristic metabolites of Aspergillus fumigatus and Candida species using ion mobility spectrometry - metabolic profiling by volatile organic compounds. Mycoses 54, e828-e837

Pletz MW, Wellinghausen N, Welte T (2011): Will polymerase chain reaction (PCR)-based diagnostics improve outcome in septic patients? A clinical view. Intensive Care Med $\underline{37}$ 1069-1076

Rabis T, Sommerwerck U, Anhenn O, Darwiche K, Freitag L, Teschler H, Bödeker B, Maddula S, Baumbach JI (2011): Detection of infectious agents in the airways by ion mobility spectrometry of exhaled breath. Int J Ion Mobil Spec 14, 187-195

Ratiu IA, Ligor T, Bocos-Bintintan V, Al-Soud H, Kowalkowski T, Rafińska K, Buszewski B (2017): The effect of growth medium on an Escherichia coli pathway mirrored into GC/MS profiles. J Breath Res 11, 036012

Revercomb HE, Mason EA (1975): Theory of plasma chromatography/gaseous electrophoresis - A review. Anal Chem $\underline{47}$, 970-983

Sander HS, Farrell DJ, Flamm RK, Jones RN (2014): Antimicrobial susceptibility of gramnegative organisms isolated from patients hospitalized in intensive care units in United States and European hospitals. Diagn Microbiol Infect Dis $\underline{78}$, 443-448

Schulz S, Dickschat JS (2007): Bacterial volatiles: the smell of small organisms. Nat Prod Rep $\underline{24}, 814-842$ 
Seng M, Drancourt M, Gouriet F, La Scola B, Fournier PE, Rolain JM, Raoult D (2009): Ongoing revolution in bacteriology: Routine identification of bacteria by matrix-assisted laser desorption ionization time-of-flight mass spectrometry. Clin Infect Dis 49, 543-551

SepNet Critical Care Trials Group (2016): Incidence of severe sepsis and septic shock in German intensive care units: the prospective, multicentre INSEPT study. Intensive Care Med $\underline{42}, 1980-1989$

Sibertech Ltd., Novosibirsk, Russland; http://www.sibertech.narod.ru/frames.htm; abgerufen am: 17.07.2020

Sielemann S (1999): Detektion flüchtiger organischer Verbindungen mittels Ionenmobilitätsspektrometrie und deren Kopplung mit Multi-Kapillar-GasChromatographie. Chem. Diss. Dortmund 1999

Simpson G, Klasmeier M, Hill H, Atkinson D, Radolovich G, Lopez-Avila V, Jones TL (1996): Evaluation of gas chromatography couples with ion mobility spectrometry for monitoring vinyl chloride and other chlorinated and aromatic compounds in air samples. J High Resolut Chromatogr 19, 301-312

Singer M, Deutschmann CS, Seymour CW, Shankar-Hari M, Djillali A, Bauer M, Bellomo R, Bernard GR, Chiche J-D, Coopersmith CM et al. (2016): The third international consensus definitions for sepsis and septic shock (Sepsis-3). JAMA $\underline{315}$, 801-810

Snyder AP, Shoff DB, Eiceman GA, Blyth DA, Parsons JA (1991): Detection of bacteria by ion mobility spectrometry. Anal Chem $\underline{63}, 526-529$

Snyder AP, Harden CS, Brittain AH, Kim MG, Arnold NS, Meuzelaar HLC (1993): Portable hand-held gas chromatography/ion mobility spectrometry device. Anal Chem $\underline{65}$, 299-306

Song JH, Cho H, Park MY, Na DS, Moon HB, Pai CH (1993): Detection of Salmonella typhi in the blood of patients with typhoid fever by polymerase chain reaction. J Clin Microbiol $\underline{31}$ $1439-1443$

St. Louis RH, Hill HH Jr., Eiceman GA (1990): Ion mobility spectrometry in analytical chemistry. Crit Rev Anal Chem 21, 321-355

Tiebe C, Miessner H, Koch B, Hübert T (2009): Detection of microbial volatile organic compounds (MVOCs) by ion-mobility spectrometry. Anal Bioanal Chem $\underline{395}$, 2313-2323 
Van Veen SQ, Claas ECJ, Kuijper EJ (2010): High-throughput identification of bacteria and yeast by matrix-assisted laser desorption ionization-time of flight mass spectrometry in conventional medical microbiology laboratories. J Clin Microbiol 48, 900-907

Vautz W, Sielemann S, Baumbach JI (2004): Determination of terpenes in humid ambient air using ultraviolet ion mobility spectrometry. Anal Chim Acta $\underline{513}$, 393-399

Vautz W, Bödeker B, Baumbach JI, Bader S, Westhoff M, Perl T (2009): An implementable approach to obtain reproducible reduced ion mobility. Int J Ion Mobil Spectrom $\underline{12}$, 47-57

Vincent JL, Rello J, Marshall J, Silva E, Anzueto A, Martin CD, Moreno R, Lipman J, Gomersall C, Sakr Y et al. (2009): International study of the prevalence and outcomes of infection in intensive care units. JAMA $\underline{302}, 2323-2329$

Vracko R, Sherris JC (1963): Indole spot test in bacteriology. Am J Clin Pathol $\underline{39}$ 429-432

Zhu J, Bean HD, Kuo Y-M, Hill JE (2010): Fast detection of volatile organic compounds from bacterial cultures by secondary electrospray ionization-mass spectrometry. J Clin Microbiol 48, 4426-4431

Zoller HF, Clark WM (1921): The production of volatile fatty acids by bacteria of the density group. J Gen Physiol 3 , 325-330 